University of Nebraska - Lincoln

DigitalCommons@University of Nebraska - Lincoln

Reconciling estimates of the contemporary North American carbon balance among terrestrial biosphere models, atmospheric inversions, and a new approach for estimating net ecosystem exchange from inventory-based data

Daniel J. Hayes

Oak Ridge National Laboratory, hayesdj@ornl.gov

David P. Turner

Oregon State University, david.turner@oregonstate.edu

Graham Stinson

Canadian Forest Service, Graham.Stinson@NRCan-RNCan.gc.ca

A. David Mcguire

U.S. Geological Survey

Yaxing Wei

Oak Ridge National Laboratory, weiy@ornl.gov

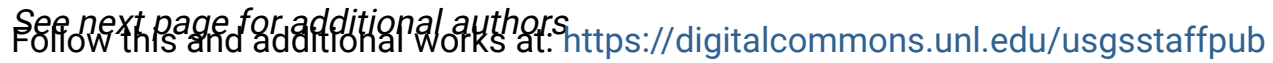

Hayes, Daniel J.; Turner, David P.; Stinson, Graham; Mcguire, A. David; Wei, Yaxing; West, Tristram O.; Heath, Linda S.; Dejong, Bernardus; Mcconkey, Brian G.; Birdsey, Richard A.; Kurz, Werner A.; Jacobson, Andrew R.; Huntzinger, Deborah N.; Pan, Yude; Post, W. Mac; and Cook, Robert B., "Reconciling estimates of the contemporary North American carbon balance among terrestrial biosphere models, atmospheric inversions, and a new approach for estimating net ecosystem exchange from inventory-based data" (2012). USGS Staff -- Published Research. 556.

https://digitalcommons.unl.edu/usgsstaffpub/556

This Article is brought to you for free and open access by the US Geological Survey at DigitalCommons@University of Nebraska - Lincoln. It has been accepted for inclusion in USGS Staff -- Published Research by an authorized administrator of DigitalCommons@University of Nebraska - Lincoln. 


\section{Authors}

Daniel J. Hayes, David P. Turner, Graham Stinson, A. David Mcguire, Yaxing Wei, Tristram O. West, Linda S. Heath, Bernardus Dejong, Brian G. Mcconkey, Richard A. Birdsey, Werner A. Kurz, Andrew R. Jacobson, Deborah N. Huntzinger, Yude Pan, W. Mac Post, and Robert B. Cook 


\title{
Reconciling estimates of the contemporary North American carbon balance among terrestrial biosphere models, atmospheric inversions, and a new approach for estimating net ecosystem exchange from inventory-based data $^{1}$
}

\author{
DANIEL J. HAYES*1, DAVID P. TURNER $\dagger$, GRAHAM STINSON $\$$, A. DAVID MCGUIRE, , \\ YAXING WEI*, TRISTRAM O. WEST $\uparrow$, LINDA S. HEATH\|\|\|, BERNARDUS DEJONG**, \\ BRIAN G. MCCONKEY††, RICHARD A. BIRDSEY,+ WERNER A. KURZ $\$$,

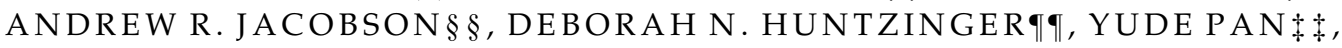 \\ W. MAC POST* and ROBERT B. COOK* \\ ${ }^{*}$ Environmental Sciences Division, Oak Ridge National Laboratory, Oak Ridge, TN 37831, USA, †Department of Forest \\ Ecosystems and Society, Oregon State University, Corvallis, OR 97331, USA, $¥$ Pacific Forestry Centre, Canadian Forest Service, \\ Victoria, BC V8Z 1M5, Canada, §U.S. Geological Survey, Alaska Cooperative Fish and Wildlife Research Unit, University of \\ Alaska Fairbanks, Fairbanks, AK 99775, USA, ๆJoint Global Change Research Institute, Pacific Northwest National Laboratory, \\ College Park, MD 20740, USA, \|USDA Forest Service, Durham, NH 03824, USA, ${ }^{*}$ El Colegio de la Frontera Sur (ECOSUR), \\ Villahermosa, C.P. 86280, Tabasco, Mexico, † $\dagger$ Agriculture and Agri-Food Canada, Ottawa, ON KIA 0C5, Canada, $\$$ \$SDA \\ Forest Service, Newtown Square, 19073, PA 19073, USA, §§NOAA Earth System Research Lab, Boulder, CO 80305, USA, \\ 9TSchool of Earth Sciences \& Environmental Sustainability, Northern Arizona University, Flagstaff, AZ 86011, USA, \\ |||Currently on secondment to the Global Environment Facility, Washington, DC 20006, USA
}

\begin{abstract}
We develop an approach for estimating net ecosystem exchange (NEE) using inventory-based information over North America (NA) for a recent 7-year period (ca. 2000-2006). The approach notably retains information on the spatial distribution of NEE, or the vertical exchange between land and atmosphere of all non-fossil fuel sources and sinks of $\mathrm{CO}_{2}$, while accounting for lateral transfers of forest and crop products as well as their eventual emissions. The total NEE estimate of a $-327 \pm 252 \mathrm{TgC} \mathrm{yr}^{-1}$ sink for NA was driven primarily by $\mathrm{CO}_{2}$ uptake in the Forest Lands sector $\left(-248 \mathrm{TgC}^{-1}\right)$, largely in the Northwest and Southeast regions of the US, and in the Crop Lands sector $\left(-297 \mathrm{TgC}^{-1}\right)$, predominantly in the Midwest US states. These sinks are counteracted by the carbon source esti-

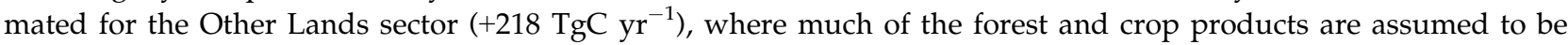
returned to the atmosphere (through livestock and human consumption). The ecosystems of Mexico are estimated to

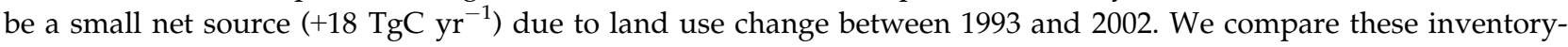
based estimates with results from a suite of terrestrial biosphere and atmospheric inversion models, where the mean

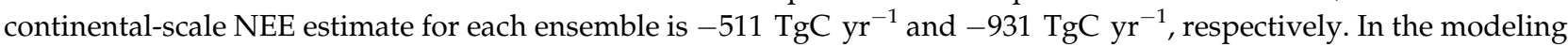
approaches, all sectors, including Other Lands, were generally estimated to be a carbon sink, driven in part by assumed $\mathrm{CO}_{2}$ fertilization and/or lack of consideration of carbon sources from disturbances and product emissions. Additional fluxes not measured by the inventories, although highly uncertain, could add an additional $-239 \mathrm{TgC}^{-1}$ to the inventory-based NA sink estimate, thus suggesting some convergence with the modeling approaches.
\end{abstract}

Keywords: agriculture, carbon cycle, climate change, $\mathrm{CO}_{2}$ emissions, $\mathrm{CO}_{2}$ sinks, forests, inventory, modeling, North America

Received 7 November 2011; revised version received 7 November 2011 and accepted 21 November 2011

Correspondence: D.J. Hayes, tel. + 865574 7322,

fax + 865241 3685, e-mail: hayesdj@ornl.gov

${ }^{1}$ This manuscript has been authored by UT-Battelle, LLC, under Contract No. DE-AC05-00OR22725 with the U.S. Department of Energy. The publisher, by accepting the article for publication, acknowledges that the United States Government retains a non-exclusive, paid-up, irrevocable, world-wide license to publish or reproduce the published form of this manuscript, or allow others to do so, for United States Government purposes.

\section{Introduction}

North American ecosystems have had a significant influence on the global carbon budget by acting as a large sink of atmospheric $\mathrm{CO}_{2}$ in recent decades (Fan et al., 1998; Myneni et al., 2001; Butler et al., 2010). Although the exact contribution is uncertain, analyses of the global $\mathrm{C}$ budget suggest that this North 
American terrestrial sink may be responsible for nearly a third of the combined global land and ocean sink of atmospheric $\mathrm{CO}_{2}$ (Pacala et al., 2007). A recent review of late 20th Century carbon balance estimates for terrestrial ecosystems in North America (NA) compiled for the State of the Carbon Cycle Report (SOCCR) found a wide range of results, with estimates of the magnitude of the continental-scale $\mathrm{CO}_{2}$ sink extending between 0.1 and $2.0{\mathrm{PgC} \mathrm{yr}^{-1}}^{-1}$ King et al., 2007), although the terrestrial sink based on inventories reported in this document was $0.5 \mathrm{PgC} \mathrm{yr}^{-1}$ with uncertainty of about $50 \%{ }^{1}$ (Pacala et al., 2007). By comparison, fossil fuel emissions over NA (from Canada, the US and Mexico combined) in the early 21st Century are estimated to be approximately $1.8 \mathrm{PgC} \mathrm{yr}^{-1}$ (Boden et al., 2010).

Although fossil fuel emissions are calculated with relatively high precision, understanding the fate of those emissions with respect to sequestration in terrestrial ecosystems requires data and methods that can reduce uncertainties in the diagnosis of land-based $\mathrm{CO}_{2}$ sinks. The wide range in the land surface flux estimates is related to a number of factors, but most generally because of the different methodologies used to develop estimates of carbon stocks and flux, and the uncertainties inherent in each approach. The alternative approaches to estimating continental scale carbon fluxes that we explored herein can be broadly classified as applying a top-down or bottom-up perspective. Topdown approaches calculate land-atmosphere carbon fluxes based on atmospheric budgets and inverse modeling. Bottom-up approaches rely primarily on measurements of carbon stock changes (the 'inventory' approach) or on spatially distributed simulations of carbon stocks and/or fluxes using process-based modeling (the 'forward model' approach).

Atmospheric inversion models (AIMs) infer surface fluxes by reference to a sample of atmospheric $\mathrm{CO}_{2}$ concentration (mixing ratio) measurements coupled with models of surface flux and atmospheric transport (Gurney et al., 2002; Ciais et al., 2010). These inverse analyses provide constraints on estimates of land-atmosphere carbon exchange at a detailed temporal resolution, relying on the strong diurnal and seasonal cycles in $\mathrm{CO}_{2}$ concentration in the observations. However, these estimates are associated with large uncertainties from the limited density of observation networks, uncertainty in the transport models, and errors in the inversion process (Gurney et al., 2004; Baker et al., 2006). Further, AIMs typically operate at a coarse spatial resolution and provide limited detail on the processes controlling the carbon sources and sinks.

Biomass inventories provide valuable constraints on changes in the size of carbon pools over years to decades (e.g. Pacala et al., 2001; Peylin et al., 2005). Invento- ries are designed to precisely measure standing stocks in forests on longer time scales, and to estimate and analyze the dynamics of growth, harvest, and mortality. However, the inventory measurement approach can only detect measurable changes in vegetation which usually occurs over a number of years, and therefore re-measurements in most inventory programs are taken periodically. There is a high likelihood that dynamics and fluxes will be under-sampled or missed altogether; for instance, inventory sampling can produce reliable estimates of biomass, but other carbon pools (e.g. litter and soil C stocks) are not sampled at the same intensity in all areas. Inventory-based modeling can be used to estimate growth and disturbance impacts, but does not yet provide full capability in partitioning the forcing brought about by non-disturbance factors (Stinson et al., 2011). On the other hand, inventory and commerce data sets can often be used to quantify the storage, emissions and/or lateral movement of carbon in product pools, which are typically not wellcharacterized in modeling approaches.

The forward model approach builds from understanding the underlying processes controlling carbon dynamics and can be used to simulate the dynamics of multiple ecosystem components through a class of models referred to as terrestrial biosphere models (TBMs). However, TBMs contain substantial uncertainty due to the sheer number of often poorly understood underlying processes simulated. They also vary widely in the data used to drive them, in the particular processes simulated, and in their level of detail (Schwalm et al., 2010, Huntzinger et al., in press). Yet, TBMs simulate the impacts of multiple driving forces and controlling mechanisms of land-atmosphere $\mathrm{CO}_{2}$ exchange, incorporate non-linear system behaviors, make predictions at spatial and temporal scales relevant to global and regional carbon cycles, and allow for exploration of the impacts of underlying processes.

Each of the three general approaches (inventory, forward and inverse modeling) build on different knowledge foundations and employ different driver data. A suite of results on NA ecosystem carbon flux from extant model simulations (based on both TBMs and AIMs) have been organized by the North American Carbon Program (NACP; Denning, 2005; Wofsy and Harris, 2002) under the regional and continental interim-synthesis (RCIS) activities (Huntzinger et al., in press). The RCIS activities focus on 'off-the-shelf' model simulations and other recently published studies as a pre-cursor to more formal model inter-comparison activities. Here, we assembled and analyzed available inventory-based data on NA ecosystem carbon cycle components as an additional perspective alongside the forward and inverse approaches avail- 
able from the RCIS. We developed novel techniques for comparison of the inventory-based data against results from the TBMs and AIMs at common spatiotemporal scales and flux indicators.

\section{Materials and methods}

The magnitude of carbon sources and sinks is defined as the vertical exchange of $\mathrm{CO}_{2}$ between the surface (land or ocean) and the atmosphere, hereafter referred to as net ecosystem exchange (NEE). In this analysis, we used estimates of NEE for the biosphere where fossil fuel emissions are excluded from the calculation. From the land perspective, NEE is primarily the balance between $\mathrm{CO}_{2}$ uptake in vegetation though net primary production (NPP) and release via the heterotrophic respiration ( $\mathrm{Rh}$ ) of dead organic matter, plus emissions from fires and the decay of harvested forest and agricultural products (Chapin et al., 2006). Here we used the sign convention from an atmospheric reference point whereby a negative value of NEE represents land surface uptake (a sink) and a positive value represents $\mathrm{CO}_{2}$ emissions to the atmosphere (a source).

The geographic domain of this study included the three countries of NA (Canada, the US, and Mexico) and the reference time period was approximately 2000-2006. NEE estimates were made at an annual time step and considered lateral in addition to vertical transfers of carbon. Spatial scale became important where a relatively large amount of carbon is transported laterally (as harvested biomass products transferred offsite or as dissolved carbon transported in rivers, for example). In these cases, the $\mathrm{CO}_{2}$ was considered a sink at the location where it was taken up, but became a source at the location where it was eventually returned to the atmosphere (through product decay or in-stream decomposition, for example). In this analysis, carbon flux was estimated at the scale allowable by the various inventory-based data sets (i.e., by inventory 'reporting zones'). We distinguished three sectors (Forest Lands, Crop Lands, and 'Other' Lands) within 97 spatial units (total number of 'reporting zones' across the three countries) in each (Table 1). The 97 'reporting zones' refer to the sum of US states, Canadian managed ecoregions, and Mexican states for which inventory data were available. The carbon flux estimates from 7 inverse and 17 forward models were compiled from those submitted to the NACP-RCIS activity (http://nacarbon. org/nacp; Huntzinger et al., in press). Here we focused on ecosystem carbon fluxes, whereas fossil fuel emissions are discussed for comparison but were not included in the budgets.

\section{Inventory-based estimates of NEE}

For the national-level reporting of greenhouse gas (GHG) inventories in the context of the Framework Convention on Climate Change (FCCC), the protocol is generally to track changes in pool sizes using data collected or modeled for carbon pools of different key land-based sectors, such as forest and agricultural lands along with other non-forest (e.g., grasslands), settled (developed and built-up) lands, and areas of land use change (Parson et al., 1992). In this study, we compiled GHG inventory-based data on productivity, ecosystem carbon stock change and harvested product stock change for managed Forest Lands and Crop Lands in Canada and the United States. Additional information was used to fill in data on carbon balance in Other Lands, including data on human and livestock use/consumption of harvested products. For Mexico, our analysis accounted primarily for carbon flux due to land use change. Data on carbon exchange for each sector were summarized by reporting zone, with spatial and temporal coverage of the data sets noted in Table 1a and details on methods by country and sector described in the Supporting Information.

The conceptual model used to organize the various sectorspecific data sets is illustrated by Fig. 1. The data for both the Forest Lands and Crop Lands sectors (left side of diagram) were based upon estimated stock changes within the vegetation and soil carbon pools. According to the conceptual model, all the stock changes in these pools represented vertical exchange of $\mathrm{CO}_{2}$ with the atmosphere (i.e., NEE) except for (1) the vertical exchange of non- $\mathrm{CO}_{2}$ trace gases, (2) the leaching of carbon from the system via river export and (3) the 'lateral' movement of carbon between sectors and reporting zones. Lateral movement occurs via changes in land use as well as the harvest and transport of forest and agricultural products. Where available, data on these fluxes were used to produce more precise estimates of NEE for each sector in each reporting zone from the stock change information. Total average annual NEE (NEE $\mathrm{NOT}$ ) is the combination of NEE estimated for the Forest Lands $\left(\mathrm{NEE}_{\mathrm{F}}\right)$, Crop Lands $\left(\mathrm{NEE}_{\mathrm{C}}\right)$ and Other Lands $\left(\mathrm{NEE}_{\mathrm{O}}\right)$ sectors for each reporting zone:

$$
\mathrm{NEE}_{\mathrm{TOT}}=\mathrm{NEE}_{\mathrm{F}}+\mathrm{NEE}_{\mathrm{C}}+\mathrm{NEE}_{\mathrm{O}} \text {. }
$$

Which and how the underlying component fluxes, and their inventory-based data sources, were used to estimate $\mathrm{NEE}_{\mathrm{F}}$, $\mathrm{NEE}_{\mathrm{C}}$, and $\mathrm{NEE}_{\mathrm{O}}$ are described in the sections below. Note that, in the equations given, not only NEE but also all component flux values were treated with the atmospheric reference sign convention whereby a negative value represents a $\mathrm{CO}_{2}$ sink effect and a positive value a source effect of that component. By this definition, fire emissions have positive values, harvest removals have negative, and positive values of stock change represent losses in different $C$ pools and vice versa.

\section{Forest lands sector inventories}

Although the equations differ depending on the data source, our calculations of $\mathrm{NEE}_{\mathrm{F}}$ were, in general, based on inventory estimates of stock changes adjusted for the lateral transfer of harvest removals:

$$
\mathrm{NEE}_{\mathrm{F}}=\Delta \text { Live }+\Delta \mathrm{DOM}+\mathrm{H}_{\mathrm{R}}+\mathrm{H}_{\mathrm{E}}
$$

The change in $\mathrm{C}$ stocks in live biomass ( $\Delta$ Live) included overstory trees, understory vegetation and roots, whereas change in dead organic matter stocks $(\triangle \mathrm{DOM})$ included dead trees, down woody debris, litter and soil organic carbon pools. Carbon removed in wood harvest $\left(\mathrm{H}_{\mathrm{R}}\right)$ was considered as a sink from the stand where to wood was grown. However, an additional variable was calculated to represent the proportion 
Table 1 (a) Characteristics (temporal coverage, spatial coverage, variables included, literature reference) of inventory-based estimates used in this study

\begin{tabular}{|c|c|c|c|c|}
\hline $\begin{array}{l}\text { Data type/ } \\
\text { Name }\end{array}$ & $\begin{array}{l}\text { Temporal } \\
\text { coverage }\end{array}$ & Spatial coverage & $\begin{array}{l}\text { Variables included } \\
\text { in NEE }\end{array}$ & Reference \\
\hline $\begin{array}{l}\text { Canada managed } \\
\text { forest }\end{array}$ & 2000-2006 & $(n=15)$ & $\begin{array}{l}\mathrm{NPP}, \mathrm{Rh}, \text { Fire }\left(\mathrm{CO}_{2}\right) \text {, } \\
\text { Harvest }\end{array}$ & $\begin{array}{l}\text { Kurz et al. (2009), } \\
\text { Stinson et al. (2011) }\end{array}$ \\
\hline Canada agriculture & 2000-2006 (avg) & Harvest area $(n=15)$ & Harvest, $\Delta \mathrm{DOM}$ & Environment Canada (2011) \\
\hline Canada ‘Other' & $\begin{array}{r}2000-2006 \\
2006\end{array}$ & $\begin{array}{l}(n=15) \\
(n=15)\end{array}$ & $\begin{array}{l}\text { Stock changes } \\
\text { Livestock emissions }\end{array}$ & $\begin{array}{l}\text { EPA (2011) } \\
\text { Environment Canada (2011) }\end{array}$ \\
\hline US forest & 2000-2006 (avg) & Forest area $(n=49)^{*}$ & $\Delta$ Live, $\Delta \mathrm{DOM}$, harvest & $\begin{array}{l}\text { Heath et al. (2011), } \\
\text { Smith et al. (2009) }\end{array}$ \\
\hline US cropland & 2000-2006 & Cropland Area $(n=48)$ & Harvest, $\triangle \mathrm{DOM}$ & West et al. (2011) \\
\hline US other & 2000-2006 & $\begin{array}{l}\text { Grasslands, } \\
\text { Settlements }(n=50)^{*, \dagger}\end{array}$ & Stock changes & EPA (2011) \\
\hline & $\begin{array}{r}2006 \\
2000-2006\end{array}$ & $\begin{array}{l}(n=50) \\
(n=50)\end{array}$ & $\begin{array}{l}\text { Livestock emissions } \\
\text { Human respiration }\end{array}$ & $\begin{array}{l}\text { EPA (2011) } \\
\text { West et al. (2009) }\end{array}$ \\
\hline Mexico & 1993-2002 (avg) & Mexico $(n=32)$ & $\begin{array}{c}\text { Stock changes (LUC), } \\
\text { forest harvest, forest } \\
\text { biomass increment }\end{array}$ & deJong et al. (2010) \\
\hline
\end{tabular}

(b) Characteristics (temporal coverage, spatial coverage, variables included, literature reference) of inverse model estimates used in this study

\begin{tabular}{llll}
\hline Data type/Name & Temporal coverage & Spatial coverage & Reference \\
\hline CarbonTracker & $2000-2007$ & North America $(n=97)$ & Peters et al. (2007) \\
Jena & $2001-2007$ & North America $(n=97)$ & Rodenbeck et al. (2003) \\
LSCE-1 & $2000-2004$ & North America $(n=97)$ & Peylin et al. (2005) \\
LSCE-2 & $2000-2006$ & North America $(n=97)$ & Chevallier et al. (2007) \\
MLEF-PCTM & $2003-2004$ & North America $(n=97)$ & Butler et al. (2010) \\
U. Michigan & $2000-2001$ & North America $(n=97)$ & Michalak et al. (2004) \\
U. Toronto & $2000-2003$ & North America $(n=97)$ & Deng et al. (2007) \\
\hline
\end{tabular}

(c) Characteristics (temporal coverage, spatial coverage, variables included, literature reference) of terrestrial biosphere model estimates used in this study

\begin{tabular}{|c|c|c|c|c|c|}
\hline Data type/Name & $\begin{array}{l}\text { Temporal } \\
\text { coverage }\end{array}$ & Spatial coverage & $\begin{array}{l}\text { Variables included } \\
\text { in NEE }\end{array}$ & $\begin{array}{l}\text { Land use (LU) } \\
\& \text { disturbance }\end{array}$ & Reference \\
\hline \multicolumn{6}{|l|}{ Diagnostic (MODIS) } \\
\hline MOD17+ & 2000-2004 & North America $(n=97)$ & $\operatorname{Re}-\mathrm{GPP}$ & & Reichstein et al. (2005) \\
\hline EC-MOD & $2000-2006$ & North America $(n=97)$ & $\mathrm{NEE}^{\ddagger}$ & & Xiao et al. (2008) \\
\hline \multicolumn{6}{|c|}{ Diagnostic (AVHRR) } \\
\hline $\mathrm{SiB} 3$ & $2000-2005$ & North America $(n=97)$ & $\operatorname{Re}-\mathrm{GPP}$ & & Baker et al. (2008) \\
\hline CASA & 2002-2003 & North America $(n=97)$ & $\operatorname{Re}-\mathrm{GPP}$ & & Randerson et al. (1997) \\
\hline CASA GFEDv2 & 2000-2005 & North America $(n=97)$ & Re-GPP + Fire & Prescribed fire & van der Werf et al. (2006) \\
\hline CLM-CASA' & 2000-2004 & North America $(n=97)$ & $(\mathrm{Ra}+\mathrm{Rh})-\mathrm{GPP}$ & & Randerson et al. (2009) \\
\hline \multicolumn{6}{|l|}{ Prognostic } \\
\hline CLM-CN & 2000-2004 & North America $(n=97)$ & $(\mathrm{Ra}+\mathrm{Rh})-\mathrm{GPP}+$ Fire & $\begin{array}{l}\text { Prescribed LU, } \\
\text { prognostic fire }\end{array}$ & Thornton et al. (2009) \\
\hline DLEM & 2000-2005 & North America $(n=97)$ & $\begin{array}{l}(\mathrm{Ra}+\mathrm{Rh}) \text {-GPP } \\
+ \text { Fire + Prod }\end{array}$ & $\begin{array}{l}\text { Prescribed LU, } \\
\text { harvest, fire, } \\
\text { storms }\end{array}$ & Tian et al. (2011) \\
\hline CanIBIS & 2000-2005 & US \& Canada $(n=66)$ & $(\mathrm{Ra}+\mathrm{Rh})-\mathrm{GPP}$ & Prescribed fire & Kucharik et al. (2000) \\
\hline ISAM & 2000-2005 & North America $(n=97)$ & $(\mathrm{Ra}+\mathrm{Rh})-\mathrm{GPP}$ & Prescribed LU & Yang et al. (2009) \\
\hline LPJmL & $2000-2005$ & North America $(n=97)$ & $\begin{array}{l}(\mathrm{Ra}+\mathrm{Rh})-\mathrm{GPP} \\
+ \text { Fire }\end{array}$ & Prescribed fire & Bondeau et al. (2007) \\
\hline
\end{tabular}


Table 1 (continued)

(c) Characteristics (temporal coverage, spatial coverage, variables included, literature reference) of terrestrial biosphere model estimates used in this study

\begin{tabular}{|c|c|c|c|c|c|}
\hline Data type/Name & $\begin{array}{l}\text { Temporal } \\
\text { coverage }\end{array}$ & Spatial coverage & $\begin{array}{l}\text { Variables included } \\
\text { in NEE }\end{array}$ & $\begin{array}{l}\text { Land use (LU) } \\
\text { \& disturbance }\end{array}$ & Reference \\
\hline MC1 & 2000-2006 & Continental US $(n=49)$ & $(\mathrm{Ra}+\mathrm{Rh})-\mathrm{GPP}+$ Fire & $\begin{array}{c}\text { Prescribed LU, } \\
\text { prognostic } \\
\text { harvest \& fire }\end{array}$ & Bachelet et al. (2003) \\
\hline BEPS & 2000-2004 & North America $(n=97)$ & $(\mathrm{Ra}+\mathrm{Rh})-\mathrm{GPP}$ & & Ju et al. (2006) \\
\hline ORCHIDEE & 2001-2005 & North America $(n=97)$ & $(\mathrm{Ra}+\mathrm{Rh})-\mathrm{GPP}+$ Fire & $\begin{array}{l}\text { Prescribed LU, } \\
\text { prognostic } \\
\text { harvest \& fire }\end{array}$ & Krinner et al. (2005) \\
\hline TEM6 & 2000-2006 & North of $45^{\circ} \mathrm{N}(n=14)$ & $\begin{array}{l}(\mathrm{Ra}+\mathrm{Rh})-\mathrm{GPP}+ \\
\text { Fire }+ \text { Prod }\end{array}$ & $\begin{array}{l}\text { Prescribed LU, } \\
\text { harvest, fire }\end{array}$ & Hayes et al. (2011) \\
\hline VEGAS2 & 2000-2005 & North America $(n=97)$ & $(\mathrm{Ra}+\mathrm{Rh})-\mathrm{GPP}+$ Fire & Prognostic fire & Zeng et al. (2005) \\
\hline
\end{tabular}

*includes Alaska.

$\dagger$ includes the District of Columbia.

$\$ N E E$ (and GPP) are empirically derived from MODIS variables.

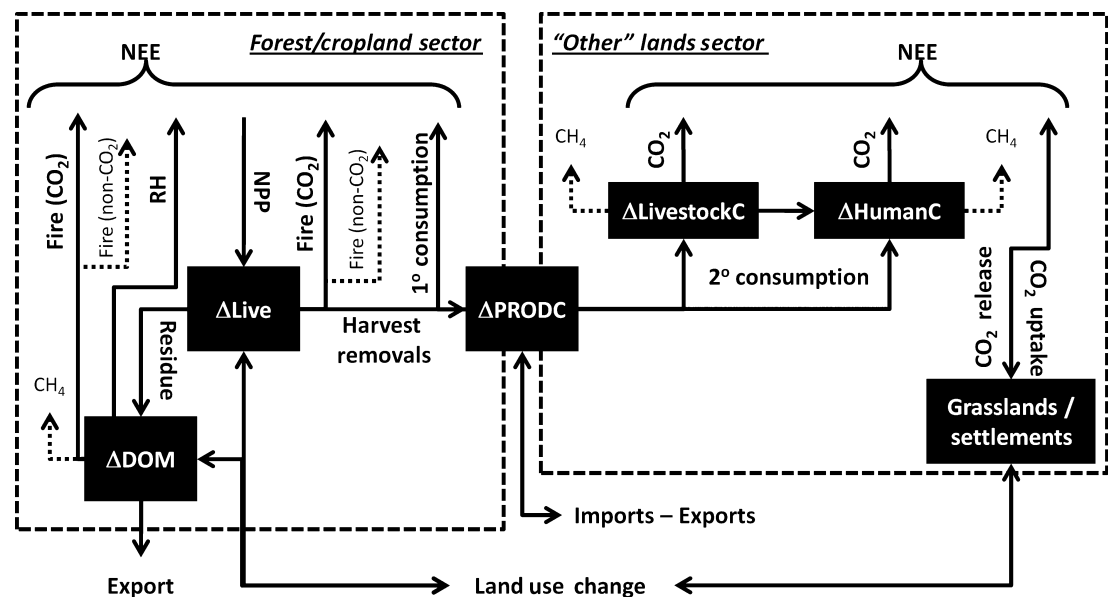

Fig. 1 Conceptual diagram of the continental-scale carbon budget, including the land-atmosphere exchange of $\mathrm{CO}_{2}(\mathrm{NEE})$, based on data available from the inventory-based approaches that estimate carbon stock changes, fluxes and transfers among forest, crop, and other lands.

of $\mathrm{H}_{\mathrm{R}}$ that was emitted during the processing of harvested wood into products $\left(\mathrm{H}_{\mathrm{E}}\right)$. This processing, or 'primary consumption', was assumed to occur largely at the mill, and so we allocated this source term within the Forest Lands sector of the reporting zone in which the wood was harvested. The remainder (i.e., $\mathrm{H}_{\mathrm{R}}-\mathrm{H}_{\mathrm{E}}$ ) was assumed to be transported offsite and added to the national-level forest product pool that resides in the Other Lands sector (described below).

The data set on forest carbon accounting in Canada's Managed Forest Area used here employed the 'stock-plus-flow' approach, which starts with data from a compiled set of inventories and then models the components of change. Flux data were produced using the Carbon Budget Model of the
Canadian Forest Sector (CBM-CFS3), which uses stand-level growth data to estimate annual carbon uptake along with detailed annual natural disturbance (e.g., fire, insects) and harvest data to track carbon transfers through the system (Kurz et al., 2009; Stinson et al., 2011). Natural disturbance and harvest removals data were from various provincial-level reporting sources in Canada (Stinson et al., 2011). The stock change terms $(\Delta$ Live $+\Delta \mathrm{DOM})$ as shown in Eqn (2) also included non- $\mathrm{CO}_{2} /$ non-vertical exchanges and these fluxes were separated out of the $\mathrm{NEE}_{\mathrm{F}}$ calculation. These more detailed component fluxes were estimated by CBM-CFS3, and so $\mathrm{NEE}_{\mathrm{F}}$ for Canada was calculated from the available indicator variables as: 
$\mathrm{NEE}_{\mathrm{F}}=\Delta$ Live $+\Delta \mathrm{DOM}-\left(\right.$ FireC - FireCO $\left._{2}\right)+\mathrm{H}_{\mathrm{R}}+\mathrm{H}_{\mathrm{E}}$

where the carbon remaining in harvested products after primary consumption (i.e., $\mathrm{H}_{\mathrm{R}}-\mathrm{H}_{\mathrm{E}}$ ) and the non- $\mathrm{CO}_{2}$ component of fire emissions (i.e., FireC - Fire $\mathrm{CO}_{2}$ ) were excluded from the vertical flux component of the overall stock change. For Canada, we used $30 \%$ as the proportion of $\mathrm{H}_{\mathrm{R}}$ emitted in primary consumption, based on an analysis of 2010 FAO statistics (FAOStat; http://faostat.fao.org/) and Canadian harvest data for the period 2000-2006. Therefore: $\mathrm{H}_{\mathrm{E}}$ is equal to $0.3 \times \mathrm{H}_{\mathrm{R}}$ for each reporting zone.

The forest inventory data sets for the US were based on the forest surveys of the U.S. Department of Agriculture (USDA) Forest Service's Forest Inventory and Analysis (FIA) program (Bechtold \& Patterson, 2005). These estimates were coupled with carbon expansion factors (Bechtold \& Patterson, 2005; Smith et al., 2006; Heath et al., 2011) and estimates of carbon stock changes were derived from the Carbon Calculation Tool (CCT; Smith et al., 2010), which is used to produce the GHG inventory for US forest lands in the UNFCCC reports (EPA, 2011). Harvest removals $\left(H_{R}\right)$ were from published US Forest Service data sets (Smith et al., 2009). Estimates of the proportion of $\mathrm{H}_{\mathrm{R}}$ emitted in primary consumption $\left(\mathrm{H}_{\mathrm{E}}\right)$ were provided by Smith et al. (2006), who showed that the proportion lost within the first year following harvest (which we assumed occurs primarily at the mill) ranges from $20 \%$ to $40 \%$ across species group and region in the US. As such, we used $30 \%$ as a representative emissions (from primary consumption) fraction, which is the same as that used for the Canada data set. State-level data on fire emissions from US forests were not available for the time period of this study; however, in terms of our NEE calculation, fire emissions were implicit in the total stock change (i.e. fire emissions would have accumulated as biomass had there been no fire) and considered a source of carbon to the atmosphere. The US forest data represents net stock change, meaning that fluxes stemming from land use change (LUC; i.e. forest land area converted to other land use, and other land converted to forest land) were also implicit (i.e. integrated in) in the stock change data. The corresponding change in carbon stocks directly attributed to fire and LUC cannot be explicitly separated from the total stock change. Therefore, $\mathrm{NEE}_{\mathrm{F}}$ for the US Forest Lands sector used exactly that as shown in Eqn (2), without the modification for non$\mathrm{CO}_{2}$ fire emissions as used in Canada.

As with the Canada forest data set, the Mexico inventory data can be described as being based on the 'stock-plus-flow' approach. For Mexican forests, the data set was based on a carbon accounting methodology in which mean carbon stock density by forest type was distributed according the areal extent of each type at an initial point in time, and stock change was estimated according to the biomass increment (growth) and harvest amount in managed forests, and area of forest conversion over a subsequent period of time. Using this methodology, the study by deJong et al. (2010) calculated for the 1993-2002 time period: (1) biomass losses resulting from the conversion of forests to other land use ( $\Delta$ Live $\left._{\mathrm{LUC}}\right)$; (2) the associated change in soil carbon stocks resulting from LUC $\left(\Delta\right.$ Soil $\left._{\mathrm{LUC}}\right) ;(3)$ carbon uptake due to the regrowth of forests on abandoned agricultural or other lands $\left(\Delta\right.$ Live $\left._{\mathrm{ABND}}\right)$; and (4) the net carbon balance between uptake (growth) and emissions (harvest) in managed forests $\left(\Delta\right.$ Live $\left._{\text {MNGD }}\right)$. Fire emissions were included with respect to burning in forest conversion, but the reporting methodology does not take into account fire emissions or other natural carbon fluxes (growth, mortality) from unmanaged land. $\mathrm{NEE}_{\mathrm{F}}$ was calculated by summing the four average annual stock change components from the study by deJong et al. (2010):

$$
\mathrm{NEE}_{\mathrm{F}}=\Delta \text { Live }_{\mathrm{LUC}}+\Delta \text { Soil }_{\mathrm{LUC}}+\Delta \text { Live }_{\mathrm{ABND}}+\Delta \text { Live }_{\mathrm{MNGD}} .
$$

For this study, we distributed the magnitude of each component flux proportionately by an estimate of the relative area of each LU/LC class contained in each state, as described in the Supporting Information. Without more detailed data, we assumed that commercial harvest and fuelwood harvest occurred proportional to the relative area of each forest type.

\section{Crop lands sector inventories}

To estimate NEE for croplands for this study, we collected estimates of crop productivity (NPP), harvest $\left(\mathrm{H}_{\mathrm{R}}\right)$ and changes in soil carbon stocks ( $\Delta$ Soil) over the 2000-2006 time period for Canada (Environment Canada, 2011) and the US (West et al., 2011). The detail regarding the source and methodologies used in the crop inventories are provided in the Supporting Information as well as by those references cited. $\mathrm{NEE}_{\mathrm{C}}$ was calculated for each reporting zone in Canada and the US as:

$$
\mathrm{NEE}_{\mathrm{C}}=\Delta \text { Soil }+\mathrm{H}_{\mathrm{R}}
$$

where all crop harvest removals (i.e., $H_{R}$ ) were considered a Crop Lands sector sink in the reporting zone where they were harvested; unlike the treatment of harvested wood products, we assumed no primary consumption emissions within the Crop Lands sector. We considered $\Delta$ Live in croplands to be equal to zero on an annual basis since the assumption of the data was that NPP is equal to the crop harvest plus residue. We then assumed that, within the same year, the residue carbon was returned to the atmosphere (via combustion or decomposition) or incorporated into the soil C pool.

Data specific to crop productivity and harvest in Mexico were not available for this study, and croplands were not mapped separate from other agricultural lands and forest plantations in the study by deJong et al. (2010). As such, we were not able to report estimates of sources and sinks for the Mexican cropland sector separately in this study, but rather included the contribution of soil carbon stock changes from agricultural establishment and abandonment in the Other Lands sector for Mexico.

\section{Other lands sector inventories}

The Other Lands sector was used in this study to include two additional fluxes: (1) net surface carbon fluxes from lands not included in Forest Land or Crop Land sectors (i.e. grasslands, settlements and other lands) and (2) $\mathrm{CO}_{2}$ emissions from the 
combustion, decay, and respiration of carbon in harvested forest and crop products. $\mathrm{NEE}_{\mathrm{O}}$ was calculated for Canada and the US by combining various component fluxes according to the following equation:

$$
\mathrm{NEE}_{\mathrm{O}}=\mathrm{NEE}_{\mathrm{G}}+\mathrm{NEE}_{\mathrm{S}}+\mathrm{E}_{\mathrm{H}}+\mathrm{E}_{\mathrm{L}}+\mathrm{E}_{\mathrm{F}},
$$

which considered the net carbon balance of grassland areas $\left(\mathrm{NEE}_{\mathrm{G}}\right)$, the net carbon balance of human settlement areas $\left(\mathrm{NEE}_{\mathrm{S}}\right), \mathrm{CO}_{2}$ emissions from human respiration $\left(\mathrm{E}_{\mathrm{H}}\right), \mathrm{CO}_{2}$ emissions from livestock respiration $\left(\mathrm{E}_{\mathrm{L}}\right)$ and $\mathrm{CO}_{2}$ emissions from the decay of harvested forest products $\left(\mathrm{E}_{\mathrm{F}}\right)$. For $\mathrm{NEE}_{\mathrm{G}}$ and $\mathrm{NEE}_{\mathrm{S}}$ we used general, area-weighted estimates of 'Grassland' and per-capita estimates of 'Settlements/Other' sink categories reported in the EPA GHG inventory for years 2000 2006 (EPA, 2011). We then extrapolated area-weighted $\mathrm{NEE}_{\mathrm{G}}$ and per-capita $\mathrm{NEE}_{\mathrm{S}}$ according to the area or human population represented by each category in each reporting zone. The area of Other Lands in each reporting zone of Canada and the US is calculated as the remainder of the total area of each zone after subtracting the Forest Land and Crop Land areas from the inventory data sets. The estimates of the product emission terms $\left(\mathrm{E}_{\mathrm{H}}+\mathrm{E}_{\mathrm{L}}+\mathrm{E}_{\mathrm{F}}\right)$ are described in the next section and in the Supporting Information.

The data set containing state-level estimates of carbon flux from the Other Lands sector in Mexico was developed using the same Eqn (4) as the Forest Lands sector. To calculate $\mathrm{NEE}_{\mathrm{O}}$ for Mexico, we included the component flux estimates for the non-forest types of the LU/LC classification used by deJong et al. (2010), which included agricultural lands, forest plantations, scrubland, grassland, wetland, and other nonforest classes. Fuelwood harvest was calculated as a sink in the Forest Lands sector, with emissions transferred to the Other Lands sector (in the same reporting zone that the fuelwood was harvested). The area represented by the Other Lands sector in each reporting zone of Mexico was calculated as the remainder of the total area of each zone after subtracting the forest class areas based on the LU/LC categories used by deJong et al. (2010).

\section{Lateral transfer and emissions of harvested products}

In this analysis, the key to linking the Forest Lands and Crop Lands sectors with the Other Lands sector was through data on harvested products (both forest and agricultural), thereby allowing for tracking the movement of carbon between sector and reporting zone. Here, we used the 'atmospheric flow' approach that, according to IPCC Guidelines, accounts for net emissions or removals within national - or, in our case, reporting zone - boundaries (Eggelston et al., 2006). Carbon removal due to growth and emissions due to primary consumption were accounted for in the Forest Land or Crop Land sector of the 'producing' zone. The carbon emissions from secondary consumption were attributed to the Other Lands sector, redistributed proportionately among the reporting zones of the relevant country according to simple assumptions about where the products are likely to be consumed (and thus where the carbon there-in will be returned to the atmosphere as $\mathrm{CO}_{2}$ ) . Our accounting reflects the assumption that some amount of the carbon in harvested products was not likely to be emitted directly from within the sector (Forest Lands or Crop Lands) that it originates from, but rather in the 'other' lands that the consumers (i.e., humans and livestock) occupy.

Harvested product emissions occurred via the combustion, decay and respiration of harvested wood products (HWP) and harvested crop products (HCP) through secondary consumption by humans (HWP and HCP) and livestock (HCP). Based on the forest and crop inventory data sets, harvested products were summed to national-level pools and adjusted for international imports and exports. Foreign trade of HWP was determined from the FAOStat database for Canada and the Environmental Protection Agency (EPA) GHG Inventory (EPA, 2011) for the US. Foreign trade of HCP was based on the Canadian Socio-Economic Information Management System (Statistics Canada) and the USDA Economic Research Service's 'Foreign Agricultural Trade of the United States' 2010 report. Our simple assumption for allocating the tradeadjusted remaining pools was based on distributing product emissions to the level of the reporting zones proportionally according to human population (HWP and HCP) and data on livestock emissions (HCP). The national-level total HCP from this study was allocated to both human and livestock consumption. The human portion was calculated based on percapita consumption and emissions (West et al., 2009). The remaining $\mathrm{HCP}$ was then allocated to livestock emissions (i.e. assuming no net annual storage of $\mathrm{HCP}$ ) considering emissions factors for different species, rather than population counts directly. $\mathrm{CO}_{2}$ emissions from livestock consumption of HCP were distributed proportional to year 2006 methane emissions through enteric fermentation per reporting zone for the US from the USDA Greenhouse Gas Inventory (2008) and for Canada from the Statistics Canada (2006) Census of Agriculture. In the case of longer lived HWP, we used data on stock change in national wood product pools (EPA, 2011) to account for both carbon storage and emissions. Since wood products can be longer lived than our study period, the product pools included 'inherited' stocks and emissions from wood products harvested prior to our study period. Details for the collection and analysis of HWP and HCP carbon data and flux estimates are provided in the Supporting Information.

\section{Uncertainty in inventories and additional fluxes}

We characterized the uncertainty of the inventory-based estimates of NEE presented herein by attaching previous analyses of the major components of the carbon budget of each sector considered in this study (Table S11). We represented the uncertainty around each component in relative terms (as\% of the estimate) based on the relevant Monte-Carlo analysis reported in national-level GHG inventories, where available, as well as expert judgment based on previous studies. The ranges of uncertainty on the sector-level mean estimates were calculated by summing the upper and lower bounds for each component flux of the sector; the percent uncertainty, then, was the range between the bounds relative to the mean total flux estimate of the sector. 
With respect to the aggregate estimate of continental-scale NEE, another major source of uncertainty came from those components of the carbon budget that are potentially important, but were not measured or estimated by the GHG inventories. These components included fluxes from unmanaged/ not inventoried lands (wetlands), potentially important mechanisms not captured (woody encroachment on non-forest landscapes), other potential carbon storage pools (rivers and reservoirs) and lateral fluxes (dissolved organic carbon export from soil through rivers to the ocean) not measured in the inventories (Table S12). The 'best estimate' flux for each of these components was reported in the SOCCR (Chapter 3; Pacala et al., 2007), where expert judgment suggests that these estimates are essentially $100 \%$ uncertain.

\section{Inventory and model data comparison}

To compare flux estimates at the national and sub-national scales, we included here results based on the inverse modeling approach from among the suite of NACP-participating AIMs that submitted surface flux estimates at $1 \times 1$ degree grid cell resolution to the RCIS activity. The models within this set of seven (Table 1b) differ in their various formulations and methodologies, including the spatial/temporal resolution, the land model for generating the $a$ priori surface fluxes, and the atmospheric transport model employed in the inversion. In two cases (Peters et al., 2007; Lokupitiya et al., 2008), emissions from biomass burning were prescribed and the reported NEE is the sum of the residual land flux (done by inversion) and the prescribed biomass burning flux.

We included in this study a set of 17 NACP-participating TBMs that contributed regional or continental scale results of recent-era ( 2000 to 2006) simulations based on the forward modeling approach. All models were required to submit their best estimate of NEE, which included different component fluxes depending on the particular model (Table 1c). Most models contributed results that cover all the reporting zones for NA used in this study $(n=97)$, whereas some models (CanIBIS, MC1, TEM6) covered subsets of the region. The individual models were based on different simplifying assumptions, used different environmental driving data and initial conditions, and formulated the processes controlling carbon exchange in different ways. Most broadly they were differentiated into prognostic models, which are self-regulating with respect to leaf area index, and diagnostic models in which leaf area (or a surrogate) is prescribed from remote sensing imagery. Among the prognostic models there were significant differences with respect to treatment of fire and other disturbances. Details of these model differences are described by Schwalm et al. (2010) and Huntzinger et al. (in press).

The contributed results from TBMs and AIMs for the NACP-RCIS were standardized to monthly flux estimates at $1 \times 1$ degree resolution over the NA land area. To allow comparison at the temporal and spatial scales of the inventories, monthly data were first aggregated to annual flux estimates. These annual flux estimates were then translated from the $1 \times 1$ degree grid to an estimate for each sector within each reporting zone (Fig. 2). The map of reporting zones consisted of 97 analysis polygons that matched the resolution of the GHG inventory-based data, as described above. The coverage of sectors (Forest Lands, Crop Lands, and Other Lands) was based on a $1 \mathrm{~km}^{2}$ grid using aggregation of land cover classes from the GLC2000 data set (Bartholome \& Belward, 2005). Juxtaposing these data layers permitted the TBMs and AIMs
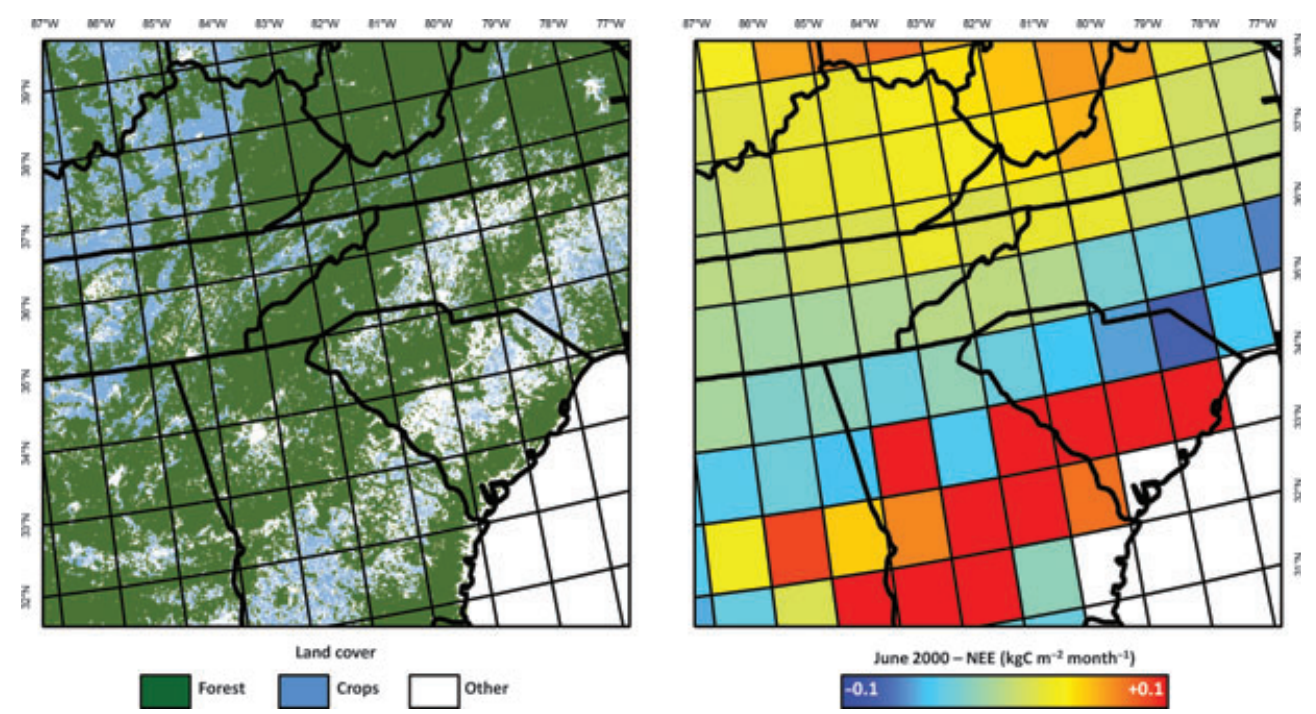

Fig. 2 Forest and cropland reclassification for model-data processing of country/sector carbon flux estimates. The left panel shows the spatial distribution of forest, crops and 'other' lands as per our categorization of the GLC2000 map product. The right panel show the results for simulated monthly NEE at $1 \times 1$ resolution from an example forward model. For each modeled monthly flux estimate (right), the grid-scale value was proportioned to the Forest Lands, Crop Lands and Other Lands sectors by weighting the flux according to the relative area of each land category (left) within a given grid cell. Model estimates at the level of the reporting zone were generated by then summing the flux across each sector within a given zone. 
simulated fluxes to be summed by reporting zone and sector. Note that this approach meant that there could be discrepancies between how an inventory or model analysis might label the land surface and how we reported it (based on GLC-2000), but that compromise was necessary to accomplish the comparison.

\section{Results}

\section{Inventory estimates}

Overall, the data and methodology used herein for combining GHG inventory-based data on surface fluxes and carbon transfers across each sector and country suggest

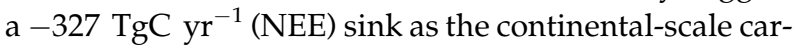
bon balance of North America over the 2000-2006 analysis period (Table 2). Our analysis finds that the continental-scale $\mathrm{CO}_{2}$ sink is driven primarily by $\mathrm{CO}_{2}$

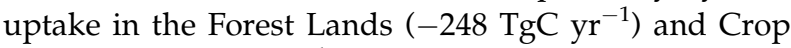

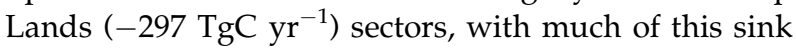
offset by the source effect from the Other Lands sector

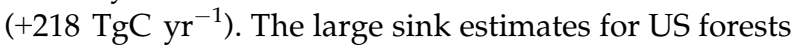

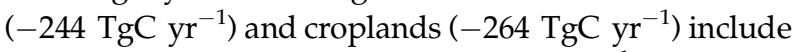

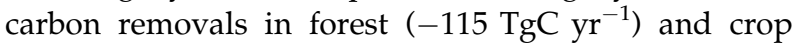

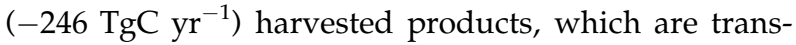
ferred to the Other Lands sector and contribute to a

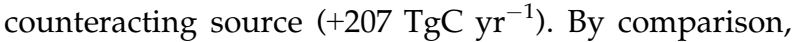
the data show smaller sink estimates for forests

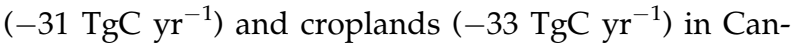
ada, which are also offset in part by a source effect from

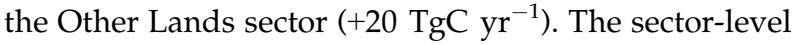
NEE estimates for Mexico show a different pattern due to the flux estimates being primarily based on land use change effects. Here, Mexican forests are estimated as a

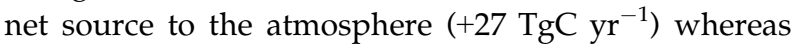
the data show a net sink effect from the Other Lands sec-

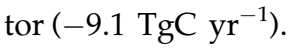

The detail on the inventory-based estimates of component fluxes that produce the patterns of NEE in the Forest Lands sector is illustrated in Fig. 3, and estimates for each reporting zone are provided in the Sup-

Table 2 Inventory-based estimates of average annual total NEE (TgC yr ${ }^{-1}$ ) by country/sector, 2000-2006

\begin{tabular}{|c|c|c|c|c|}
\hline \multirow[b]{2}{*}{ Country } & \multicolumn{3}{|l|}{ Sector } & \multirow[b]{2}{*}{ Total } \\
\hline & $\begin{array}{l}\text { Forest } \\
\text { lands }\end{array}$ & $\begin{array}{l}\text { Crop } \\
\text { lands }\end{array}$ & $\begin{array}{l}\text { Other } \\
\text { lands }\end{array}$ & \\
\hline Canada & -31.00 & -32.79 & 20.21 & -43.58 \\
\hline US & -244.38 & -264.32 & 206.69 & -302.01 \\
\hline Mexico & 27.47 & $n / a$ & -9.06 & 18.42 \\
\hline North America & -247.91 & -297.11 & 217.84 & -327.17 \\
\hline
\end{tabular}

porting Information (Tables S1, Canada; S2, the US; and S3, Mexico). Forests in Canada and the US show carbon gains over the 2000-2006 time period in the dead

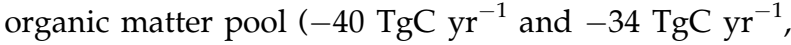
respectively) and the data suggest a large sink in live

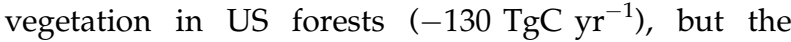
inventory-based estimate of $\Delta$ Live in Canada's managed forest area represents an overall decrease in car-

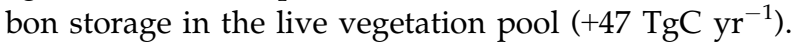

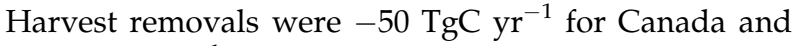

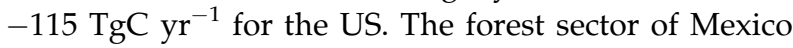
shows an overall loss of carbon over the time period of the inventory data (1993-2002) driven by biomass

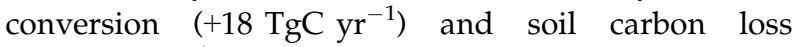

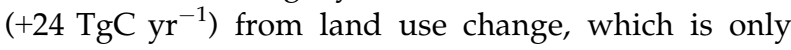
partially offset by regenerating forests on abandoned

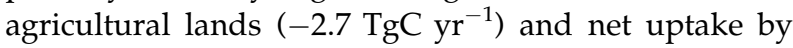

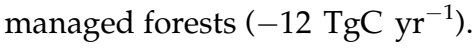

The inventory-based estimates of component crop NPP and harvest removals, along with $\triangle$ Soil and NEE in the Crop Lands sector of each reporting zone in Canada and the US over the 2000-2006 time period are provided in the Supporting Information (Tables S4, Canada; and S5, the US). Overall, total carbon uptake by croplands (crop NPP) was more than six times greater in the US $\left(-569 \mathrm{TgC} \mathrm{yr}^{-1}\right)$ than Canada $\left(-89 \mathrm{TgC}^{-1}\right)$. With small amounts of gain in cropland SOC stocks $(\Delta$ Soil $)$ over this time period

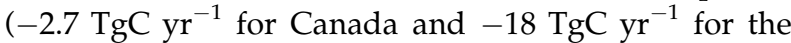
US), Crop Lands NEE was dominated by the crop har-

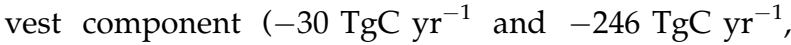
respectively). The concentration of the Crop Land NEE sink in the mid-continent region is illustrated in Fig. 3.

The magnitude of the contribution of forest and crop products to the national-/continental- scale net sink is a function of the relative amount of harvest that is stored over the time period, exported internationally, or returned to the atmosphere as non- $\mathrm{CO}_{2}$ emissions. Most of the forest harvest contribution to the continental-scale sink (Table S6) is attributed to carbon storage

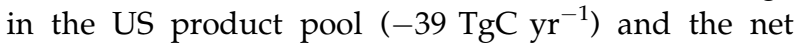

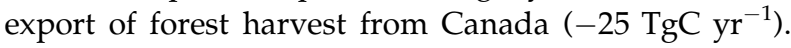
On the fate of Canada and US harvested crop products, $79 \%$ is emitted as $\mathrm{CO}_{2}$ on the continent, with another $20 \%$ accounted for by international exports (a small amount is emitted as $\mathrm{CH}_{4}$ from livestock plus the contribution to stock increase in the human population). The contribution of harvested wood and crop products to the spatial pattern of NEE was assessed by calculating, for reporting zone, the net balance between product harvest and emissions (Fig. 4). This measure of each reporting zone's net product balance (NBP) highlights the large producers of forest (Northwest and Southeast) and crop (mid-West) products next to the 
FOREST LANDS

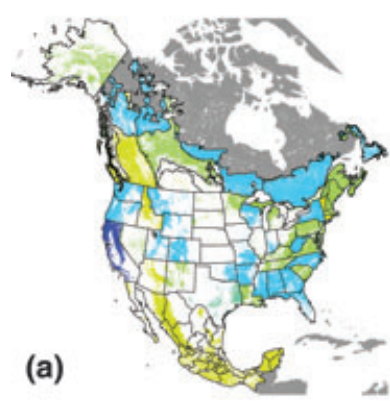

CROP LANDS

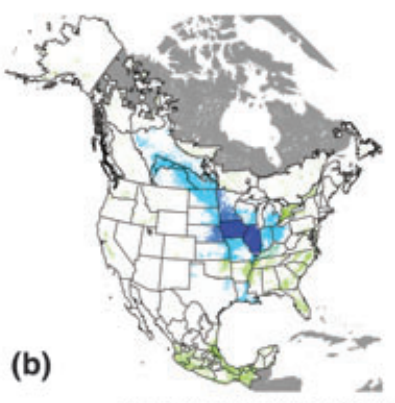

OTHER LANDS

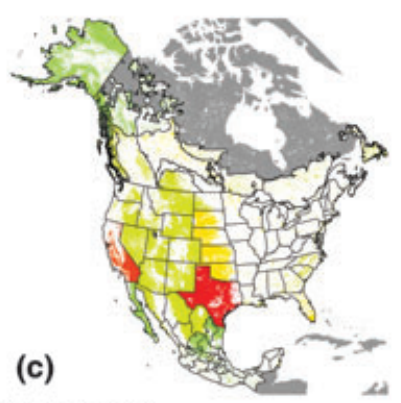

(c)

Average annual NEE $\left(\mathrm{TgC}^{-1} \mathrm{r}^{-1}\right), 2000-2006$

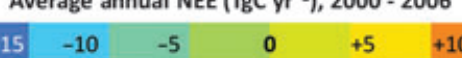

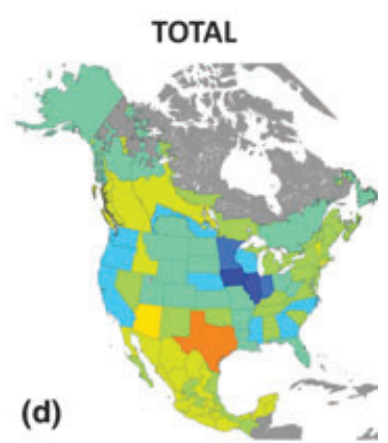

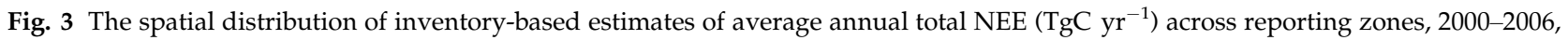
for the (a) Forest Lands, (b) Crop Lands, and (c) Other Lands sectors, as well as for (d) all land area.

large consumers based on large human and livestock populations (California and Texas).

The magnitudes of the contribution of the various flux components to the total NEE from the Other Lands sector in each reporting zone over the 2000-2006 time period are illustrated in Fig. 3 and provided in the Supporting Information (Tables S7, Canada; and S8, the US). Grassland and settled areas contribute a small

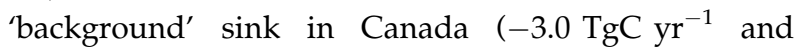

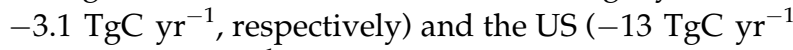
and $\left.-27 \mathrm{TgC}^{-1}\right)$. However, the emission of carbon that is transferred from the Forest Lands and Crop Lands sectors in the form of harvested (wood and crop) products overwhelm this small sink, resulting in a net $\mathrm{CO}_{2}$ source from the Other Lands sectors of both Canada and the US over this time period. Livestock emissions of $\mathrm{CO}_{2}$ related to the consumption of harvested crop products account for the largest portion of this

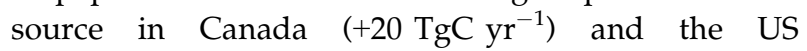

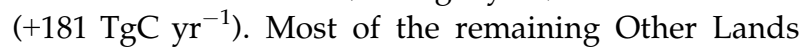
sector source effect is due to emissions from the decay of harvested wood products in Canada $\left(+5.4{\left.\mathrm{TgC} \mathrm{yr}^{-1}\right)}^{-1}\right.$

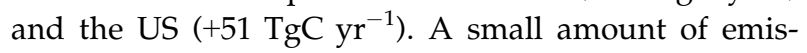
sions is attributed to human consumption of harvested crop products in Canada $\left(+1.8 \mathrm{TgC}^{-1}\right)$ and the US

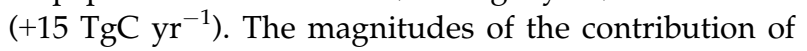
the various flux components to the total NEE from non-forest lands (Other Lands sector) in each reporting zone of Mexico over the 1993-2002 time period are provided in the Supporting Information (Table S9). The net sink effect estimated for the other lands sector of Mexico over this time period is driven by carbon storage in

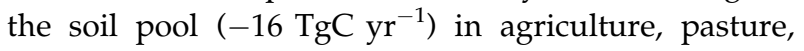
and forest plantation lands. Some of this sink is offset
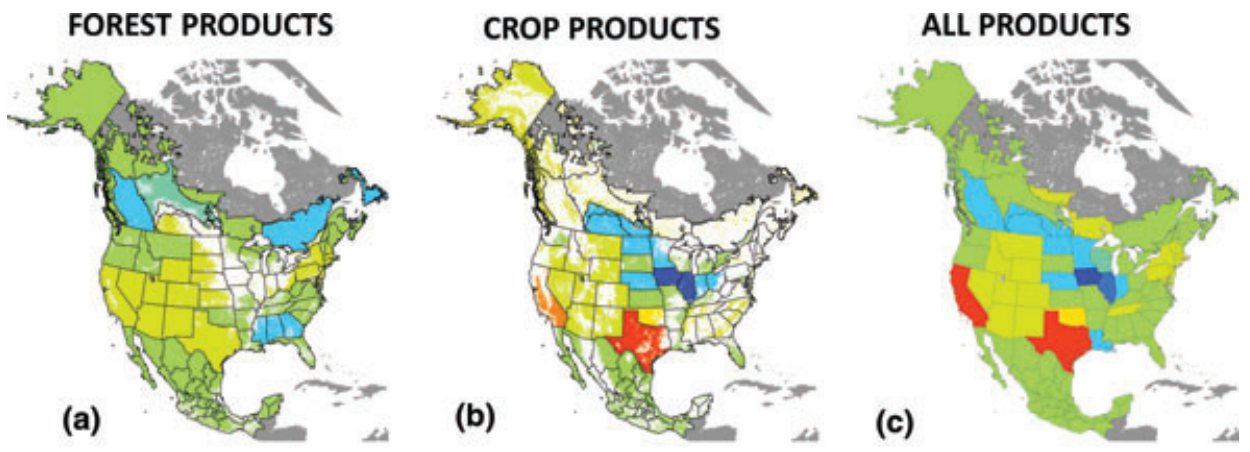

Net product harvest - emissions $\left(\mathrm{TgC}_{\mathrm{gr}} \mathrm{r}^{-1}\right), 2000-2006$

$\begin{array}{llllllll}-25 & -20 & -15 & -10 & -5 & 0 & +5 & +10+15+20\end{array}$

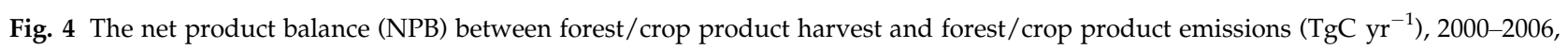
for each reporting zone from the inventory-based estimates, shown for (a) forest harvest products balance, $N_{P B}=\left(H_{R}+H_{E}\right)+E_{F}$, with croplands masked; (b) crop harvest products, $\mathrm{NPB}_{\mathrm{C}}=\mathrm{H}_{\mathrm{R}}+\left(\mathrm{E}_{\mathrm{H}}+\mathrm{E}_{\mathrm{L}}\right)$, with forest lands masked; and (c) all products, $\mathrm{NPB}_{\mathrm{TOT}}=\mathrm{NPB}_{\mathrm{F}}+\mathrm{NPB}_{\mathrm{C}}$. A negative value represents a net producing (exporting) zone and a positive value represents a net consuming (importing/emitting) zone. 
by $\mathrm{CO}_{2}$ emissions attributed to fuelwood harvest $\left(+6.8 \mathrm{TgC} \mathrm{yr}^{-1}\right)$, which is assumed here to be used within the same reporting zone that it was harvested.

\section{Uncertainties and additional fluxes}

Based on summing the upper and lower bounds on the range of uncertainty for each major component flux of the three sectors, the aggregate percent uncertainty on the inventory-based, continental-scale NEE estimate is approximately $77 \%$, giving a range of -76 to -556 $\mathrm{TgC} \mathrm{yr}^{-1}$ (Table 3). At the sector-level, percent uncertainty on the inventory-based NEE estimates range from $17 \%$ for Crop Lands to $41 \%$ and $45 \%$ for Forest Lands and Other Lands, respectively. More detail on the uncertainty estimates for individual components, and the sources of these estimates, are given in the Supporting Information (Table S11). We also considered an additional $-239 \mathrm{TgC} \mathrm{yr}^{-1} \mathrm{NEE}$ from 'best estimates' of additional components of the NA carbon budget that are not measured or estimated by the inventories, which are potentially significant but highly uncertain mostly due to the lack of available data. These estimates, primarily from those reported in the SOCCR (Pacala et al., 2007), include additions to the continen-

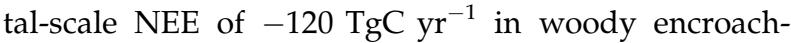

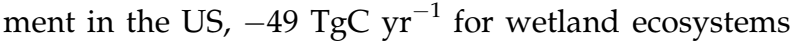

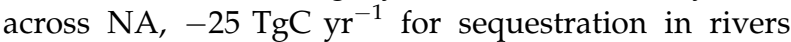
and reservoirs of the US, and $-45 \mathrm{TgC} \mathrm{yr}^{-1}$ for DOC export from Canada and US rivers (Table S12). Given

Table 3 The continental-scale, aggregate uncertainty around the inventory-based mean estimates of sector-level fluxes analyzed in this study, along with 'additional fluxes' not represented by the inventories. The detailed uncertainty estimates and additional fluxes for the various underlying components are provided in the Supporting Information (Tables S11 and S12)

\begin{tabular}{|c|c|c|c|c|}
\hline \multirow[b]{2}{*}{ Sector } & \multirow[b]{2}{*}{$\begin{array}{l}\text { Mean } \\
\text { estimate }\end{array}$} & \multicolumn{3}{|c|}{$\begin{array}{l}\text { Uncertainty range relative } \\
\text { to estimate }\end{array}$} \\
\hline & & $\%$ & 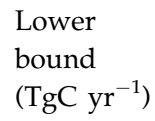 & 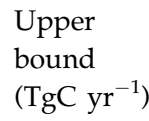 \\
\hline Forest lands & -245.30 & 41 & -346.21 & -144.40 \\
\hline Crop lands & -297.11 & 17 & -347.54 & -246.68 \\
\hline Other lands & 217.84 & 45 & 120.82 & 314.86 \\
\hline Continental total & -324.57 & 77 & -556.14 & -76.21 \\
\hline $\begin{array}{l}\text { Total 'additional } \\
\text { fluxes' }\end{array}$ & -239.00 & 100 & -572.93 & 0.00 \\
\hline $\begin{array}{l}\text { Continental total } \\
\text { w/'additional } \\
\text { fluxes' }\end{array}$ & -563.57 & 86 & -1050.93 & -76.21 \\
\hline
\end{tabular}

that each of these estimates carries at least 100\% uncertainty, the aggregate additional flux could add anywhere from 0 to $-573{\mathrm{TgC} \mathrm{yr}^{-1}}^{-1}$ our overall inventory-based estimate of continental-scale NEE.

\section{Comparing inventory estimates to alternative scaling approaches}

The mean model estimates (Table 4) from both the inverse $\left(-931 \mathrm{TgC}_{\mathrm{yr}}^{-1}\right.$ NEE) and forward (-511 $\left.\mathrm{TgC} \mathrm{yr}^{-1}\right)$ approaches suggest a larger continental-scale total sink than does the result of our analysis of the various inventory-based data sets $\left(-327 \mathrm{TgC}^{-1}\right.$, from Table 2). At the level of the reporting zone, different patterns among the three scaling approaches were compared by showing area-weighted NEE estimates for each sector in map format (Fig. 5). The range for mean annual NEE over North America among the inverse

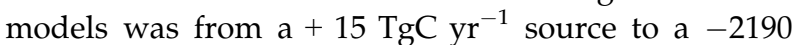
$\mathrm{TgC} \mathrm{yr}^{-1}$ sink, with the five mid-range estimates clustering around a mean of $-869 \pm 223 \mathrm{TgC} \mathrm{yr}^{-1}$. The range of forward model estimates was from a small

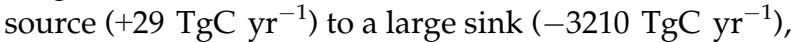
with no real central tendency.

The mean modeled NEE estimates from the forward and inverse approaches (Table 4) follow a similar pattern of relative magnitude by country/sector as the inventory-based estimates, where the largest sink estimates are for the Forest Lands sector of the US $\left(-282{\mathrm{TgC} \mathrm{yr}^{-1}}^{-1}\right.$ from the AIMs and $-158 \mathrm{TgC} \mathrm{yr}^{-1}$ from the TBMs), with smaller sink estimates for Can-

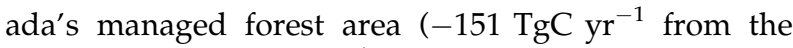
AIMs and $-73 \mathrm{TgC} \mathrm{yr}^{-1}$ from the TBMs). The mean NEE estimate for the Forest Lands sector of the US from the sets of AIMs represents a similar sink as we calculated from our analysis of the inventory data $\left(-244 \mathrm{TgC}^{-1}\right)$, while the TBMs mean suggests a smaller sink. For Canada, both sets of models estimate a larger sink than the inventory-based results

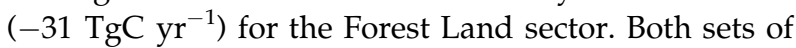
models also estimate a smaller total Crop Lands sector sink for NA $\left(-167{\mathrm{TgC} \mathrm{yr}^{-1}}^{-1}\right.$ from the AIMs and $-134 \mathrm{TgC}^{-1} r^{-1}$ from the TBMs) than does the inventory-based approach $\left(-295 \mathrm{TgC}^{-1}{ }^{-1}\right)$, which does not include in its estimate any data for the Crop Lands sector of Mexico. Compared to the relatively large $\mathrm{CO}_{2}$ source from the Forest Lands sector of Mexico as estimated by the inventory data $\left.\left(+27 \mathrm{TgC}^{-1}\right)^{-1}\right)$, the mean Forest Lands sector NEE is near neutral $\left(+0.9 \mathrm{TgC} \mathrm{yr}^{-1}\right)$ from the AIMs and a small sink $\left(-15 \mathrm{TgC}^{-1}{ }^{-1}\right)$ from the TBMs, although it should be noted that the time period covered by the inventory data (1993-2002) is different than that of the model estimates ( 2000-2006). Beyond the Forest Lands and Crop 
Table 4 The count (n), mean and standard deviation (SD) of average annual NEE estimates (TgC $\left.\mathrm{yr}^{-1}\right), 2000-2006$ by country and sector, for the sets of inverse and forward models. The mean estimates from the inventory-based approach (from Table 2) for each country and sector are included for comparison

\begin{tabular}{|c|c|c|c|c|c|c|c|}
\hline \multirow[b]{2}{*}{ Country/Sector } & \multicolumn{3}{|c|}{ Inverse models } & \multicolumn{3}{|c|}{ Forward models } & \multirow{2}{*}{$\frac{\text { Inventory-based }}{\text { Mean estimate }}$} \\
\hline & $n$ & Mean & SD & $n$ & Mean & SD & \\
\hline Canada total & 7 & -237.6 & 96.7 & 15 & -124.6 & 205.5 & -43.6 \\
\hline Forestland & 7 & -150.9 & 55.4 & 15 & -73.3 & 141.3 & -31.0 \\
\hline Cropland & 7 & -35.5 & 24.3 & 15 & -22.1 & 27.5 & -32.8 \\
\hline Other & 7 & -51.2 & 28.3 & 15 & -29.3 & 41.0 & 20.2 \\
\hline U. S. Total & 7 & -685.1 & 573.7 & 17 & -357.0 & 575.5 & -302.0 \\
\hline Forestland & 7 & -282.0 & 214.1 & 17 & -157.6 & 309.5 & -244.4 \\
\hline Cropland & 7 & -136.8 & 124.0 & 17 & -94.6 & 160.3 & -264.3 \\
\hline Other & 7 & -266.2 & 263.2 & 17 & -104.8 & 127.9 & 206.7 \\
\hline Mexico total & 7 & -8.7 & 159.2 & 12 & -29.0 & 71.8 & 18.4 \\
\hline Forestland & 7 & 0.9 & 63.6 & 12 & -15.1 & 48.1 & 27.5 \\
\hline Cropland & 7 & 5.5 & 33.2 & 12 & -17.5 & 33.0 & $n / a$ \\
\hline Other & 7 & -15.1 & 63.8 & 12 & 3.6 & 34.1 & -9.1 \\
\hline N. America total & 7 & -931.3 & 670.3 & 12 & -510.7 & 729.3 & -327.2 \\
\hline Forestland & 7 & -432.1 & 254.1 & 12 & -246.0 & 419.2 & -247.9 \\
\hline Cropland & 7 & -166.8 & 150.9 & 12 & -134.2 & 194.3 & -297.1 \\
\hline Other & 7 & -332.5 & 301.3 & 12 & -130.5 & 151.8 & 217.8 \\
\hline
\end{tabular}

Lands sector comparisons, it is primarily the difference in NEE estimates for the Other Lands sector that is responsible for the larger continental-scale sink estimates from the model means vs. the inventory-based data. At the continental-scale, the model mean NEE estimates from the AIMs $\left(-333 \mathrm{TgC} \mathrm{yr}^{-1}\right)$ and TBMs $\left.\left(-131 \mathrm{TgC}^{-1}\right)^{-1}\right)$ show a large sink in the Other Lands sector, whereas the results of the inventory-based methodology used herein suggests a large source

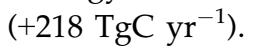

\section{Discussion}

\section{Inventory-based estimates}

Our GHG inventory-based results are derived from, and so are generally consistent with, recent inventorybased updates of the carbon budgets reported for Canada forests (Pan et al., 2011; Stinson et al., 2011), US forests (Heath et al., 2011; Pan et al., 2011) and agriculture (West et al., 2011), and the agriculture and forest sector in Mexico (deJong et al., 2010). The new information provided in this study comes from the combination of those national- and sector- specific estimates into a continental-scale analysis, while using a novel conceptual model to estimate land-atmosphere exchange of $\mathrm{CO}_{2}$ at the sub-national scale. As a result, the inventory-based data and the methodology used in this study suggest considerable spatial variability in NEE estimates across sectors and reporting zones (Fig. 3). The spatial patterns are driven both by the estimated direct, vertical surface fluxes as well as the lateral transfer of carbon between sectors in the form of harvested products (Fig. 4). The spatial patterns show a negative balance (i.e., sink effect) between product emissions and harvest in reporting zones that have relatively smaller human and livestock populations but productive forests and croplands with high harvest rates (and vice versa).

The largest Forest Lands sector $\mathrm{CO}_{2}$ sinks are located primarily on the west coast and in the southeast of the US, and these estimates are similar in magnitude to sub-regional analyses by Turner et al. (2011) and Masek \& Collatz (2006). Despite covering roughly similar area, Canada shows a much smaller magnitude sink in the Forest Lands sector than does the US. Although some of this difference could be related to methodology (Kurz et al., 2009; Heath et al., 2011), Canada's forests are likely to be storing less carbon than US forests due to older age class structure, lower growth rates and higher frequency and severity of disturbances in boreal forests vs. temperate forests (Kurz et al., 2008; Stinson et al., 2011). All the reporting zones for Mexico show a small source from the forest sector, with the largest sources in southern states that have higher proportions of lowland tropical forest, where most of the forest clearing has occurred (deJong et al., 2010). The analysis of the net 


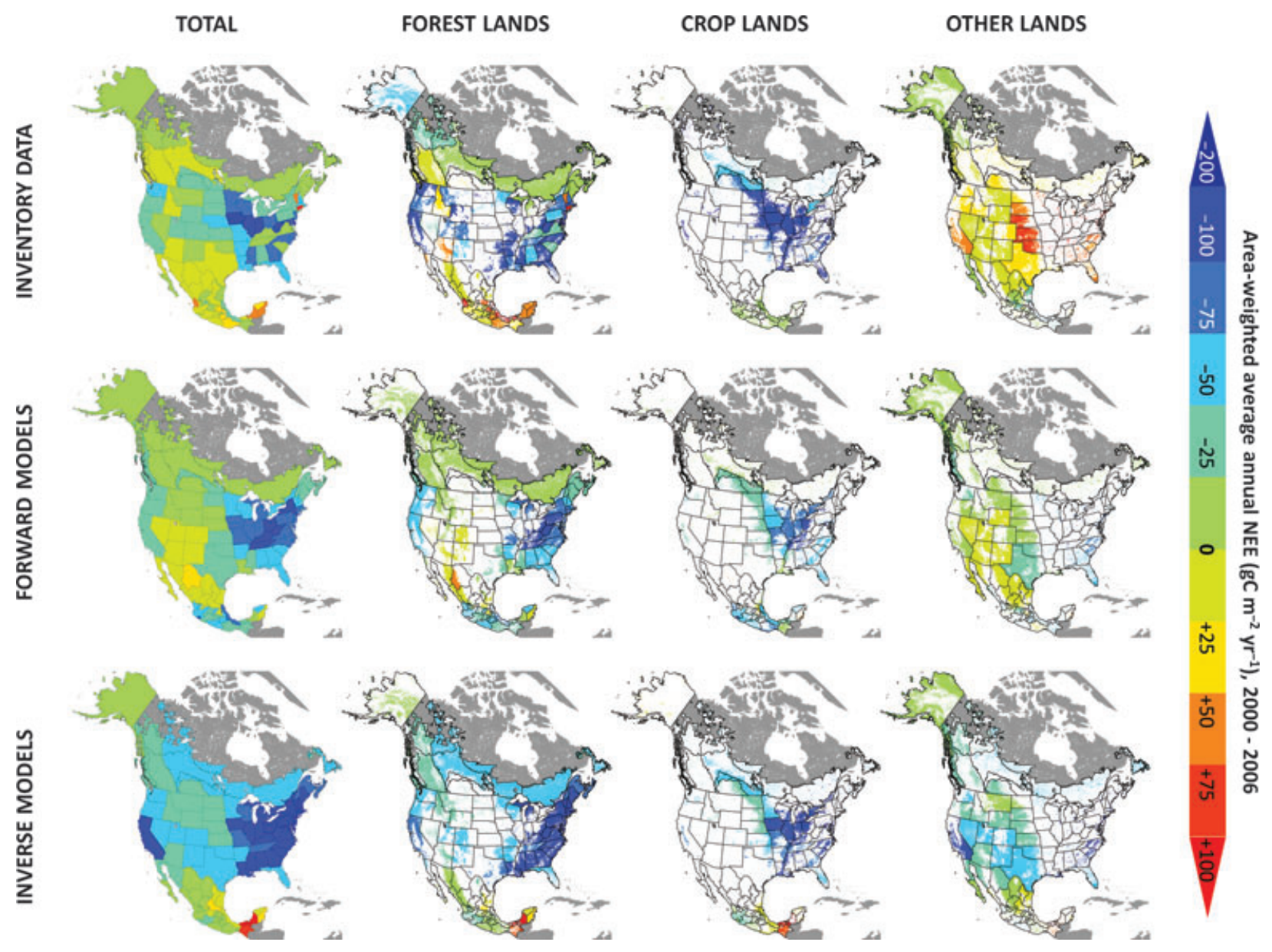

Fig. 5 Mean area-weighted average annual NEE $\left(\mathrm{g} \mathrm{C} \mathrm{m}^{-2} \mathrm{yr}^{-1}\right), 2000-2006$ for the Forest Lands, Crop Lands and Other Lands sectors, along with all land (total), in each reporting zone, from inventory-based estimates against mean results from the sets of terrestrial biosphere (forward) models and inverse models.

land use change impact implies that, at the nationallevel, emissions from biomass conversion across Mexico are outpacing uptake from forests re-growing after agricultural abandonment.

The continental-scale mapping of NEE for the Crop Lands sector reflects the pattern of strong net carbon uptake over the mid-western US, as discussed in other studies (Corbin et al., 2010; West et al., 2010). Although we assign this uptake to the Crop Lands sector sink, most (79\%) of this carbon is returned to the atmosphere after consumption and respiration by humans and livestock (West et al., 2009) within North America, which we attribute to the Other Lands sector source. Nearly all the remaining balance of harvested crop product $\mathrm{C}$ is exported internationally. Although emissions of this remaining balance are not counted from the atmospheric perspective over North America, these emissions will occur in other countries. Thus, from a global atmospheric perspective, the net contribution of harvested crop product $C$ to NEE is near neutral.

\section{Comparison to model estimates}

The mean model estimates from both the forward (TBMs) and inverse (AIMs) approaches suggest a much stronger overall NA sink than the inventory-based estimate. Yet model estimates generally do follow similar spatial patterns as the inventory-based data where the strongest sinks are found in US forests on the east and west coasts and in croplands of the mid continent, with a smaller source from the tropical area of southern Mexico (Fig. 5). However, the model vs. inventory differences are mostly in the magnitude of the estimates, where the sector-specific model means suggest (1) a larger sink over forested regions, (2) a smaller sink over crop land areas, and (3) a substantial contribution of non-forest/non-cropland areas to the continental-scale sink (Table 4).

At the national-level, the breakdown of model means for the Forest Lands sectors show good agreement with the inventory-based estimate for the US, but a much 
larger sink than that estimated by inventory-based modeling for the Forest Lands sector in Canada. Inventory-based studies indicate that $\mathrm{CO}_{2}$ uptake in Canada's forests is being increasingly offset by emissions due to disturbance (Kurz \& Apps, 1999; Kurz et al., 2008; Stinson et al., 2011), but our comparisons here suggest that the impacts of these disturbances are not being resolved by the model approaches. In contrast to the Forest Lands sector comparison, the model means estimate less than half of the sink strength compared to the inventory-based estimate for the US Crop Lands sector. There is clearly information in the $\mathrm{CO}_{2}$ observations indicating a strong drawdown in the crop intensive region of the US (Corbin et al., 2010; Crevoisier et al., 2010), but the model ensembles analyzed herein appear to be underestimating its strength, relative to the inventory estimates.

The difference in the sign and magnitude between the inventory and model approaches in the case of the Other Lands sector highlights (1) our inventory-based approach for allocating product respiration and decomposition based on populations of humans and livestock and (2) the data gaps and uncertainties associated with GHG inventory-based estimates of carbon stocks and fluxes outside of managed forest and agricultural lands. Although a subset of the TBMs included herein considers forest and/or crop product emissions, none considers the lateral transfer of these products (i.e. product emissions occur in the same grid cell as growth and harvest). AIMs derive the 'land flux' after prescribing the fossil fuel and fire emissions. In practice, the land flux thus includes the product sources. However, it is generally acknowledged that uncertainty remains high for inversion-based flux estimates at the sub-continental scale (Butler et al., 2010; Bruhwiler et al., 2011). As such, source areas associated with the respiration of harvested products may not be spatially resolved. On the other hand, potential sinks in the Other Lands sector that may be included in the model estimates could be missing or are of highly uncertain magnitude based on GHG inventory methods. For example, the SOCCR reports an additional $120 \mathrm{TgC} \mathrm{yr}^{-1}$ of uptake through woody encroachment in the US, but other field-based studies (Goodale \& Davidson, 2002b; Jackson et al., 2002) do not support a sink of that magnitude. Further, it is not clear how much of this mechanism is captured in the inventory sampling if and where it is occurring. It is evident in the US forest statistics that a large proportion of the increase in US forest land has occurred in the West. Due to long re-measurement periods and changes in methods over recent time periods, however, it is not possible determine how much of that increase is directly attributable to woody encroachment.

\section{Synthesis}

Multi-method flux comparisons over other large regions are similar to our comparison in several respects. In both Europe (Janssens et al., 2003) and China (Piao et al., 2009), the land base was a sink for carbon and represented a significant proportion of fossil fuel emissions (7-12\% in Europe and $28-37 \%$ in China). In both cases the inversion-based sink estimate was about double the inventory or process modelbased sink estimates. An updated, multi-sector study of the European C balance (Schulze et al., 2010), based primarily on inventory methods, suggests that $C$ sinks (e.g., forests and grassland) are largely offset by emissions (e.g., from croplands). As with our North American study, the lateral movement of harvested products was also considered to be a large influence on the spatial distribution of sources and sinks in Europe (Ciais et al., 2006; Luyssaert et al., 2010). Over the 2000-2006 time period, our national-level inventory-based NEE estimates represent approximately $29 \%$ and $19 \%$ of fossil fuel emissions for Canada $\left(0.15 \mathrm{PgC} \mathrm{yr}^{-1} \pm 4 \%\right)$ and the US (1.56 $\mathrm{PgC} \mathrm{yr}^{-1} \pm 4 \%$ ), respectively (Boden $e t$ al., 2010). Our inventory-based NEE estimate for Mexico adds approximately $18 \%$ to the fossil fuel source from

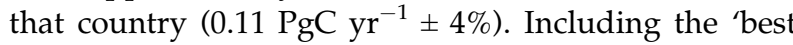
estimates' for additional component fluxes not measured in the inventories would increase the inventorybased sink estimate to approximately $31 \%$ of total continental-scale fossil emissions (1.83 ${\mathrm{PgC} \mathrm{yr}^{-1}}^{-1}$. Mean NEE estimates from the ensembles of TBMs and AIMs represent land-based sinks that offset $28 \%$ and $51 \%$, respectively, of total continental-scale fossil emissions (1.83 $\mathrm{PgC} \mathrm{yr}^{-1}$ ).

A large land-based $\mathrm{CO}_{2}$ sink over NA has been a persistent feature of inversion analyses and comparisons of inversions to bottom-up estimates at the regional (Hayes et al., 2011; Turner et al., 2011) and continental (Pacala et al., 2001) scales have suggested that it is an overestimate. First, the biases in vertical mixing in the transport models could lead to the overestimates of the source strength in tropical latitudes and overestimates of the sink strength in mid latitudes (Stephens et al., 2007; Gatti et al., 2010). Second, overestimates of NA west coast boundary conditions for $\mathrm{CO}_{2}$ concentration may force the AIMs to create an artificial sink to maintain consistency with the measured $\mathrm{CO}_{2}$ observations encountered further east (Göckede et al., 2010; Schuh et al., 2010). With respect to the forward modeling approach, the extremely large range in the flux estimates from the TBMs can be attributed to variation in model formulation and process representation along with differences in the climate and land use data sets used as model drivers (Schwalm et al., 2010; Huntzin- 
ger et al., in press). In many cases, the large estimated sinks in TBMs are associated with assumptions of robust favorable effects of rising $\mathrm{CO}_{2}$ on vegetation growth, but the magnitude of the effect of this mechanism remains highly uncertain (Joos et al., 2002; Girardin et al., 2011). The relative impact of any $\mathrm{CO}_{2}$ fertilization effect is generally not possible to ascertain from the inventory data. In the Canada forest inventory approach, the species and site specific yield curves used to model NPP would not likely capture this effect. The US forest inventory should, in theory, capture this effect between re-measurement periods, but it is impossible to separate it from all other effects on growth.

This study's inventory-based, continental-scale NEE

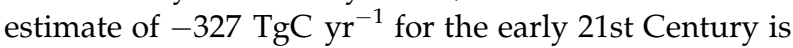
generally lower than estimates from previous decades,

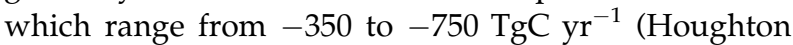
et al., 1999; Pacala et al., 2001, 2007; Goodale et al., 2002a). The SOCCR is the most recent and comprehensive study, which yielded a NEE estimate of

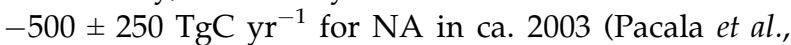
2007). Although the sector-level NEE estimates presented herein are generally consistent with those reported for 'forests' and 'agricultural soils' in the SOC$\mathrm{CR}$, the largest difference contributing to the lower continental carbon sink estimate here is that we did not include the large but highly uncertain additional fluxes associated with land-based sinks of atmospheric $\mathrm{CO}_{2}$ (Table 3).

We would need to assume a large contribution of these non-inventoried 'additional fluxes' on top of the inventory-based sink estimate to approach the magnitude suggested by the means of the model ensembles analyzed in this study. For example, adding the 'best guess' of these non-inventoried 'additional fluxes' gives

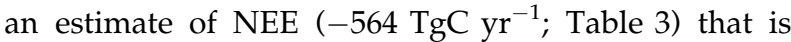
similar to the mean of the TBMs ensemble

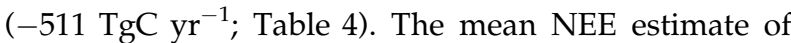
the AIMs ensemble (-931 $\mathrm{TgC}_{\mathrm{yr}}^{-1}$; Table 4) is found only near the extreme lower bound of the uncertainty around the inventory-based NEE estimate for the 'con-

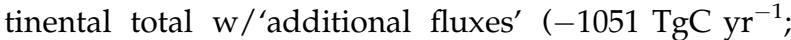
Table 3). However, given that this analysis highlights the (1) uncertainties in component fluxes, (2) mismatches in spatial patterns, and (3) large spread in estimates across models, any convergence between the approaches would not necessarily occur for the 'right' reasons. Rather, this study draws attention to those components of the NA carbon budget that require more careful study through measurement and inventory methods. Regarding the modeling approaches, the comparisons here strongly suggest the need to better understand the causes underlying the large spread in estimates, most likely achieved through formal and controlled (i.e. common protocol) model inter-comparison studies informed by benchmarking frameworks based on reliable measurements and observational data sets.

This study highlights the differences in three general scaling approaches to NEE (inventory, forward and inverse modeling), and by comparing and evaluating their estimates several strengths and weaknesses emerge (Table 5). Our study suggests that, even considering the data gaps and uncertainties, the inventory-based approach to estimating NEE can still provide a substantial amount of important information at the sub-continental scale, and help inform estimates of both vertical and lateral transfers of most key carbon budget components. The strength of the inventory-based measurement approach is primarily its reliance on a large

Table 5 A comparison of the strengths and weaknesses of alternative NEE scaling approaches (inventory-based, AIMs and TBMs)

\begin{tabular}{|c|c|c|c|}
\hline & Inventory-based & $\begin{array}{l}\text { Atmospheric inversion models } \\
\text { (AIMs) }\end{array}$ & $\begin{array}{l}\text { Terrestrial biosphere models } \\
\text { (TBMs) }\end{array}$ \\
\hline Strengths & $\begin{array}{l}\text { 1) Employs a large number of } \\
\text { repeated biomass measurements } \\
\text { 2) Allows estimation of product- } \\
\text { related } C \text { sources }\end{array}$ & $\begin{array}{l}\text { 1) assimilates measurements of } \\
\text { atmospheric } \mathrm{CO}_{2} \text { concentration } \\
\text { 2) Employs atmospheric mass } \\
\text { balance }\end{array}$ & $\begin{array}{l}\text { 1) Processes are represented so } \\
\text { attribution is possible } \\
\text { 2) Sensitive to interannual variation } \\
\text { in climate } \\
\text { 3) Many opportunities for } \\
\text { validation }\end{array}$ \\
\hline Weaknesses & $\begin{array}{l}\text { 1) Not all C pools are measured } \\
\text { 2) Possible undersampling } \\
\text { 3) Limited attribution ability } \\
\text { 4) Missing NEE of unmanaged } \\
\text { ecosystems } \\
\text { 5) Poorly resolved temporally }\end{array}$ & $\begin{array}{l}\text { 1) Transport model uncertainty } \\
\text { 2) Limited number of } \mathrm{CO}_{2} \\
\text { measurements } \\
\text { 3) Low spatial resolution } \\
\text { 4) Limited attribution ability }\end{array}$ & $\begin{array}{l}\text { 1) Many inputs, each with their } \\
\text { own uncertainty } \\
\text { 2) Many parameters, each with their } \\
\text { own uncertainty } \\
\text { 3) Spatial resolution may not } \\
\text { resolve management scale } \\
\text { disturbances }\end{array}$ \\
\hline
\end{tabular}


number of ground-based measurements of components useful to estimate carbon stocks and stock changes. Although there are benefits in retaining independence among approaches for estimating carbon fluxes, progress can also be made by more formally integrating them. For example, TBMs are increasingly making use of inventory and remote sensing data for model drivers, parameterization, calibration, and validation (e.g. Hurtt et al., 2002; Running et al., 2004). Such integrated 'bottom up' modeling frameworks could provide the initial land surface flux estimates for inversion analyses and, in turn, information about errors in predicted $\mathrm{CO}_{2}$ concentration would inform further model development. Furthermore, observations and inventory-based measurements can provide critical benchmarking data sets for model evaluation (Randerson et al., 2009). Ultimately, confidence in our ability to understand and predict the role of the NA carbon cycle in the global climate system will increase as the estimates from these different approaches begin to more closely converge and are combined in more fully integrated modeling systems.

\section{Acknowledgements}

Research was conducted in part at Oak Ridge National Laboratory, and supported by the US Department of Energy (DOE), Office of Science, Biological and Environmental Research. Oak Ridge National Laboratory is managed by UT-Battelle for DOE under contract DE-AC05-00OR22725. The research reported in this paper was supported by multiple sources, including USDA CSREES grant 2008-35615-18959, NASA New Investigator Program grant NNX10AT66G and NASA Terrestrial Ecology Program grant NNX09AL51G. The authors would like to thank all of the modeling teams participating in the North American Carbon program and providing simulation result for this analysis through the Regional - Continental Interim Synthesis activity (http://nacarbon.org) and Robert Andres of the Los Alamos National Laboratory for provision of the data on fossil fuel emissions. We also acknowledge the efforts of Chris Williams, Jim Collatz, and the anonymous reviewers for greatly improving the quality of this manuscript through their added insight and constructive criticism.

\section{References}

Bachelet D, Neilson RP, Hickler T et al. (2003) Simulating past and future dynamics of natural ecosystems in the United States. Global Biogeochem. Cycles, 17, 1045, 21 pp, doi: 10.1029/2001GB001508.

Baker DF, Law RM, Gurney KR et al. (2006) TransCom 3 inversion intercomparison: impact of transport model errors on the interannual variability of regional $\mathrm{CO}_{2}$ fluxes, 1988-2003. Global Biogeochemical Cycles, 20, GB1002, 17 pp.

Baker IT, Prihodko L, Denning AS, Goulden M, Miller S, da Rocha HR (2008) Seasonal drought stress in the Amazon: Reconciling models and observations. J. Geophys. Res., 113, G00B01, 10 pp, doi: 10.1029/2007JG000644.

Bartholome E, Belward AS (2005) GLC2000: a new approach to global land cover mapping from earth observation data. International Journal of Remote Sensing, $\mathbf{2 6}$ 1959-1977.

Bechtold WA, Patterson PL (2005) The Enhanced Forest Inventory and Analysis Program - National Sampling Design and Estimation Procedures. SRS GTR-80. USDA Forest Service, Southern Research Station, Asheville, NC, USA.
Boden TA, Marland G, Andres RJ (2010) Global, Regional, and National Fossil-Fuel $\mathrm{CO}_{2}$ Emissions. Carbon Dioxide Information Analysis Center, Oak Ridge National Laboratory, U.S. Department of Energy, Oak Ridge, TN, USA, doi: 10.3334/CDIAC/ 00001_V2010.

Bondeau A, Smith PC, Zaehle S et al. (2007) Modelling the role of agriculture for the 20th century global terrestrial carbon balance. Global Change Biology, 13, 679-706.

Bruhwiler LM, Michalak AM, Tans PP (2011) Spatial and temporal resolution of carbon flux estimates for 1983-2002. Biogeosciences, 8, 1309-1331.

Butler MP, Davis KJ, Denning AS, Kawa SR (2010) Using continental observations in global atmospheric inversions of $\mathrm{CO}_{2}$ : North American carbon sources and sinks. Tellus Series B-Chemical and Physical Meteorology, 62, 550-572.

Chapin FS III, Woodwell GM, Randerson JT et al. (2006) Reconciling carbon-cycle concepts, terminology, and methods. Ecosystems, 9, 1041-1050.

Chevallier F, Bréon F-M, Rayner PJ (2007) Contribution of the Orbiting Carbon Observatory to the estimation of $\mathrm{CO}_{2}$ sources and sinks: Theoretical study in a variational data assimilation framework. J. Geophys. Res., 112, D09307, 11 pp, doi: 10.1029/2006JD007375.

Ciais P, Canadell JG, Luyssaert S et al. (2010) Can we reconcile atmospheric estimates of the Northern terrestrial carbon sink with land-based accounting? Current Opinion in Environmental Sustainability, 2, 225-230.

Ciais P, Borges AV, Abril G, Meybeck M, Folberth G, Hauglustaine D, Janssens IA (2006) The impact of lateral carbon fluxes on the European carbon balance. Biogeosciences Discuss, 3, 1529-1559.

Corbin KD, Denning AS, Lokupitiya EY et al. (2010) Assessing the impact of crops on regional $\mathrm{CO}_{2}$ fluxes and atmospheric concentrations. Tellus Series B-Chemical and Physical Meteorology, 62, 521-532.

Crevoisier C, Sweeney C, Gloor M, Sarmiento JL, Tans PP (2010) Regional US carbon sinks from three-dimensional atmospheric $\mathrm{CO}_{2}$ sampling. Proceedings of the National Academy of Sciences, 107, 18348-18353.

deJong B, Anaya C, Masera O et al. (2010) Greenhouse gas emissions between 1993 and 2002 from land-use change and forestry in Mexico. Forest Ecology and Management, 260, 1689-1701.

Deng F, Chen JM, Ishizawa M et al. (2007) Global monthly $\mathrm{CO}_{2}$ flux inversion with a focus over North America. Tellus Series B-Chemical and Physical Meteorology, 59, 179-190.

Denning AS, Oren R, McGuire AD et al. (2005) Science implementation strategy for the North American carbon program. Report of the NACP Implementation Strategy Group of the U.S. Carbon Cycle Interagency Working Group, U.S. Carbon Cycle Science Program, Washington, DC.

Eggelston HS, Buendia L, Miwa K, Ngara T, Tanabe K. (2006) Guidelines for National Greenhouse Gas Inventories. IPCC National Greenhouse Gas Inventories Programme, Hayama, Japan.

EPA (2011) Inventory of U.S. Greenhouse Gas Emissions and Sinks: 1990-2009. USEPA \#430-R-11-005. U.S. Environmental Protection Agency, Washington, DC. Available at: http://www.epa.gov/climatechange/emissions/usinventoryreport.html (accessed 15 April 2011)

Environment Canada (2011) National Inventory Report 1990-2009: Greenhouse Gas Sources and Sinks in Canada. The Government of Canada's Submission to the UN Framework Convention on Climate Change. Environment Canada, Ottawa, ON. Available at: http://www.ec.gc.ca/ges-ghg/(accessed 16 May 2011).

Fan S, Gloor M, Mahlman J, Pacala S, Sarmiento J, Takahashi T, Tans P (1998) A large terrestrial carbon sink in North America implied by atmospheric and oceanic carbon dioxide data and models. Science, 282, 442-446.

Gatti LV, Miller JB, D'Amelio MTS et al. (2010) Vertical profiles of $\mathrm{CO}_{2}$ above eastern Amazonia suggest a net carbon flux to the atmosphere and balanced biosphere between 2000 and 2009. Tellus Series B-Chemical and Physical Meteorology, 62, 581594.

Girardin MP, Bernier PY, Raulier F, Tardif JC, Conciatori F, Guo XJ (2011) Testing for a $\mathrm{CO}_{2}$ fertilization effect on growth of Canadian boreal forests. Journal of Geophysical Research-Biogeosciences, 116, G01012, 16 pp, doi: 10.1029/ $2010 J G 001287$.

Göckede M, Turner DP, Michalak AM, Vickers D, Law BE (2010) Sensitivity of a subregional scale atmospheric inverse $\mathrm{CO}_{2}$ modeling framework to boundary conditions. Journal of Geophysical Research, 115, D24112.

Goodale CL, Apps MJ, Birdsey RA et al. (2002a) Forest carbon sinks in the Northern Hemisphere. Ecological Applications, 12, 891-899.

Goodale CL, Davidson EA (2002b) Carbon cycle: uncertain sinks in the shrubs. Nature, 418, 593-594.

Gurney KR, Law RM, Denning AS et al. (2002) Towards robust regional estimates of $\mathrm{CO}_{2}$ sources and sinks using atmospheric transport models. Nature, 415, 626-630. 
Gurney KR, Law RM, Denning AS et al. (2004) Transcom 3 inversion intercomparison: model mean results for the estimation of seasonal carbon sources and sinks. Global Biogeochemical Cycles, 18, GB1010, 18 pp, doi: 10.1029/2003GB002111.

Hayes DJ, McGuire AD, Kicklighter DW, Gurney KR, Burnside TJ, Melillo JM (2011) Is the northern high latitude land-based $\mathrm{CO}_{2}$ sink weakening? Global Biogeochemical Cycles, 25, GB3018, 14 pp, doi: 10.1029/2010GB003813.

Heath LS, Smith JE, Skog KE, Nowak DJ, Woodall CW (2011) Managed forest carbon estimates for the US greenhouse gas inventory, 1990-2008. Journal of Forestry, 109, 167-173.

Houghton RA, Hackler JL, Lawrence KT (1999) The US carbon budget: contributions from land-use change. Science, 285, 574-578.

Huntzinger DN, Post WM, Wei $Y$ et al. (in press) North american carbon project (NACP) regional interim synthesis: terrestrial biospheric model intercomparison. Ecological Modeling.

Hurtt GC, Pacala SW, Moorcroft PR, Caspersen J, Shevliakova E, Houghton RA, Moore B 3rd (2002) Projecting the future of the U.S. carbon sink. Proceedings of the National Academy of Sciences of the United States of America, 99, 1389-1394.

Jackson RB, Banner JL, Jobbagy EG, Pockman WT, Wall DH (2002) Ecosystem carbon loss with woody plant invasion of grasslands. Nature, 418, 623-626.

Janssens IA, Freibauer A, Ciais P et al. (2003) Europe's terrestrial biosphere absorbs 7 to $12 \%$ of European anthropogenic $\mathrm{CO}_{2}$ emissions. Science, 300, 1538-1542.

Joos F, Prentice IC, House JI (2002) Growth enhancement due to global atmospheric change as predicted by terrestrial ecosystem models: consistent with US forest inventory data. Global Change Biology, 8, 299-303.

Ju W, Chen JM, Black TA, Barr AG, Liu J, Chen B (2006) Modelling multi-year coupled carbon and water fluxes in a boreal aspen forest. Agricultural and Forest Meteorology, 140, 136-151

King AW, Dilling L, Zimmerman GP et al. (2007). What is the carbon cycle and why care? In: The First State of the Carbon Cycle Report (SOCCR): The North American Carbon Budget and Implications for the Global Carbon Cycle. A Report by the U.S. Climate Change Science Program and the Subcommittee on Global Change Research (eds King AW, Dilling L, Zimmerman GP, Fairman DM, Houghton RA, Marland G, Rose AZ, Wilbanks TJ). pp. 15-20. National Oceanic and Atmospheric Administration, National Climatic Data Center, Asheville, NC, USA.

Krinner G, Viovy N, de Noblet-Ducoudré N et al. (2005) A dynamic global vegetation model for studies of the coupled atmosphere-biosphere system. Global Biogeochem. Cycles, 19, GB1015, 33 pp, doi: 10.1029/2003GB002199.

Kucharik CJ, Foley JA, Delire C et al. (2000) Testing the performance of a dynamic global ecosystem model: Water balance, carbon balance, and vegetation structure. Global Biogeochem. Cycles, 14, 795-825.

Kurz WA, Apps MJ (1999) A 70-year retrospective analysis of carbon fluxes in the Canadian forest sector. Ecological Applications, 9, 526-547.

Kurz WA, Dymond CC, Stinson G et al. (2008) Mountain pine beetle and forest carbon feedback to climate change. Nature, 452, 987-990.

Kurz WA, Dymond CC, White TM et al. (2009) CBM-CFS3: a model of carbon-dynamics in forestry and land-use change implementing IPCC standards. Ecological Modelling, 220, 480-504.

Lokupitiya RS, Zupanski D, Denning AS, Kawa SR, Gurney KR, Zupanski M (2008) Estimation of global $\mathrm{CO}_{2}$ fluxes at regional scale using the maximum likelihood ensemble filter. Journal of Geophysical Research-Atmospheres, 113, D20110, 19 pp, doi: 10.1029/2007JD009679.

Luyssaert S, Ciais P, Piao SL et al. (2010) The European carbon balance. Part 3: forests. Global Change Biology, 16, 1429-1450.

Masek JG, Collatz GJ (2006) Estimating forest carbon fluxes in a disturbed southeastern landscape: integration of remote sensing, forest inventory, and biogeochemical modeling. Journal of Geophysical Research-Biogeosciences, 111, G01006, 15 pp, doi 10.1029/2005JG000062

Michalak AM, Bruhwiler L, Tans PP (2004) A geostatistical approach to surface flux estimation of atmospheric trace gases. J. Geophys. Res., 109, D14109, 19 pp, doi: 10.1029/2003JD004422

Myneni RB, Dong J, Tucker CJ et al. (2001) A large carbon sink in the woody biomass of Northern forests. Proceedings of the National Academy of Sciences of the United States of America, 98, 14784-14789.

Pacala S, Birdsey RA, Bridgham SD et al. (2007) The North American carbon budget past and present. In: The First State of the Carbon Cycle Report (SOCCR): The North American Carbon Budget and Implications for the Global Carbon Cycle (eds King AW, Dilling L, Zimmerman GP, Fairman DM, Houghton RA, Marland G, Rose AZ, Wilbanks TJ), pp. 29-36. National Oceanic and Atmospheric Administration, National Climatic Data Center, Asheville, NC, USA.
Pacala SW, Hurtt GC, Baker D et al. (2001) Consistent land- and atmosphere-based US carbon sink estimates. Science, 292, 2316-2320.

Pan Y, Birdsey RA, Fang J et al. (2011) A large and persistent carbon sink in the world's forests. Science, 333, 988-993.

Parson EA, Haas PM, Levy MA (1992) A summary of the major documents signed at the Earth Summit and the Global Forum. Environment, 34, 12-15.

Peters W, Jacobson AR, Sweeney C et al. (2007) An atmospheric perspective on North American carbon dioxide exchange: carbonTracker. Proceedings of the National Academy of Sciences of the United States of America, 104, 18925-18930.

Peylin P, Bousquet P, Le Quéré C et al. (2005) Multiple constraints on regional $\mathrm{CO}_{2}$ flux variations over land and oceans. Global Biogeochemical Cycles, 19, GB1011, 21 pp, doi: 10.1029/2003GB002214

Piao S, Fang J, Ciais P, Peylin P, Huang Y, Sitch S, Wang T (2009) The carbon balance of terrestrial ecosystems in China. Nature, 458, 1009-1013.

Randerson JT, Hoffman FM, Thornton PE et al. (2009) Systematic assessment of terrestrial biogeochemistry in coupled climate - carbon models. Global Change Biology, 15, 2462-2484.

Randerson JT, Thompson MV, Conway TJ, Fung IY, Field CB (1997) The contribution of terrestrial sources and sinks to trends in the seasonal cycle of atmospheric carbon dioxide. Global Biogeochem. Cycles, 11, 535-560.

Reichstein M, Falge E, Baldocchi D et al. (2005) On the separation of net ecosystem exchange into assimilation and ecosystem respiration: review and improved algorithm. Global Change Biology, 11, 1424-1439.

Rodenbeck C, Houweling S, Gloor M, Heimann M (2003) CO flux history 1982-2001 inferred from atmospheric data using a global inversion of atmospheric transport. Atmospheric Chemistry and Physics, 3, 1919-1964.

Running SW, Nemani RR, Heinsch FA, Zhao M, Reeves M, Hashimoto H (2004) A continuous satellite-derived measure of global terrestrial primary production. BioScience, 54, 547-560.

Schuh AE, Denning AS, Corbin KD et al. (2010) A regional high-resolution carbon flux inversion of North America for 2004. Biogeosciences, 7, 1625-1644.

Schulze ED, Ciais P, Luyssaert S et al. (2010) The European carbon balance. Part 4 integration of carbon and other trace-gas fluxes. Global Change Biology, 16, 14511469.

Schwalm CR, Williams CA, Schaefer K et al. (2010) A model-data intercomparison of $\mathrm{CO}_{2}$ exchange across North America: results from the North American carbon program site synthesis. Journal of Geophysical Research, 115, G00H05, 22 pp, doi 10.1029/2009JG001229.

Stephens BB, Gurney KR, Tans PP et al. (2007) Weak northern and strong tropical land carbon uptake from vertical profiles of atmospheric $\mathrm{CO}_{2}$. Science, 316, 1732-1735.

Stinson G, Kurz WA, Smyth CE et al. (2011) An inventory-based analysis of Canada's managed forest carbon dynamics, 1990 to 2008. Global Change Biology, 17, 2227 2244.

Smith JE, Heath LS, Nichols MC (2010) U.S. forest carbon calculation tool: forestland carbon stocks and net annual stock change. Revised for use with FIADB4.0. NRS GTR-13. USDA Forest Service, Northern Research Station, Newtown Square, PA, USA [DVD-ROM].

Smith JE, Heath LS, Skog KE, Birdsey RA (2006) Methods for calculating forest ecosystem and harvested carbon with standard estimates for forest types of the United States. Gen. Tech. Rep. NE-343. U.S. Department of Agriculture, Forest Service, Northeastern Research Station, Newtown Square, PA.

Smith WB, Miles PD, Perry CH, Pugh SA (2009) Forest resources of the United States, 2007. WO GTR-78. USDA Forest Service, Washington Office, Washington, DC, USA.

Thornton PE, Doney SC, Lindsay K et al. (2009) Carbon-nitrogen interactions regulate climate-carbon cycle feedbacks: results from an atmosphere-ocean general circulation model. Biogeosciences, 6, 2099-2120.

Tian H, Melillo J, Lu C et al. (2011) China's terrestrial carbon balance: Contributions from multiple global change factors. Global Biogeochem. Cycles, 25, GB1007, 16 pp doi: 10.1029/2010GB003838.

Turner DP, GÖCkede M, Law BE et al. (2011) Multiple constraint analysis of regional land - surface carbon flux. Tellus Series B-Chemical and Physical Meteorology, 63, 207-221.

van der Werf GR, Randerson JT, Giglio L, Collatz GJ, Kasibhatla PS, Arellano AF Jr (2006) Interannual variability in global biomass burning emissions from 1997 to 2004. Atmos. Chem. Phys., 6, 3423-3441.

West T, Marland G, Singh N, Bhaduri B, Roddy A (2009) The human carbon budget: an estimate of the spatial distribution of metabolic carbon consumption and release in the United States. Biogeochemistry, 94, 29-41. 
West TO, Bandaru V, Brandt CC, Schuh AE, Ogle SM (2011) Regional uptake and release of crop carbon in the United States. Biogeosciences Discuss, 8, 631654

West TO, Brandt CC, Baskaran LM et al. (2010) Cropland carbon fluxes in the United States: increasing geospatial resolution of inventory-based carbon accounting. Ecological Applications, 20, 1074-1086.

Wofsy SC, Harriss RC (2002) The North American carbon program (NACP). Report of the NACP Committee of the U.S. Interagency Carbon Cycle Science Program. US Global Change Research Program, Washington, DC

Xiao J, Zhuang Q, Baldocchi DD et al. (2008) Estimation of net ecosystem carbon exchange for the conterminous United States by combining MODIS and AmeriFlux data. Agricultural and Forest Meteorology, 148, 1827-1847.

Yang X, Wittig V, Jain AK, Post W (2009) Integration of nitrogen cycle dynamics into the Integrated Science Assessment Model for the study of terrestrial ecosystem responses to global change. Global Biogeochem. Cycles, 23, GB4029, 18 pp, doi: $10.1029 / 2009$ GB003474.

Zeng N, Mariotti A, Wetzel P (2005) Terrestrial mechanisms of interannual CO2 variability. Global Biogeochem. Cycles, 19, GB1016, 15 pp, doi: 10.1029/ 2004GB002273.

\section{Supporting Information}

Additional Supporting Information may be found in the online version of this article:

Data S1. Materials and Methods: National GHG Inventories

Data S2. Comparison with Model-based Estimates

Data S3. Uncertainties and Data Gaps

Data S4. Supporting Information Tables and Figures

Data S5. Supporting Information References

Please note: Wiley-Blackwell are not responsible for the content or functionality of any supporting materials supplied by the authors. Any queries (other than missing material) should be directed to the corresponding author for the article. 


\section{S1. Materials and Methods: National GHG Inventories}

In this study, we have compiled inventory-based data on productivity, ecosystem carbon stock change and harvested product stock change to produce estimates of landatmosphere exchange of $\mathrm{CO}_{2}$ (net ecosystem exchange; NEE) for the 2000 to 2006 time period for the Forest Lands and Crop Lands sectors in Canada and the United States. Additional information from national-level greenhouse gas (GHG) inventories was used to fill in data on carbon balance in the Other Lands sector, including data on human and livestock consumption of harvested products. For Mexico, our analysis accounts primarily for carbon flux due to land use change according to the study by deJong et al. (2010), which covers the period of 1993 to 2002. Data on carbon exchange for each sector are summarized according to GHG inventory "reporting zones". The details on methods by country and sector are described in the following Supporting Information (SI).

The methodology for producing estimates of NEE for each country / sector during our study period is illustrated in this SI primarily through a series of tables detailing the quantitative estimates of the indicator variables representing the main components of the carbon budget for each reporting zone. The indicator variables are represented with the sign convention referenced to the atmosphere in which a negative value signifies a carbon gain in the ecosystem (note the sign of the variables in Table 1). By this definition, productivity and harvest removals have negative values, product and fire emissions have positive values, and negative values of stock change ( $\Delta$ Live, $\Delta \mathrm{DOM}$ and various product pools) represent carbon gains in these pools and vice-versa. The definition, description, data source(s), and equations / calculation(s) used for each indicator variable in each country / sector are provided in the table footnotes. To accompany these tables, brief descriptions of the underlying inventorybased methodologies are provided in the SI text here. 


\section{S1.1 Forest Lands GHG inventories and $N E E_{F}$}

\section{$\underline{\text { S1.1.1 Canada Forest Lands }}$}

Canadian national forest inventory data cover the country's Managed Forest Area and were derived from interpretation of stereo ortho-photography at one initial point in time, where forest cover polygons are delineated and stand attributes interpreted, providing a wallto-wall delineation of forest lands defined as managed. The data set on Canadian forest carbon used here was produced by the Carbon Budget Model of the Canadian Forest Sector (CBMCFS3, Kurz et al., 2009), which employs extensive stand-level growth data to estimate annual carbon uptake (net primary productivity; NPP) along with detailed annual natural disturbance (e.g., fire, insects) and harvest data to track carbon transfers on inventoried lands (i.e. the Managed Forest Area), which comprise $2.3 \times 10^{6} \mathrm{~km}^{2}$ out of the $3.5 \times 10^{6} \mathrm{~km}^{2}$ total Canadian forest area (Stinson et al., 2011). The model provides a spatially referenced, hierarchical system for integrating datasets originating from different forest inventory and monitoring programs. To simulate forest growth and carbon uptake, the model uses an extensive data set of age-based merchantable volume curves in combination with a spatially-explicit representation of the distribution of forest age. The model explicitly simulates carbon transfers according to individual annual disturbance events (natural and anthropogenic). The current model version includes expanded representation and improved prediction of dead organic matter and soil carbon, new algorithms for converting volume to biomass, and improved parameters for organic matter decay (heterotrophic respiration; Rh), fire, insect disturbances, and forest management (Kurz et al., 2009). The Canada forest data set used in this study includes several carbon flux indicator variables at annual resolution over the 2000 to 2006 time period for each reporting zone within the managed forest area (Table S1). 


\section{S1.1.2 U.S. Forest Lands}

The GHG forest inventory data sets for the US are based on traditional forest surveys using the Forest Inventory and Analysis (FIA) program, which includes extensive field plot measurements from which forest area and carbon stock per area are estimated, and a phase related to precision enhancement now usually based on remote sensing imagery. These estimates are coupled with carbon expansion factors (Smith et al., 2006, Heath et al., 2011, EPA 2011), and estimates of carbon stock changes are derived using the Carbon Calculation Tool (CCT; Smith et al., 2010). The CCT is an interactive executable program that reads publicly available forest inventory data collected by FIA and generates state-level annualized estimates of forest carbon stocks based on carbon conversion factors (see EPA 2011), with the down dead wood factors based on results from FORCARB2 (Heath et al., 2010). The results are the forest US GHG inventory estimates reported to the UNFCCC (EPA 2011). For this study, harvest removals were based on published U.S. Forest Service data sets (Smith et al., 2009).

The data set on U.S. forest carbon flux for the 2000 to 2006 time period (Table S2) contains the estimates for average net annual carbon stock change on forest lands based on differences between successive non-redundant estimates of forest stocks. The pools for which carbon stock change data are provided in this data set include: above-ground biomass in live trees, below-ground biomass in live trees, live understory vegetation, standing dead, down dead ("coarse woody debris"), forest floor ("litter and fine woody debris"), and soil organic carbon (SOC). We can aggregate these stock change data into two pools: the change in live biomass ( $\Delta$ Live), which includes above- and below- ground biomass in trees and understory vegetation, and the change in dead organic matter $(\triangle \mathrm{DOM})$, which includes standing dead trees, coarse woody debris, litter and fine woody debris, and SOC. The calculation of NEE for the U.S. Forest Land Sector differs from that used for Canada in that we do not have an 
estimate at the level of the reporting zone for the proportion of carbon emitted in fires that is released as $\mathrm{CO}_{2}$.

\section{$\underline{\text { S1.1.3 Mexico Forest Lands }}$}

The data set containing state-level estimates of carbon flux from forests in Mexico (Table S3) was developed from the results of the study by deJong et al. (2010), which assessed changes in biomass and soil carbon stocks as a result of forest management and land use change (LUC) between 1993 and 2002. The methodology is based on the carbonaccounting approach proposed by the IPCC (IPCC, 1997) and used field-based estimates of carbon stock densities in live biomass and soil (i.e. $\mathrm{MgC} \mathrm{ha}^{-1}$ ) for each mapped land cover / land use (LU/LC) class (including forest types) extrapolated by the national area of that class at each date (1993 and 2002) to calculate the two-date difference and derive estimates of $\Delta$ Live $_{\text {LUC }}$ and $\Delta$ Soil $_{L U C}$. Estimates of $\Delta$ Live $_{A B N D}$ are based on the rates of biomass increment

(i.e. $\mathrm{MgC} \mathrm{ha}{ }^{-1} \mathrm{yr}^{-1}$ ) extrapolated by the area of each forest type regrowing on lands abandoned between the two dates. The change in live biomass carbon stocks in managed forests ( $\triangle$ Live $_{\mathrm{MNGD}}$; "forestland remaining forestland") is based on estimated rates of wood related uptake in forest vegetation and harvested removals. The area of managed forests (43.7 Mha) represents $61 \%$ of the total area of forest in Mexico in 1993 (71.6 Mha) used here. The methodology does not take into account natural carbon fluxes (growth, mortality, fire) from unmanaged land, as those are not included in the reporting protocol.

For this study, we distributed the national-level estimates of each component flux from the study by deJong et al. (2010) proportionately by an estimate of the relative area of each LU/LC class contained in each state. For the LU/LC area data, we used the Global Land Cover 2000 database (GLC2000) for North America (Latifovic et al., 2002), re-categorized with tropical vs. temperate climatic zone designation from an ecoregion map (Bailey et al., 1994), to match the LU/LC classes used by deJong et al. (2010). This results in the same 
national-level estimates for each component flux in each as LU/LC class as in deJong et al. (2010), while allowing for a more spatially-detailed comparison with model results by generating state-level estimates (and consistent with the estimates for other countries and sectors at the level of the reporting zone). Although this may be the best way to parse the data by reporting zone, a limitation of this approach is that we could potentially miss important differences not attributable to ecoregion, such as land use history and management practices.

Following the LU/LC classification used by deJong et al. (2010), we consider only the component fluxes from the forest classes in the calculation of Forest Lands sector NEE here. The fluxes from scrubland, grassland, wetland, and agricultural classes are considered in the Other Lands sector for the Mexico inventory, described below. As with the approach described for the U.S. Forest Lands inventory, the effects of fire are implicit in the stock changes. Without more detailed data, we assumed that commercial harvest and fuelwood harvest occurred proportional to the relative area of each forest type. As with the Canada and U.S. forest sector data sets, carbon transferred to the product pool (including both commercial and fuelwood harvest) is considered a sink in the Mexican forest sector, and fuelwood was transferred as emissions to the Other Lands sector.

\section{S1.2 Crop Lands sector inventories and $N E E_{C}$}

To estimate surface fluxes of carbon from the North American Crop Lands sector for this study, we collected estimates of crop productivity, harvest and changes in soil carbon stocks over the 2000 to 2006 time period for Canada (Table S4) and the U.S. (Table S5). Data specific to crop productivity and harvest in Mexico were not available for this study, and croplands were not mapped separate from other agricultural lands and forest plantations in the study by deJong et al. (2010). As such, we do not report estimates for the Mexican cropland 
sector in this study, but rather include the contribution of soil carbon stock changes from agricultural establishment and abandonment in the Other Lands sector for Mexico.

The calculation of Crop Lands sector NEE (for Canada and the U.S.) follows that used for the Forest Lands sector, described above, and is consistent with our conceptual model of the vertical, land-atmosphere exchange of $\mathrm{CO}_{2}$ (Figure 1). For crop systems we consider $\Delta$ Live to be equal to zero on an annual basis since the assumption of the data is that NPP is equal to the crop harvest plus residue. We then assumed that, within the same year, the residue carbon is returned to the atmosphere (via combustion or decomposition) or incorporated into the SOC pool. All crop harvest removals (i.e., $\mathrm{H}_{\mathrm{R}}$ ) are considered a Crop Lands sector sink in the reporting zone where they are harvested; unlike the treatment of harvested wood products, we assume no primary consumption emissions within the Crop Lands sector.

\section{S1.2.1 Canada Crop Lands}

For the Canadian Crop Lands sector data set, we extracted information from Canada's national GHG inventory (Environment Canada, 2011) for years 2000 through 2006. These data were already calculated at the level of our reporting zones (modified terrestrial ecozones of Canada, Table S1). Soil organic carbon change factors from changes in agricultural land management practices were calculated using the CENTURY model, version 4.0 (Parton et al., 1988), with focus on key management practices and changes in practices known to cause changes in soil C stocks (Janzen et al., 1997; VandenBygaart et al., 2003). The time series of these changes in practices on agricultural lands across Canada (activity data) were compiled from Canada's Census of Agriculture that is conducted every 5 years. The activity data of the changes in agricultural management practices were combined with the carbon change factor information to calculate sector fluxes for each reporting unit (Environment Canada, 2011). 


\section{S1.2.2 U.S. Crop Lands}

For the U.S. Crop Lands sector data set, we collected the annual, county-level carbon budget estimates from the Carbon Dioxide Information and Analysis Center (http://cdiac.ornl.gov) for years 2000 through 2006 and aggregated them to the level of the reporting zones used in this study (i.e. the 48 contiguous U.S. states; data were not recorded for Alaska or the District of Columbia). The crop NPP and harvest data were derived using a statistical method that includes factors for dry weight, harvest indices, and root:shoot ratios multiplied by yield data from the USDA National Agriculture Statistics Service (NASS), as described by West et al. (2010). The method for estimating $\Delta$ Soil in croplands, as described by West et al. (2008), is based on empirical relationships between crop type, land management (e.g., tillage intensity), soil attributes and climate regime with SOC stocks in the agricultural land use sector.

\section{S1.3 Harvested Product Transfers}

National-level emissions (for Canada and the U.S.) from the secondary consumption of harvested wood products $\left(\mathrm{HWP}_{\mathrm{E}}\right)$ are calculated using estimates of stock changes in the domestic consumption product pools $\left(\Delta \mathrm{HWP}_{\mathrm{IU} D C}, \Delta \mathrm{HWP}_{\mathrm{SWDS} D C}\right)$ adjusted by annual inputs (imports; $\mathrm{HWP}_{\mathrm{IMP}}$ ) and outputs (exports; $\mathrm{HWP}_{\mathrm{EXP}}$ ) to this pool over the 2000 to 2006 time period (Table S6). The carbon in harvested wood (remaining in use and stored in landfills) was estimated for the U.S. using a model that converts removals data to C stocks based on tracking of wood processing and decay rate functions (Skog, 2008). Because of long-term decay rates, these stock change estimates for the wood product pool include "inherited emissions" from products harvested prior to our study period. Product pool stock change data were not available for Canada and so were estimated using the U.S. data based on the same 
ratio of stock change in each pool relative to annual inputs (inputs $=\mathrm{H}_{\mathrm{R}}-\mathrm{H}_{\mathrm{E}}+\mathrm{HWP}_{\mathrm{IMP}}-$ $\left.\mathrm{HWP}_{\mathrm{EXP}}\right)$

National-level emissions (for Canada and the U.S.) from the secondary consumption of harvested crop products $\left(\mathrm{HCP}_{\mathrm{E}}\right)$ are calculated based on inputs of carbon in harvest removals $\left(\mathrm{H}_{\mathrm{R}}\right)$ from the Crop Lands sector adjusted by estimates of international imports ( $\left.\mathrm{HCP}_{\mathrm{IMP}}\right)$ and exports $\left(\mathrm{HCP}_{\mathrm{EXP}}\right)$ over the 2000 to 2006 time period. For HCP, we assume no primary consumption emissions (i.e., $\mathrm{H}_{\mathrm{E}}=0$ ) and no net annual storage of crop harvest (i.e., $\left.\Delta \mathrm{HCP}_{\mathrm{IU} \mathrm{DC}}+\Delta \mathrm{HCP}_{\mathrm{SWDS} D C}=0\right)$

\section{S1.4 Components of $N E E_{O}$ in the Other Lands Sector}

To produce carbon flux estimates for each component of NEE in the Other Lands sector (i.e., $\mathrm{NEE}_{\mathrm{O}}$ ) for each reporting zone in Canada (Table S7) and the U.S. (Table S8), the data base consists of the following information: area of other lands $\left(A_{O}\right)$; human population ( $\left.\mathrm{Pop}_{\mathrm{H}}\right)$; human crop consumption $\left(\mathrm{C}_{\mathrm{H}}\right) ; \mathrm{CO}_{2}$ emissions from human respiration $\left(\mathrm{E}_{\mathrm{H}}\right) ; \mathrm{CH}_{4}$ emissions from livestock $\left(\mathrm{E}_{\mathrm{L}}-\mathrm{CH}_{4}\right) ; \mathrm{CO}_{2}$ emissions from livestock respiration $\left(\mathrm{E}_{\mathrm{L}}\right) ; \mathrm{CO}_{2}$ emissions from the decay of harvested forest products $\left(\mathrm{E}_{\mathrm{F}}\right)$; the net carbon balance of grassland areas $\left(\mathrm{NEE}_{\mathrm{G}}\right)$; the net carbon balance of human settlement areas $\left(\mathrm{NEE}_{\mathrm{S}}\right)$; and the overall, total net land-atmosphere exchange of $\mathrm{CO}_{2}$ from other lands $\left(\mathrm{NEE}_{\mathrm{O}}\right)$. $\mathrm{NEE}_{\mathrm{O}}$ for each reporting zone in Canada and the U.S. is the sum of $E_{H}, E_{L}, E_{F}, N E E_{G}$, and $N_{E} E_{S}$.

National-level emissions, in both Canada and the U.S., from the decay of harvested wood products $\left(\mathrm{HWP}_{\mathrm{E}}\right.$; from Table $\mathrm{S6}$ ) are re-distributed across reporting zones proportionally based on their human population. Assuming that humans are responsible for the secondary consumption of HWP, this re-distribution provides a state-level estimate of $\mathrm{E}_{\mathrm{F}}$ to be used in the overall calculation of $\mathrm{NEE}_{\mathrm{O}}$. 
County-level estimates of human $\mathrm{CO}_{2}$ respiration $\left(\mathrm{E}_{\mathrm{H}}\right)$ for the U.S. in each year 2000 through 2006 were taken from the results of the study by West et al. (2009) and aggregated to the reporting zone (i.e. for each U.S. state). To estimate total human carbon consumption for each state $\left(\mathrm{C}_{\mathrm{H}}\right)$, we applied the consistent consumption-to-respiration ratio (1.14) across all age / gender classes shown in the data produced by West et al. (2009). This ratio implies a small net storage of carbon in humans (i.e. $\mathrm{C}_{\mathrm{H}}>\mathrm{E}_{\mathrm{H}}$ ). Using an average human population per state between 2000 and 2006 based on statistics from the U.S. Census Bureau (2009), we then calculate per capita human consumption $\left(61.6 \mathrm{kgC} \mathrm{yr}^{-1}\right)$ and respiration $\left(54.0 \mathrm{kgC} \mathrm{yr}^{-1}\right)$. We assume here that the difference between $\mathrm{C}_{\mathrm{H}}$ and $\mathrm{E}_{\mathrm{H}}$ does not include $\mathrm{CO}_{2}$ emissions; rather it is the sum of human body weight increase and carbon excreted and emitted as non- $\mathrm{CO}_{2}$ gases (West et al., 2009) and so not included as a component of NEE. These per capita rates from the U.S. data were used to calculate consumption and respiration rates based on the human population of each reporting zone of Canada, which was estimated by overlaying reporting zone boundaries on a map of census units containing year 2006 population estimates from Statistics Canada.

The remaining national-level pool of available crop harvest after human consumption $\left(\mathrm{HCP}_{\mathrm{E}}-\mathrm{C}_{\mathrm{H}}\right)$ is then emitted to the atmosphere by livestock, assuming no net annual storage of carbon in the livestock pool itself (i.e. $\mathrm{C}_{\mathrm{L}}=\mathrm{E}_{\mathrm{L}}-\mathrm{CH}_{4}+\mathrm{E}_{\mathrm{L}}$ ). Not all livestock respiration is included in $\mathrm{NEE}_{\mathrm{O}}$, however, because a certain amount of the carbon is emitted as methane (i.e., $\mathrm{E}_{\mathrm{L}}-\mathrm{CH}_{4}$ ) as a result of enteric fermentation. We used year 2006 methane emissions by livestock through enteric fermentation as reported per reporting zone for the U.S. from the USDA GHG Inventory (2008) and for Canada from the Statistics Canada 2006 Census of Agriculture. In Canada and the U.S., $\mathrm{E}_{\mathrm{L}}$ was estimated for each reporting zone by distributing the national-level estimate of $\mathrm{E}_{\mathrm{L}}$ proportionately by the estimate of $\mathrm{E}_{\mathrm{L}}-\mathrm{CH}_{4}$ in each zone. 
To estimate the $\mathrm{NEE}_{\mathrm{G}}$ and $\mathrm{NEE}_{\mathrm{S}}$ components of the Other Lands sector carbon balance, we used general estimates of "Grassland", "Settlements" and "Other" sink categories reported for national-level inventories. For the U.S., we used carbon balance estimates reported in the EPA Greenhouse Gas Inventory for years 2000 to 2006 (EPA 2011). We calculated annual, national-level $\mathrm{NEE}_{\mathrm{G}}$ as the sum of categories "Grassland Remaining Grassland" and "Land Converted to Grassland" and distributed this flux across reporting zones proportionally according to the area represented by "other land" in each zone. Note that, by definition (EPA IPCC 1997), trees, shrubs and other non-treed lands are considered in the "Grassland" category if they do not meet the criteria for Forest Land (EPA 2011). Annual, national-level NEES is the sum of categories "Settlements Remaining Settlements" and "Other (Landfilled Yard Trimmings and Food Scraps)" and distributed this flux across reporting zones proportionally according to the human population for each zone. For Canada, we estimate $\mathrm{NEE}_{\mathrm{G}}$ by applying the average Grassland sink per area from the U.S. data $\left(2.1 \mathrm{gC} \mathrm{m}^{-}\right.$ $\left.{ }^{2} \mathrm{yr}^{-1}\right)$ by the area represented by "other land" in each reporting zone. NEE for each reporting zone in Canada was estimated by applying the average Settlement / Other sink per capita in the U.S. (95.6 $\mathrm{kgC}$ per capita $\mathrm{yr}^{-1}$ ) by the human population of each reporting zone.

The data set containing state-level estimates of carbon flux from the Other Lands sector in Mexico (Table S9) was developed based on the same flux components as the Forest Lands sector. For this sector, we include the estimates for the non-forest types of the LU/LC classification used by deJong et al. (2010), which include agricultural lands, forest plantations, scrubland, grassland, wetland, and other non-forest classes. The area of "other lands" in each reporting zone of Mexico is calculated as the remainder of the total area of each zone after subtracting the forest class areas based on the LU/LC categories used by deJong et al. (2010). Fuelwood harvest was calculated as a sink in the forest sector, with emissions transferred to the other sector (in the same reporting zone that the fuelwood was 
harvested) where it is considered a source of $\mathrm{CO}_{2}$ to the atmosphere in the calculation of $\mathrm{NEE}_{\mathrm{O}}$ for Mexico. 


\section{S2. Comparison with Model-based Estimates}

The areas represented by the flux estimates in each sector and reporting zone for each country from the model data processing can be compared with the area of each represented by the inventory data at the beginning $(\mathrm{t} 1)$ and end $(\mathrm{t} 2)$ of the time period of analysis (Table S10). Whereas the modeled land areas are static in this analysis and effectively represent year 2000 land cover (i.e. using the GLC2000 base map), the inventory data do show changes in area represented by the different sectors in each country over the 2000 to 2006 time period. The inventory data sets suggest a decrease in cropland area of 2.5 Mha (-1.4\%) in Canada and the U.S. over the time period. The inventory data show a 4.1 Mha $(+1.6 \%)$ increase in forest area in the U.S., with Canada forest area unchanged over the time period. The data presented in the study by deJong et al. (2010) suggest a 2.1 Mha (-2.9\%) decrease in the forest area of Mexico due to land use change, which was added to the area of the Other Lands sector in this study. The model data processing using the GLC2000 classification results in the overestimation by 91 Mha of North American forest area compared to the initial (t1) forest area from the combined Canada, U.S. and Mexico inventory information. That difference is driven by factors such as the break between woodland and forest in the remote sensing classification. It has a small impact on how fluxes are distributed but not on the continental sums. Cropland area, on the other hand, shows good agreement between the model estimates and inventory data for Canada and the U.S. (cropland area was not separated in the Mexico inventory data set, and therefore included in the area of the Other Lands sector). 


\section{S3. Uncertainties and Data Gaps}

Under our inventory-based approach, there are some components of NEE that are 1) included in the stock change data but not explicitly separated (e.g. fire emissions, harvest and land use change effects); 2) included and/or explicitly separated but have uncertainty associated with the estimates (e.g., due to measurement error, sampling design and extrapolation, process understanding, etc.); and 3) are not measured / estimated by the inventories (e.g., unmanaged lands, woody encroachment, wetland and aquatic stocks, fluxes and transfers). In this section, we discuss the importance of these unknown, uncertain and unmeasured components on the interpretation of our inventory-based NEE estimates.

\section{S3.1 Land Use Change}

The inventory-based carbon flux data represent estimates of net stock change, meaning that all flux components that govern total stocks at two points in time are integrated in the estimates. There is the special case concerning the issue of the impact of land use change (LUC) on both the carbon stock change data and our estimates of sector-level NEE. The effect of LUC is implicit (i.e. integrated in) in the data, but the corresponding change in carbon stocks directly attributed to LUC cannot be explicitly separated from the total stock change. Because of this issue, we consider the uncertain role of LUC in the stock change data sets to be an important caveat in the interpretation of our inventory-based, sector-level NEE estimates.

This issue is less important for Canada, where there was not significant change in the managed forest area in Canada during the 2000 to 2006 time period (Stinson et al., 2011). In Mexico, LUC is explicit in the calculation of component carbon flux from the terrestrial 
ecosystems of Mexico (deJong et al., 2010). Where LUC effects are likely most important is in the stock change data set representing the U.S. sectors. Whether changes in component stocks are the result of "real" LUC impacts, that would be reflected in NEE, versus artifacts of the inventory sample, is difficult to ascertain. However: 1) area is conserved among the three sectors (i.e., the area "gained" in the Forest Lands sector is "lost" from the Crop lands and Other Lands sectors); and 2) the effect of changes in inventoried area are integrated with other changes (e.g., growth, harvest, etc.) within the overall estimates of carbon stock change in each sector. Therefore, we can interpret the inventory-based, sector-level estimates of NEE as each sector's contribution to the overall, continental-scale NEE.

\section{S3.2 Characterizing Uncertainty in Flux Estimates}

The assessment presented in this study represents our "best estimates", or central tendencies, that quantify the various components of the continental-scale carbon balance. In a large, complex system, such as that which defines the carbon balance of the North America, it is generally not possible to specify the full uncertainty of estimates based on the sheer number of various "moving parts", each with their own often unknown level of uncertainty. Instead, other statistical techniques can be employed, such as Monte-Carlo type analysis that generates a range of possible outcomes around a mean estimate based on variations through a defined parameter space. Such is often available for GHG inventories, as per IPCC guidelines on Tier 1 uncertainty analysis. Where this more formal characterization is not available, uncertainty can be presented as "expert opinion" based on relevant previous studies (e.g., see SOCCR; King et al., 2007). For the same reasons, within model uncertainty is difficult to characterize in complex TBMs and atmospheric inverse models that are based on large numbers of processes. The alternative is to evaluate ensembles of multiple models, and use the range in 
estimates from the ensemble as a representation of uncertainty via across model variability (see Table 5 in the main text).

Here we characterize the uncertainty of the inventory-based estimates of NEE by attaching previous analyses of the major components of the carbon budget of each sector considered in this study (Table S11). We represent the uncertainty around each component in relative terms (as \% of the estimate) based on the relevant Monte-Carlo analysis reported in national-level greenhouse gas inventories, where available, as well as expert judgment based on previous studies. The ranges of uncertainty on the sector-level mean estimates are calculated by summing the upper and lower bounds for each component flux of the sector; the percent uncertainty, then, is the range between the bounds relative to the mean total flux estimate of the sector.

The upper and lower bounds of ecosystem stock change ( $\Delta$ Live $+\Delta \mathrm{DOM})$ and percent uncertainty around the mean harvested wood products estimate in the Canada Forest Lands sector are based on Monte-Carlo analysis (per IPCC Guidelines on Tier 1 uncertainty analysis) as reported in Environment Canada (2011). Using similar methodology, percent uncertainty around the mean ecosystem stock change and harvested wood products estimate are from the EPA (2011) U.S. GHG Inventory, Chapter 7. Uncertainty associated with the various components of the Mexican carbon budget (both Forest Lands and Other Lands sectors) are also based on IPCC Tier 1 uncertainty analysis, as reported by deJong et al. (2010). Percent uncertainty in $\Delta$ SoilC in U.S. croplands is based on West and Post (2002) as applied spatially and by crop type in West et al. (2008). Percent uncertainty in U.S. Crop $\mathrm{H}_{\mathrm{R}}$ is based on percent error derived from comparison between USDA NASS and AgCensus data (West et al., unpublished data). Percent uncertainty around Canada Crop Lands flux estimates was not available, so the U.S. uncertainty values were applied. Percent uncertainty estimate on $\mathrm{NEE}_{\mathrm{s}}$ is from the analysis by Nowak and Crane (2002) for the conterminous U.S., as cited 
in the SOCCR report (King et al., 2007). Uncertainty on $\mathrm{NEE}_{\mathrm{G}}$ is not available from EPA

(2011); we apply our "expert judgment" that this flux estimate is essentially $100 \%$ uncertain.

\section{S3.3 Additional Fluxes Not Inventoried}

With respect to the aggregate estimate of continental-scale NEE, a major source of uncertainty comes from those components of the carbon budget that are potentially important, but not measured or estimated by the inventories. These components include fluxes from unmanaged / not inventoried lands, (wetlands), potentially important mechanisms not captured (woody encroachment on non-forest landscapes), other potential carbon storage pools (rivers and reservoirs) and lateral fluxes (dissolved organic carbon export from rivers to ocean; DOC) not measured in the inventories. For consideration next to the inventory-based estimates provided here, we provide in Table S12 the "best estimate" flux for each of these components as presented in SOCCR (Chapter 3; Pacala et al., 2007). The estimate of DOC export includes only the contiguous 48 U.S. states, so we added an estimate for Alaska and Canada based on the studies by McGuire et al. (2010) and Manizza et al. (2009). The best estimates of these fluxes all suggest that including them would increase the apparent $\mathrm{CO}_{2}$ sink in North America. However, the expert judgment as reported in SOCCR suggests that these estimates are essentially $100 \%$ uncertain, meaning that we cannot say with confidence whether including these components would have only little effect on the continental-scale estimate, or whether they would substantially increase the sink estimate. 


\section{S4. Supporting Information Tables and Figures}

Table S1. The forest sector carbon budget and estimated land-atmosphere exchange of $\mathrm{CO}_{2}$ by Canada reporting zone based on the

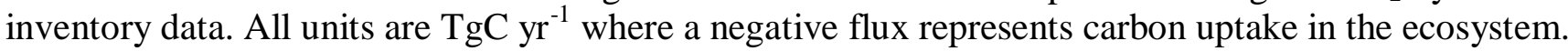

\begin{tabular}{lccccccccc} 
Reporting Zone & \multicolumn{1}{c}{$\mathbf{L i v e C}$} & $\Delta \mathbf{D O M}^{\mathbf{a}}$ & Fire $(\mathbf{C})$ & $\mathbf{H}_{\mathbf{R}}^{\mathbf{b}}$ & $\mathbf{N P P}$ & $\mathbf{R h}$ & Fire $\left._{(\mathbf{C O}}\right)$ & $\mathbf{H}_{\mathbf{E}}^{\mathbf{c}}$ & $\mathbf{N E E}^{\mathbf{d}}$ \\
\hline Atlantic Maritime & 2.61 & 0.45 & 0.05 & -7.11 & -55.86 & 51.77 & 0.05 & 2.13 & -1.91 \\
Boreal Cordillera & -3.04 & -2.54 & 3.39 & -0.50 & -58.64 & 49.17 & 3.05 & 0.15 & -6.26 \\
Boreal Plains & 7.86 & -2.83 & 6.08 & -7.94 & -127.99 & 119.00 & 5.47 & 2.38 & -1.13 \\
Boreal Shield East & -1.65 & -0.21 & 2.03 & -11.61 & -179.27 & 163.77 & 1.83 & 3.48 & -10.19 \\
Boreal Shield West & -3.09 & -0.18 & 4.13 & -2.70 & -70.45 & 60.35 & 3.71 & 0.81 & -5.57 \\
Hudson Plains & -0.38 & 0.07 & 0.00 & 0.00 & -2.41 & 2.10 & 0.00 & 0.00 & -0.31 \\
Mixedwood Plains & -2.06 & 0.15 & 0.02 & -0.29 & -11.80 & 9.58 & 0.01 & 0.09 & -2.12 \\
Montane Cordillera & 47.99 & -37.66 & 6.13 & -11.16 & -141.52 & 134.56 & 5.52 & 3.35 & 1.91 \\
Pacific Maritime & 5.08 & 3.13 & 0.46 & -7.50 & -91.34 & 91.59 & 0.42 & 2.25 & 2.91 \\
Semiarid Prairies & 0.00 & 0.01 & 0.00 & 0.00 & -0.04 & 0.05 & 0.00 & 0.00 & 0.01 \\
Subhumid Prairies & -0.20 & 0.14 & 0.12 & -0.09 & -6.25 & 5.98 & 0.11 & 0.03 & -0.13 \\
Taiga Cordillera & 0.32 & -0.10 & 0.38 & 0.00 & -1.07 & 0.91 & 0.34 & 0.00 & 0.18 \\
Taiga Plains & -5.88 & -1.42 & 2.31 & -0.96 & -52.18 & 41.60 & 2.08 & 0.29 & -8.20 \\
Taiga Shield East & -0.53 & 0.49 & 0.02 & 0.00 & -8.17 & 8.11 & 0.01 & 0.00 & -0.04 \\
Taiga Shield West & -0.14 & 0.09 & 0.89 & 0.00 & -3.63 & 2.70 & 0.80 & 0.00 & -0.13 \\
\hline Canada Totals & $\mathbf{4 6 . 9 1}$ & $\mathbf{- 4 0 . 4 0}$ & $\mathbf{2 6 . 0 1}$ & $\mathbf{- 4 9 . 8 6}$ & $\mathbf{- 8 1 0 . 6 1}$ & $\mathbf{7 4 1 . 2 5}$ & $\mathbf{2 3 . 4 1}$ & $\mathbf{1 4 . 9 6}$ & $\mathbf{- 3 1 . 0 0}$
\end{tabular}

${ }^{\mathrm{a}} \triangle \mathrm{DOM}$ represents carbon stock changes in soil organic matter and in non-live, non-soil pools (standing dead, litter, coarse woody debris)

${ }^{b} \mathrm{H}_{\mathrm{R}}=$ total $\mathrm{C}$ removed from the stand as harvests in the Managed Forest sector of each reporting zone

${ }^{c} \mathrm{H}_{\mathrm{E}}=$ the amount of $\mathrm{C}$ emitted from the processing of harvested products within the forest sector $=-0.3 * \mathrm{H}_{\mathrm{R}}$

${ }^{\mathrm{d}} \mathrm{NEE}=\Delta$ LiveC $+\Delta \mathrm{DOM}-\left(\right.$ Fire $(\mathrm{C})-$ Fire $\left.\left(\mathrm{CO}_{2}\right)\right)+\mathrm{H}_{\mathrm{R}}+\mathrm{H}_{\mathrm{E}}=\mathrm{NPP}+\mathrm{Rh}+$ Fire $\left(\mathrm{CO}_{2}\right)+\mathrm{H}_{\mathrm{E}}$ 
Table S2. The forest sector carbon budget and estimated land-atmosphere exchange of $\mathrm{CO}_{2}$ by U.S. reporting zone based on the inventory data. Negative stock change and flux values represent carbon uptake in the ecosystem. All units are in $\mathrm{TgC} \mathrm{yr}^{-1}$.

\begin{tabular}{|c|c|c|c|c|c|}
\hline Reporting Zone & $\Delta$ Live & $\Delta \mathrm{DOM}^{\mathrm{a}}$ & $\mathbf{H}_{\mathbf{R}}{ }^{\mathrm{b}}$ & $\mathbf{H}_{\mathrm{E}}^{\mathrm{c}}$ & NEE $^{d}$ \\
\hline Alabama & -1.34 & 1.09 & -9.02 & 2.71 & -6.56 \\
\hline Alaska & -1.68 & -1.25 & -0.41 & 0.12 & -3.22 \\
\hline Arizona & 2.12 & 2.63 & -0.06 & 0.02 & 4.71 \\
\hline Arkansas & -3.12 & -0.46 & -6.36 & 1.91 & -8.02 \\
\hline California & -15.04 & -7.69 & -2.78 & 0.83 & -24.67 \\
\hline Colorado & -4.14 & -3.39 & -0.07 & 0.02 & -7.58 \\
\hline Connecticut & -0.31 & 1.54 & -0.05 & 0.01 & 1.19 \\
\hline Delaware & -0.49 & -0.13 & -0.05 & 0.01 & -0.65 \\
\hline Florida & -5.04 & -0.84 & -4.41 & 1.32 & -8.96 \\
\hline Georgia & -7.34 & -0.04 & -10.37 & 3.11 & -14.64 \\
\hline Idaho & 1.96 & 2.18 & -1.42 & 0.43 & 3.15 \\
\hline Illinois & -1.92 & 0.26 & -0.60 & 0.18 & -2.08 \\
\hline Indiana & -4.71 & -1.71 & -0.78 & 0.24 & -6.97 \\
\hline Iowa & -2.90 & -2.77 & -0.17 & 0.05 & -5.79 \\
\hline Kansas & -1.55 & -1.68 & -0.04 & 0.01 & -3.26 \\
\hline Kentucky & -1.03 & 0.78 & -2.43 & 0.73 & -1.96 \\
\hline Louisiana & 0.28 & -0.58 & -6.69 & 2.01 & -4.98 \\
\hline Maine & -0.45 & 1.96 & -3.62 & 1.09 & -1.02 \\
\hline Maryland & -2.43 & -0.24 & -0.28 & 0.08 & -2.86 \\
\hline Massachusetts & -1.71 & -0.58 & -0.07 & 0.02 & -2.34 \\
\hline Michigan & -4.53 & 4.65 & -2.62 & 0.79 & -1.72 \\
\hline Minnesota & -0.57 & -1.07 & -2.68 & 0.80 & -3.52 \\
\hline Mississippi & -1.90 & -4.87 & -8.54 & 2.56 & -12.75 \\
\hline Missouri & -5.39 & -1.53 & -1.43 & 0.43 & -7.93 \\
\hline Montana & -2.85 & -5.13 & -1.15 & 0.34 & -8.78 \\
\hline Nebraska & -0.78 & -0.86 & -0.04 & 0.01 & -1.68 \\
\hline Nevada & -0.30 & -0.85 & -0.01 & 0.00 & -1.15 \\
\hline New Hampshire & -1.05 & -0.26 & -0.30 & 0.09 & -1.52 \\
\hline New Jersey & -2.19 & -0.63 & -0.03 & 0.01 & -2.84 \\
\hline New Mexico & -3.25 & -1.53 & -0.08 & 0.02 & -4.84 \\
\hline New York & -4.86 & -1.11 & -1.19 & 0.36 & -6.81 \\
\hline North Carolina & -5.30 & -1.63 & -8.46 & 2.54 & -12.85 \\
\hline North Dakota & -0.12 & -0.71 & -0.02 & 0.00 & -0.84 \\
\hline Ohio & -2.96 & 0.02 & -0.55 & 0.16 & -3.32 \\
\hline Oklahoma & -3.70 & -2.20 & -1.08 & 0.32 & -6.66 \\
\hline Oregon & -9.65 & 2.68 & -6.14 & 1.84 & -11.27 \\
\hline Pennsylvania & -3.62 & 0.15 & -1.77 & 0.53 & -4.70 \\
\hline
\end{tabular}




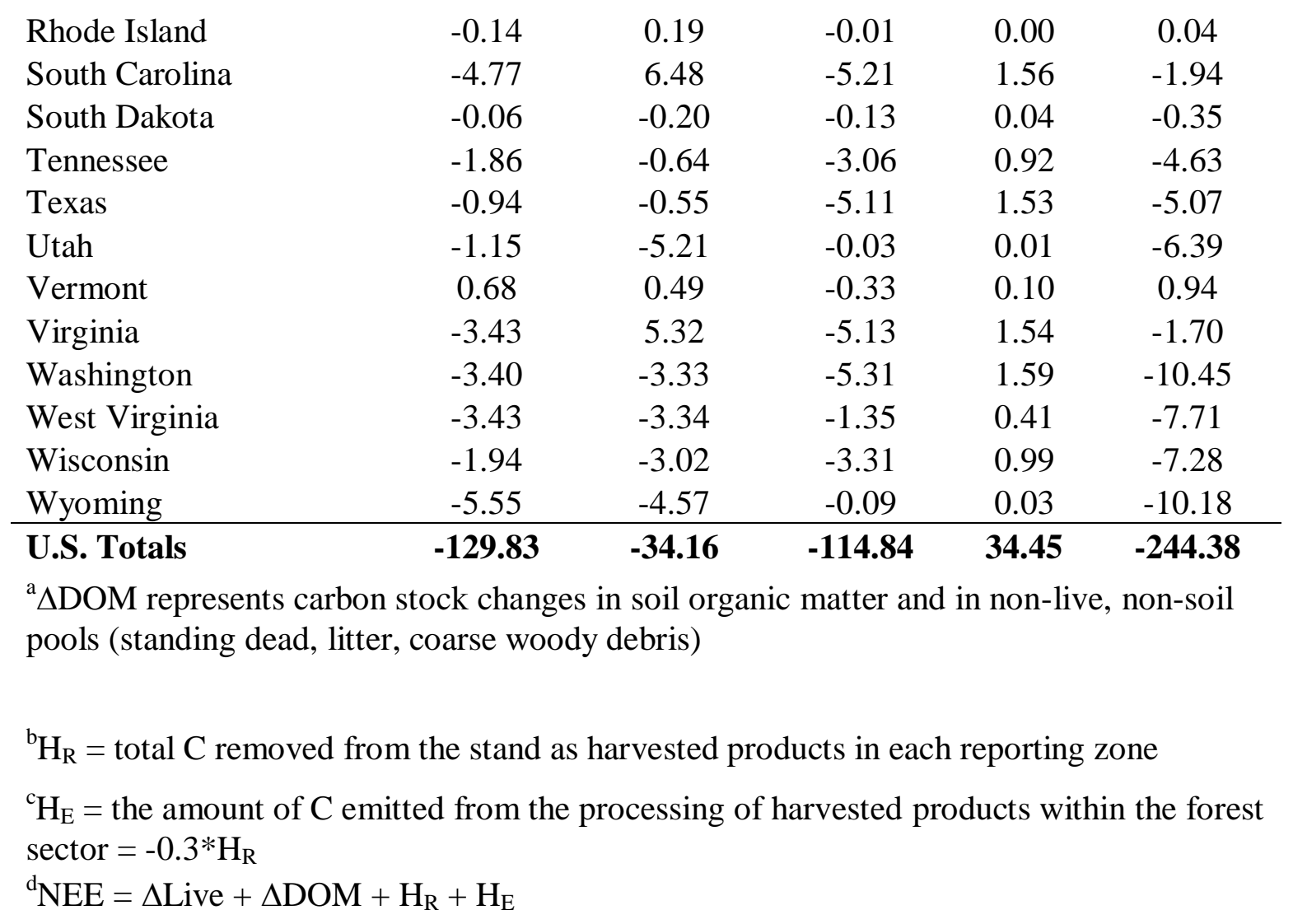


Table S3. The forest sector carbon budget and estimated land-atmosphere exchange of $\mathrm{CO}_{2}$ by Mexico reporting zone based on the inventory data. Negative stock change and flux values

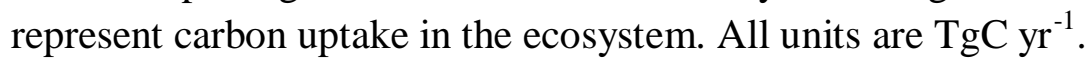

\begin{tabular}{|c|c|c|c|c|c|}
\hline Reporting Zone & $\Delta$ Live $_{\text {LUC }}$ & $\Delta$ Soil $_{\text {LUC }}$ & $\Delta$ Live $_{\mathrm{ABND}}$ & $\Delta$ Live $_{\text {MNGD }}$ & Total NEE \\
\hline Aguascalientes & 0.01 & 0.03 & 0.00 & -0.02 & 0.02 \\
\hline Baja California & 1.07 & 0.13 & -0.03 & -0.35 & 0.81 \\
\hline Baja California Sur & 0.12 & 0.08 & 0.00 & -0.09 & 0.12 \\
\hline Campeche & 1.95 & 1.92 & -0.42 & -0.57 & 2.87 \\
\hline Chiapas & 0.92 & 1.01 & -0.18 & -0.37 & 1.37 \\
\hline Chihuahua & 1.00 & 0.57 & -0.04 & -1.30 & 0.24 \\
\hline Coahuila & 0.33 & 0.13 & -0.01 & -0.32 & 0.12 \\
\hline Colima & 0.01 & 0.01 & 0.00 & -0.01 & 0.01 \\
\hline Distrito Federal & 0.02 & 0.01 & 0.00 & -0.02 & 0.01 \\
\hline Durango & 0.58 & 0.52 & -0.02 & -0.97 & 0.11 \\
\hline Guanajuato & 0.13 & 0.18 & -0.01 & -0.20 & 0.10 \\
\hline Guerrero & 0.33 & 0.70 & -0.02 & -0.50 & 0.51 \\
\hline Hidalgo & 0.33 & 0.89 & -0.07 & -0.18 & 0.97 \\
\hline Jalisco & 0.42 & 1.14 & -0.06 & -0.42 & 1.08 \\
\hline Mexico & 0.30 & 0.18 & -0.01 & -0.26 & 0.22 \\
\hline Michoacan & 0.33 & 0.40 & -0.01 & -0.47 & 0.24 \\
\hline Morelos & 0.04 & 0.04 & 0.00 & -0.05 & 0.03 \\
\hline Nayarit & 0.64 & 1.62 & -0.14 & -0.27 & 1.85 \\
\hline Nuevo Leon & 0.13 & 0.10 & -0.01 & -0.21 & 0.02 \\
\hline Oaxaca & 1.39 & 3.43 & -0.28 & -0.72 & 3.81 \\
\hline Puebla & 0.56 & 1.15 & -0.10 & -0.35 & 1.25 \\
\hline Queretaro & 0.08 & 0.09 & 0.00 & -0.12 & 0.04 \\
\hline Quintana Roo & 2.17 & 1.95 & -0.47 & -0.63 & 3.02 \\
\hline San Luis Potosi & 0.40 & 1.17 & -0.08 & -0.26 & 1.23 \\
\hline Sinaloa & 0.45 & 0.65 & -0.03 & -0.62 & 0.44 \\
\hline Sonora & 0.78 & 1.26 & -0.04 & -1.21 & 0.79 \\
\hline Tabasco & 0.50 & 1.32 & -0.12 & -0.15 & 1.55 \\
\hline Tamaulipas & 0.20 & 0.23 & -0.01 & -0.31 & 0.11 \\
\hline Tlaxcala & 0.05 & 0.03 & 0.00 & -0.05 & 0.03 \\
\hline Veracruz & 0.89 & 2.16 & -0.20 & -0.31 & 2.54 \\
\hline Yucatan & 1.39 & 1.10 & -0.29 & -0.43 & 1.77 \\
\hline Zacatecas & 0.10 & 0.23 & -0.01 & -0.14 & 0.17 \\
\hline Mexico Totals & 17.59 & 24.44 & -2.67 & -11.90 & 27.47 \\
\hline
\end{tabular}


Table S4. The cropland sector carbon budget and estimated land-atmosphere exchange of $\mathrm{CO}_{2}$ by Canada reporting zone based on the inventory data. All units are $\mathrm{TgC} \mathrm{yr}^{-1}$ where a negative flux represents carbon uptake in the ecosystem.

\begin{tabular}{lcccc} 
Reporting Zone & NPP & $\mathbf{H}_{\mathbf{R}}$ & $\Delta$ SOILC & NEE $^{\mathbf{a}}$ \\
\hline Atlantic Maritime & -0.73 & -0.30 & 0.10 & -0.20 \\
Boreal Cordillera & 0.00 & 0.00 & 0.00 & 0.00 \\
Boreal Plains & -15.45 & -5.03 & -0.61 & -5.64 \\
Boreal Shield East & -1.23 & -0.51 & 0.09 & -0.41 \\
Boreal Shield West & -0.14 & -0.05 & 0.00 & -0.05 \\
Mixedwood Plains & -10.79 & -4.26 & 0.62 & -3.64 \\
Montane Cordillera & -0.23 & -0.08 & 0.01 & -0.07 \\
Pacific Maritime & -0.04 & -0.01 & 0.00 & -0.01 \\
Semiarid Prairies & -28.56 & -9.44 & -1.59 & -11.04 \\
Subhumid Prairies & -31.64 & -10.37 & -1.35 & -11.72 \\
Taiga Plains & -0.01 & 0.00 & 0.00 & 0.00 \\
\hline Canada Totals & $\mathbf{- 8 8 . 8 1}$ & $\mathbf{- 3 0 . 0 5}$ & $\mathbf{- 2 . 7 3}$ & $\mathbf{- 3 2 . 7 9}$ \\
${ }^{a}$ NEE $=H_{R}+\Delta$ SOILC & & & &
\end{tabular}

Table S5. The cropland sector carbon budget and estimated land-atmosphere exchange of $\mathrm{CO}_{2}$ by U.S. reporting zone based on the inventory data. All units are $\mathrm{TgC} \mathrm{yr}^{-1}$ where a negative flux represents carbon uptake in the ecosystem.

\begin{tabular}{lcccc} 
Reporting Zone & $\mathbf{N P P}$ & $\mathbf{H}_{\mathbf{R}}$ & $\Delta \mathbf{S O I L C}^{-}$ & $\mathbf{N E E}^{\mathbf{a}}$ \\
\hline Alabama & -2.28 & -1.08 & -0.12 & -1.20 \\
Alaska & 0.00 & 0.00 & 0.00 & 0.00 \\
Arizona & -2.07 & -0.99 & 0.00 & -0.99 \\
Arkansas & -13.81 & -4.34 & -0.09 & -4.43 \\
California & -7.60 & -3.04 & -0.03 & -3.07 \\
Colorado & -9.05 & -4.08 & -0.48 & -4.56 \\
Connecticut & 0.00 & 0.00 & 0.00 & 0.00 \\
Delaware & -0.91 & -0.38 & -0.02 & -0.40 \\
District of Columbia & 0.00 & 0.00 & 0.00 & 0.00 \\
Florida & -7.79 & -4.57 & -0.03 & -4.60 \\
Georgia & -2.58 & -0.98 & -0.08 & -1.06 \\
Idaho & -8.30 & -3.21 & -0.24 & -3.45 \\
Illinois & -58.45 & -24.91 & -1.03 & -25.95 \\
Indiana & -29.73 & -12.67 & -0.62 & -13.29 \\
Iowa & -65.42 & -28.65 & -1.63 & -30.28 \\
Kansas & -33.51 & -13.69 & -1.22 & -14.91 \\
Kentucky & -10.06 & -4.61 & -0.40 & -5.02
\end{tabular}




\begin{tabular}{|c|c|c|c|c|}
\hline Louisiana & -10.87 & -5.23 & -0.11 & -5.34 \\
\hline Maine & 0.00 & 0.00 & -0.01 & -0.01 \\
\hline Maryland & -2.76 & -1.23 & -0.09 & -1.32 \\
\hline Massachusetts & 0.00 & 0.00 & 0.00 & 0.00 \\
\hline Michigan & -12.71 & -5.53 & -0.32 & -5.85 \\
\hline Minnesota & -43.67 & -18.75 & -1.22 & -19.97 \\
\hline Mississippi & -4.73 & -1.70 & -0.23 & -1.93 \\
\hline Missouri & -22.59 & -9.72 & -0.93 & -10.65 \\
\hline Montana & -9.79 & -3.93 & -0.95 & -4.88 \\
\hline Nebraska & -41.62 & -18.36 & -0.95 & -19.30 \\
\hline Nevada & -1.09 & -0.58 & -0.01 & -0.58 \\
\hline New Hampshire & 0.00 & 0.00 & 0.00 & 0.00 \\
\hline New Jersey & -0.50 & -0.22 & -0.01 & -0.23 \\
\hline New Mexico & -1.71 & -0.90 & -0.09 & -1.00 \\
\hline New York & -4.99 & -2.81 & -0.12 & -2.93 \\
\hline North Carolina & -6.01 & -2.58 & -0.18 & -2.76 \\
\hline North Dakota & -23.48 & -8.80 & -1.88 & -10.69 \\
\hline Ohio & -21.12 & -8.92 & -0.67 & -9.59 \\
\hline Oklahoma & -9.22 & -3.80 & -0.28 & -4.08 \\
\hline Oregon & -4.40 & -1.94 & -0.14 & -2.08 \\
\hline Pennsylvania & -8.96 & -4.68 & -0.22 & -4.90 \\
\hline Rhode Island & 0.00 & 0.00 & 0.00 & 0.00 \\
\hline South Carolina & -1.85 & -0.79 & -0.11 & -0.91 \\
\hline South Dakota & -23.41 & -10.23 & -1.26 & -11.49 \\
\hline Tennessee & -5.25 & -2.28 & -0.24 & -2.52 \\
\hline Texas & -14.89 & -5.90 & -0.70 & -6.60 \\
\hline Utah & -2.15 & -1.12 & -0.07 & -1.19 \\
\hline Vermont & 0.00 & 0.00 & 0.00 & 0.00 \\
\hline Virginia & -4.42 & -2.17 & -0.14 & -2.31 \\
\hline Washington & -8.93 & -3.61 & -0.30 & -3.91 \\
\hline West Virginia & -0.87 & -0.46 & -0.04 & -0.50 \\
\hline Wisconsin & -23.62 & -11.93 & -0.58 & -12.51 \\
\hline Wyoming & -2.07 & -1.02 & -0.08 & -1.10 \\
\hline U.S. Totals & -569.21 & -246.38 & -17.94 & -264.32 \\
\hline
\end{tabular}


Table S6. The contribution of harvested wood products (HWP) transfer and stock change to the carbon balance of the Forest Lands

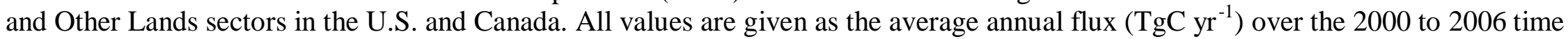
period.

\begin{tabular}{lccccccc} 
& $(\mathrm{A})$ & $(\mathrm{B})$ & $(\mathrm{C})$ & $(\mathrm{D})$ & $(\mathrm{E})$ & $(\mathrm{F})$ & $(\mathrm{G})$ \\
& $\mathbf{H}_{\mathbf{R}}$ & $\mathbf{H}_{\mathbf{E}}$ & $\mathbf{H W P}_{\mathbf{I M P}}$ & $\mathbf{H W P}_{\mathbf{E X P}}$ & $\Delta \mathbf{H W P}_{\mathbf{I U} \text { DC }}$ & $\Delta \mathbf{H W P}_{\mathbf{S W D S} \text { DC }}$ & HWP $_{\mathbf{E}}$ \\
\hline Canada & 49.863 & 14.959 & 0.590 & 26.045 & 2.191 & 1.909 & 5.350 \\
U.S. & 114.844 & 34.453 & 26.402 & 16.682 & 20.967 & 18.178 & 50.967 \\
\hline Total & 164.708 & 49.412 & 26.992 & 42.727 & 23.157 & 20.087 & 56.316
\end{tabular}

(A) Forest harvest removals from Canada (Table S1) and the U.S. (Table S2)

(B) Emissions from forest harvest processing in Canada (Table S1) and the U.S. (Table S2)

HWP imports from (C) and exports to (D) other countries; data for Canada from FAOStat database (2010) and for the U.S. from the EPA GHG Inventory (2010), Table A-220 in Annex 3.

Change in $\mathrm{C}$ stocks in the HWP pools that are currently in use (E) and stored in solid waste disposal sites (F), based on domestic consumption. Data for the U.S. from the EPA GHG Inventory (2010), Table A-220 in Annex 3. For Canada, data were not available and so were estimated based on the same ratio of stock change in each pool relative to annual inputs (inputs $=\mathrm{H}_{R}-\mathrm{H}_{\mathrm{E}}+\mathrm{HWP}_{\mathrm{IMP}}-$ $\mathrm{HWP}_{\text {EXP }}$ ), which is 0.23 for $\Delta \mathrm{HWP}_{\mathrm{IU} D C}$ and 0.20 for $\Delta \mathrm{HWP}_{\text {SWDS DC. }}$

(G) $\mathrm{HWP}_{\mathrm{E}}=\left(\mathrm{H}_{\mathrm{R}}-\mathrm{H}_{\mathrm{E}}\right)+\mathrm{HWP}_{\mathrm{IMP}}-\mathrm{HWP}_{\mathrm{EXP}}-\left(\Delta \mathrm{HWP}_{\mathrm{IU} \mathrm{DC}}+\Delta \mathrm{HWP}_{\mathrm{SWDS} D C}\right)$ 
Table S7. Inventory-based data used to estimate the land-atmosphere exchange of $\mathrm{CO}_{2}$ in "other" lands, by Canada reporting zone based on the inventory data. Negative flux values represent carbon uptake in the ecosystem.
(A)
(B)
(C)
(D)
(E)
(F)
(G)
(H)
(I)
(J)

$\begin{array}{llllllllll}A_{0} & P_{0} & C_{H} & E_{H} & E_{L}-C_{4} & E_{L} & E_{F} & N_{G E} & N_{S} & N_{S E E}\end{array}$

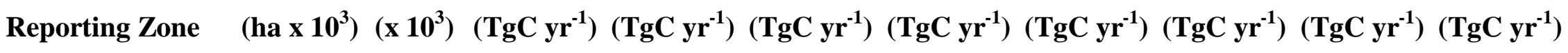

\begin{tabular}{|c|c|c|c|c|c|c|c|c|c|c|}
\hline Atlantic Maritime & 3203 & 2816 & 0.17 & 0.15 & 0.03 & 0.61 & 0.46 & -0.07 & -0.27 & 0.88 \\
\hline Boreal Cordillera & 21244 & 73 & 0.00 & 0.00 & 0.01 & 0.16 & 0.01 & -0.44 & -0.01 & -0.35 \\
\hline Boreal Plains & 22006 & 1853 & 0.11 & 0.10 & 0.37 & 8.05 & 0.30 & -0.45 & -0.18 & 7.74 \\
\hline Boreal Shield East & 26114 & 4693 & 0.29 & 0.25 & 0.13 & 2.93 & 0.77 & -0.54 & -0.45 & 2.86 \\
\hline Boreal Shield West & 15263 & 429 & 0.03 & 0.02 & 0.11 & 2.50 & 0.07 & -0.32 & -0.04 & 2.18 \\
\hline Hudson Plains & 0 & 0 & 0.00 & 0.00 & 0.00 & 0.00 & 0.00 & 0.00 & 0.00 & 0.00 \\
\hline Mixedwood Plains & 2994 & 14874 & 0.91 & 0.80 & 0.02 & 0.44 & 2.44 & -0.06 & -1.42 & 2.19 \\
\hline Montane Cordillera & 12171 & 895 & 0.05 & 0.05 & 0.02 & 0.41 & 0.15 & -0.25 & -0.09 & 0.23 \\
\hline Pacific Maritime & 7275 & 3327 & 0.20 & 0.18 & 0.01 & 0.27 & 0.55 & -0.15 & -0.32 & 0.50 \\
\hline Semiarid Prairies & 11180 & 1133 & 0.07 & 0.06 & 0.15 & 3.19 & 0.19 & -0.23 & -0.11 & 3.06 \\
\hline Subhumid Prairies & 3829 & 2343 & 0.14 & 0.13 & 0.05 & 1.19 & 0.39 & -0.08 & -0.22 & 1.38 \\
\hline Taiga Cordillera & 3257 & 0 & 0.00 & 0.00 & 0.00 & 0.00 & 0.00 & -0.07 & 0.00 & -0.08 \\
\hline Taiga Plains & 15254 & 110 & 0.01 & 0.01 & 0.00 & 0.10 & 0.02 & -0.31 & -0.01 & -0.26 \\
\hline Taiga Shield East & 0 & 0 & 0.00 & 0.00 & 0.00 & 0.00 & 0.00 & 0.00 & 0.00 & 0.00 \\
\hline Taiga Shield West & 4441 & 0 & 0.00 & 0.00 & 0.00 & 0.00 & 0.00 & -0.09 & 0.00 & -0.11 \\
\hline Canada Totals & 148230 & 32545 & 2.00 & 1.76 & 0.91 & 19.84 & 5.35 & -3.06 & -3.11 & 20.21 \\
\hline
\end{tabular}

(A) Area (thousand hectares) represented in the Other Lands sector: the Total Reporting Zone Area minus Inventory Forest Area minus Inventory Crop Area 
(B) Human population (thousand persons) in each reporting zone estimated by overlaying reporting zone boundaries on census units containing year 2006 population estimates from Statistics Canada (www.statcan.gc.ca)

Human crop consumption (C) and $\mathrm{CO}_{2}$ emissions from human respiration (D) estimated using per capita consumption (61.6 $\left.\mathrm{kgC}_{\mathrm{yr}} \mathrm{r}^{-1}\right)$ and respiration (54.0) rates from the U.S. data ([West et al., 2009], see Table S8)

(E) Livestock (cattle and swine) methane emissions from Statistics Canada 2006 Census of Agriculture

(F) Estimated livestock $\mathrm{CO}_{2}$ emissions; the column total is equal to the national total $\mathrm{H}_{\mathrm{R}}$ (from Table $\mathrm{S} 4$ ), adjusted for the net crop harvest export out of the country $(27 \% *)$, minus national total human crop consumption and total $\mathrm{C}$ emitted as $\mathrm{CH}_{4}$ from livestock; the column total is distributed proportional to $\mathrm{C}$ emitted as $\mathrm{CH}_{4}$ from livestock in each reporting zone; *national-level crop harvest imports vs. exports is based on cash value, from the Canadian Socio-Economic Information Management System (Statistics Canada)

(G) Estimated $\mathrm{CO}_{2}$ emissions from decay of forest products; the column total is equal to the national total emissions from $\mathrm{HWP}_{\mathrm{E}}$ (Table S6), which is distributed proportional to human population in each reporting zone

(H) NEE for grasslands estimated by multiplying the average grassland sink per area from the U.S. data $\left(2.1 \mathrm{gC} \mathrm{m}^{-2} \mathrm{yr}^{-1}\right.$, see Table S8) by the "other" land area in each reporting zone

(I) NEE for settled areas estimated by multiplying the average settlements sink per capita from the U.S. data (95.6 kgC per capita yr ${ }^{-1}$, see Table S8) by the human population in each reporting zone

(J) Total NEE for the Other Lands sector is the sum of columns (D), (F), (G), (H), and (I) 
Table S8. Inventory-based data used to estimate the land-atmosphere exchange of $\mathrm{CO}_{2}$ in "other" lands, by U.S. reporting zone based on the inventory data. Negative flux values represent carbon uptake in the ecosystem.
(A)
(B)
(C)
(D)
(E)
(F)
(G)
(H)
(I)
(J)

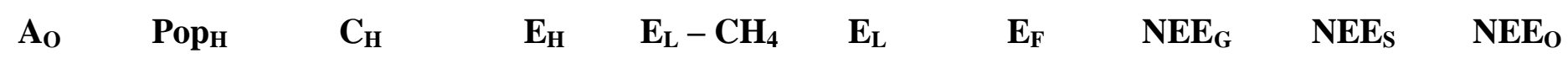

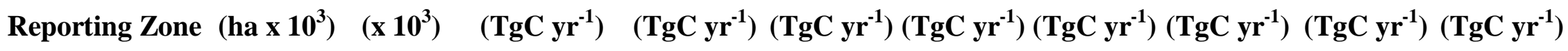

\begin{tabular}{lccccccccccc}
\hline Alabama & 3281 & 4598 & 0.27 & 0.24 & 0.02 & 2.42 & 0.81 & -0.08 & -0.43 & 2.96 \\
Alaska & 144880 & 677 & 0.04 & 0.04 & 0.00 & 0.03 & 0.12 & -3.55 & -0.06 & -3.43 \\
Arizona & 21446 & 6192 & 0.34 & 0.30 & 0.01 & 1.84 & 1.01 & -0.53 & -0.54 & 2.08 \\
Arkansas & 3244 & 2815 & 0.16 & 0.14 & 0.03 & 3.34 & 0.49 & -0.08 & -0.26 & 3.63 \\
California & 26056 & 35979 & 2.14 & 1.88 & 0.10 & 12.59 & 6.29 & -0.64 & -3.36 & 16.76 \\
Colorado & 14686 & 4753 & 0.28 & 0.24 & 0.03 & 4.02 & 0.81 & -0.36 & -0.44 & 4.28 \\
Connecticut & 538 & 3485 & 0.21 & 0.18 & 0.00 & 0.15 & 0.62 & -0.01 & -0.33 & 0.60 \\
Delaware & 153 & 853 & 0.05 & 0.04 & 0.00 & 0.06 & 0.15 & 0.00 & -0.08 & 0.17 \\
D.C. & 16 & 584 & 0.04 & 0.03 & 0.00 & 0.00 & 0.10 & 0.00 & -0.06 & 0.08 \\
Florida & 7782 & 18089 & 1.02 & 0.90 & 0.03 & 3.60 & 3.05 & -0.19 & -1.63 & 5.73 \\
Georgia & 4015 & 9330 & 0.53 & 0.47 & 0.02 & 2.41 & 1.57 & -0.10 & -0.84 & 3.50 \\
Idaho & 11494 & 1300 & 0.08 & 0.07 & 0.03 & 4.34 & 0.23 & -0.28 & -0.12 & 4.24 \\
Illinois & 3336 & 12438 & 0.76 & 0.67 & 0.02 & 2.65 & 2.23 & -0.08 & -1.19 & 4.27 \\
Indiana & 2555 & 6092 & 0.37 & 0.33 & 0.02 & 1.95 & 1.09 & -0.06 & -0.58 & 2.73 \\
Iowa & 3270 & 2928 & 0.18 & 0.16 & 0.05 & 6.67 & 0.52 & -0.08 & -0.28 & 6.99 \\
Kansas & 10056 & 2693 & 0.16 & 0.14 & 0.07 & 9.28 & 0.48 & -0.25 & -0.26 & 9.40 \\
Kentucky & 3234 & 4049 & 0.25 & 0.22 & 0.04 & 4.36 & 0.73 & -0.08 & -0.39 & 4.84 \\
Louisiana & 4526 & 4469 & 0.27 & 0.24 & 0.01 & 1.73 & 0.80 & -0.11 & -0.43 & 2.22
\end{tabular}




\begin{tabular}{|c|c|c|c|c|c|c|c|c|c|c|}
\hline Maine & 1234 & 1277 & 0.08 & 0.07 & 0.00 & 0.23 & 0.23 & -0.03 & -0.12 & 0.37 \\
\hline Maryland & 886 & 5311 & 0.33 & 0.29 & 0.00 & 0.58 & 0.95 & -0.02 & -0.51 & 1.29 \\
\hline Massachusetts & 834 & 6363 & 0.39 & 0.34 & 0.00 & 0.13 & 1.14 & -0.02 & -0.61 & 0.98 \\
\hline Michigan & 4492 & 9955 & 0.61 & 0.53 & 0.02 & 2.36 & 1.78 & -0.11 & -0.95 & 3.61 \\
\hline Minnesota & 6720 & 4934 & 0.31 & 0.27 & 0.04 & 4.87 & 0.88 & -0.16 & -0.47 & 5.39 \\
\hline Mississippi & 2692 & 2848 & 0.17 & 0.15 & 0.02 & 2.02 & 0.51 & -0.07 & -0.27 & 2.34 \\
\hline Missouri & 6513 & 5606 & 0.35 & 0.30 & 0.06 & 8.05 & 1.00 & -0.16 & -0.54 & 8.67 \\
\hline Montana & 23117 & 903 & 0.06 & 0.05 & 0.04 & 4.73 & 0.16 & -0.57 & -0.09 & 4.29 \\
\hline Nebraska & 11410 & 1713 & 0.10 & 0.09 & 0.08 & 9.67 & 0.31 & -0.28 & -0.16 & 9.62 \\
\hline Nevada & 24062 & 2018 & 0.14 & 0.12 & 0.01 & 0.97 & 0.36 & -0.59 & -0.19 & 0.67 \\
\hline New Hampshire & 463 & 1240 & 0.08 & 0.07 & 0.00 & 0.11 & 0.22 & -0.01 & -0.12 & 0.27 \\
\hline New Jersey & 955 & 8431 & 0.52 & 0.45 & 0.00 & 0.13 & 1.51 & -0.02 & -0.81 & 1.26 \\
\hline New Mexico & 24032 & 1821 & 0.11 & 0.10 & 0.03 & 3.39 & 0.33 & -0.59 & -0.17 & 3.05 \\
\hline New York & 3821 & 18998 & 1.16 & 1.02 & 0.03 & 3.79 & 3.40 & -0.09 & -1.82 & 6.31 \\
\hline North Carolina & 3310 & 8079 & 0.51 & 0.45 & 0.02 & 2.16 & 1.45 & -0.08 & -0.77 & 3.21 \\
\hline North Dakota & 8133 & 641 & 0.04 & 0.03 & 0.03 & 3.34 & 0.11 & -0.20 & -0.06 & 3.23 \\
\hline Ohio & 3270 & 11364 & 0.69 & 0.61 & 0.02 & 2.82 & 2.04 & -0.08 & -1.09 & 4.30 \\
\hline Oklahoma & 10505 & 3454 & 0.21 & 0.19 & 0.07 & 8.85 & 0.62 & -0.26 & -0.33 & 9.06 \\
\hline Oregon & 11740 & 3431 & 0.22 & 0.19 & 0.02 & 2.91 & 0.61 & -0.29 & -0.33 & 3.09 \\
\hline Pennsylvania & 3114 & 12286 & 0.74 & 0.65 & 0.03 & 3.92 & 2.20 & -0.08 & -1.17 & 5.52 \\
\hline Rhode Island & 118 & 1051 & 0.06 & 0.06 & 0.00 & 0.02 & 0.19 & 0.00 & -0.10 & 0.16 \\
\hline South Carolina & 2207 & 4024 & 0.25 & 0.22 & 0.01 & 0.86 & 0.72 & -0.05 & -0.38 & 1.36 \\
\hline South Dakota & 11748 & 756 & 0.05 & 0.04 & 0.05 & 6.78 & 0.14 & -0.29 & -0.07 & 6.60 \\
\hline Tennessee & 3476 & 5703 & 0.36 & 0.31 & 0.03 & 4.04 & 1.02 & -0.09 & -0.55 & 4.74 \\
\hline Texas & 55261 & 20946 & 1.34 & 1.18 & 0.19 & 23.23 & 3.75 & -1.35 & -2.00 & 24.80 \\
\hline Utah & 14010 & 2244 & 0.15 & 0.13 & 0.01 & 1.82 & 0.40 & -0.34 & -0.21 & 1.80 \\
\hline
\end{tabular}




\begin{tabular}{lcccccccccc} 
Vermont & 607 & 610 & 0.04 & 0.03 & 0.01 & 0.79 & 0.11 & -0.01 & -0.06 & 0.86 \\
Virginia & 2788 & 7105 & 0.45 & 0.39 & 0.02 & 3.07 & 1.27 & -0.07 & -0.68 & 3.98 \\
Washington & 6282 & 5911 & 0.37 & 0.33 & 0.02 & 2.31 & 1.06 & -0.15 & -0.57 & 2.98 \\
West Virginia & 1112 & 1807 & 0.11 & 0.10 & 0.01 & 0.77 & 0.32 & -0.03 & -0.17 & 0.99 \\
Wisconsin & 3272 & 5374 & 0.33 & 0.29 & 0.06 & 7.89 & 0.96 & -0.08 & -0.51 & 8.55 \\
Wyoming & 20126 & 494 & 0.03 & 0.03 & 0.02 & 2.68 & 0.09 & -0.49 & -0.05 & 2.25 \\
\hline US Totals & $\mathbf{5 3 6 8 7 6}$ & $\mathbf{2 8 8 0 2 1}$ & $\mathbf{1 7 . 5 2}$ & $\mathbf{1 5 . 3 7}$ & $\mathbf{1 . 4 5}$ & $\mathbf{1 8 0 . 7 3}$ & $\mathbf{5 0 . 9 7}$ & $\mathbf{- 1 3 . 1 6}$ & $\mathbf{- 2 7 . 2 1}$ & $\mathbf{2 0 6 . 6 9}$
\end{tabular}

(A) Area (thousand hectares) represented in the Other Lands sector: the Total Reporting Zone Area minus Inventory Forest Area minus Inventory Crop Area (average area years 2000 - 2006)

(B) Human population (thousand persons) is the average state population between 2000 and 2006, estimates from U.S. Census Bureau [2009]

For human consumption of crop products (C), there is a consistent respiration-to-consumption multiplier (1.14) across all age/gender classes in Table 1 of West et al., [2009], which was applied to the data on human respiration in column (D)

(E) Livestock methane emissions from enteric fermentation from the USDA Greenhouse Gas Inventory [2008]

(F) Estimated livestock $\mathrm{CO}_{2}$ emissions; the column total is equal to the national total crop harvest ( $\mathrm{H}_{\mathrm{R}}$ from Table A5), adjusted for the net crop harvest export out of the country $\left(\mathrm{HCP}_{\mathrm{IMP}}-\mathrm{HCP}_{\mathrm{EXP}}=-46.7 \mathrm{TgC} \mathrm{yr}^{-1}\right.$ between 2000 and $\left.2006^{*}\right)$, minus national total human crop consumption and total $\mathrm{C}$ emitted as $\mathrm{CH}_{4}$ from livestock; the column total is distributed proportional to $\mathrm{C}_{\text {emitted as }} \mathrm{CH}_{4}$ from livestock in each reporting zone; *national-level crop harvest imports vs. exports is based on volume converted to dry-weight biomass carbon using data in USDA Economic Research Service "Foreign Agricultural Trade of the United States (FATUS)" [2010] http://www.ers.usda.gov/data/fatus/

(G) Estimated $\mathrm{CO}_{2}$ emissions from decay of forest products; the column total is equal to the national total emissions from HWP (Table S6); the column total is distributed proportional to human population in each reporting zone

(H) NEE for grasslands estimated by distributing the annual, national-level grassland sink estimates from the U.S. Environmental Protection Agency Greenhouse Gas Inventory [2010] proportional to the area of the Other Land sector in each reporting zone 
(H) NEE for settled areas estimated by distributing the annual, national-level settlements / other sink estimates from the U.S.

Environmental Protection Agency Greenhouse Gas Inventory [2010] proportional to the human population in each reporting zone

(J) Total NEE for the Other Lands sector is the sum of columns (D), (F), (G), (H), and (I) 
Table S9. Inventory-based data used to estimate the land-atmosphere exchange of $\mathrm{CO}_{2}$ in "other" lands, by Mexico reporting zone based on the inventory data. All units are $\mathrm{TgC} \mathrm{yr}^{-1}$ where a negative flux represents carbon uptake in the ecosystem.

\begin{tabular}{lccccc} 
Reporting Zone & $\Delta$ Live $_{\mathbf{L U C}}$ & $\Delta$ Soil $_{\mathbf{L U C}}$ & $\Delta$ Live $_{\text {ABND }}$ & $\Delta$ Live $_{\text {MNGD }}$ & Total NEE \\
\hline Aguascalientes & 0.00 & -0.24 & -0.01 & 0.00 & -0.24 \\
Baja California & 0.06 & -0.54 & -0.02 & 0.07 & -0.42 \\
Baja California Sur & 0.07 & -0.43 & -0.02 & 0.02 & -0.37 \\
Campeche & 0.00 & -0.51 & -0.01 & 0.37 & -0.15 \\
Chiapas & 0.03 & -1.98 & -0.04 & 0.18 & -1.81 \\
Chihuahua & 0.20 & 0.24 & -0.03 & 0.68 & 1.10 \\
Coahuila & 0.13 & 0.54 & -0.06 & 0.14 & 0.76 \\
Colima & 0.00 & -0.15 & 0.00 & 0.00 & -0.15 \\
Distrito Federal & 0.00 & -0.02 & 0.00 & 0.01 & -0.02 \\
Durango & 0.07 & -0.05 & -0.02 & 0.56 & 0.57 \\
Guanajuato & 0.01 & -0.53 & -0.02 & 0.11 & -0.43 \\
Guerrero & 0.02 & -0.12 & -0.01 & 0.43 & 0.33 \\
Hidalgo & 0.00 & -0.28 & -0.01 & 0.10 & -0.19 \\
Jalisco & 0.04 & -0.68 & -0.02 & 0.28 & -0.38 \\
Mexico & 0.00 & -0.20 & 0.00 & 0.15 & -0.06 \\
Michoacan & 0.03 & -0.08 & -0.01 & 0.32 & 0.26 \\
Morelos & 0.00 & -0.04 & 0.00 & 0.03 & 0.00 \\
Nayarit & 0.01 & -0.12 & 0.00 & 0.17 & 0.05 \\
Nuevo Leon & 0.03 & -0.07 & -0.05 & 0.10 & 0.00 \\
Oaxaca & 0.03 & -0.64 & -0.03 & 0.49 & -0.14 \\
Puebla & 0.01 & -0.29 & -0.01 & 0.23 & -0.07 \\
Queretaro & 0.00 & -0.05 & 0.00 & 0.07 & 0.02 \\
Quintana Roo & 0.00 & -0.15 & -0.01 & 0.43 & 0.28 \\
San Luis Potosi & 0.04 & -0.51 & -0.03 & 0.12 & -0.38 \\
Sinaloa & 0.01 & -0.29 & -0.01 & 0.44 & 0.15 \\
Sonora & 0.10 & -0.51 & -0.03 & 0.87 & 0.43 \\
Tabasco & 0.00 & -1.27 & -0.03 & 0.02 & -1.28 \\
Tamaulipas & 0.02 & -1.61 & -0.07 & 0.10 & -1.55 \\
Tlaxcala & 0.00 & -0.07 & 0.00 & 0.03 & -0.04 \\
Veracruz & 0.01 & -4.46 & -0.08 & -0.04 & -4.57 \\
Yucatan & 0.00 & -0.48 & -0.01 & 0.28 & -0.20 \\
Zacatecas & 0.06 & -0.64 & -0.03 & 0.08 & -0.54 \\
\hline TOTAL & $\mathbf{0 . 9 8}$ & $\mathbf{- 1 6 . 2 2}$ & $\mathbf{- 0 . 6 4}$ & $\mathbf{6 . 8 3}$ & $\mathbf{- 9 . 0 6}$
\end{tabular}


Table S10. Comparison of area (Mha) of each country / sector from the inventory data against that from the model data, which are based on a reclassification of the GLC-2000 land cover.

Model Inventory (t1) Inventory (t2)

Canada

$\begin{array}{lccc}\text { Forest Lands } & 269.7 & 236.1 & 236.1 \\ \text { Crop Lands } & 48.8 & 48.2 & 47.9 \\ \text { Other Lands } & 112.8 & 146.8 & 147.2 \\ \text { Total } & 431.2 & 431.2 & 431.2\end{array}$

United States

$\begin{array}{llll}\text { Forest Lands } & 305.6 & 254.5 & 258.6 \\ \text { Crop Lands } & 137.0 & 137.2 & 135.0 \\ \text { Other Lands } & 486.0 & 536.9 & 534.9 \\ \text { Total } & 928.6 & 928.6 & 928.6\end{array}$

Mexico

$\begin{array}{lccc}\text { Forest Lands } & 78.3 & 71.6 & 69.6 \\ \text { Crop Lands } & 29.7 & & \\ \text { Other Lands } & 87.7 & 124.1 & 126.1 \\ \text { Total } & 195.7 & 195.7 & 195.7\end{array}$

North America

$\begin{array}{lccc}\text { Forest Lands } & 653.5 & 562.2 & 564.3 \\ \text { Crop Lands } & 215.4 & 185.4 & 182.9 \\ \text { Other Lands } & 686.5 & 807.8 & 808.2 \\ \text { Total } & 1555.5 & 1555.5 & 1555.5\end{array}$


Table S11. Quantitative uncertainty estimates for component fluxes among the countries and sectors analyzed in this study. A negative flux represents carbon uptake in the ecosystem.

\begin{tabular}{|c|c|c|c|c|}
\hline \multirow[b]{2}{*}{ Flux Component } & \multirow{2}{*}{$\begin{array}{l}\text { Mean Estimate } \\
\quad\left({\left.\operatorname{TgC~} \mathrm{yr}^{-1}\right)}^{-1}\right.\end{array}$} & \multicolumn{3}{|c|}{ Uncertainty Range Relative to Estimate } \\
\hline & & $\%$ & 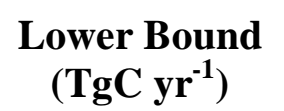 & $\begin{array}{l}\text { Upper Bound } \\
\left({\left.\mathrm{TgC} \mathrm{yr}^{-1}\right)}^{\text {Un }}\right.\end{array}$ \\
\hline $\begin{array}{l}\text { Canada Forest Stock Change } \\
(\Delta \text { Live }+\Delta \mathrm{DOM})^{1}\end{array}$ & 6.51 & $\mathrm{n} / \mathrm{a}$ & -13.13 & 26.15 \\
\hline Canada HWP $\left(\mathrm{H}_{\mathrm{R}}+\mathrm{H}_{\mathrm{E}}\right)^{1}$ & -34.90 & $10 \%$ & -38.39 & -31.41 \\
\hline $\begin{array}{l}\text { U.S. Forest Stock Change } \\
(\Delta \text { Live }+\Delta \mathrm{DOM})^{2}\end{array}$ & -163.99 & $19 \%$ & -195.15 & -132.83 \\
\hline U.S. HWP $\left(\mathrm{H}_{\mathrm{R}}+\mathrm{H}_{\mathrm{E}}\right)^{2}$ & -80.39 & $27 \%$ & -102.10 & -58.69 \\
\hline Mexico Forest $\Delta$ Live $_{\mathrm{LUC}}{ }^{3}$ & 17.59 & $12 \%$ & 15.48 & 19.71 \\
\hline Mexico Forest $\Delta$ Soil $_{\mathrm{LUC}}{ }^{3}$ & 24.44 & $84 \%$ & 3.91 & 44.98 \\
\hline Mexico Forest $\Delta$ Live $_{\mathrm{ABND}}{ }^{3}$ & -2.67 & $36 \%$ & -3.63 & -1.71 \\
\hline Mexico Forest $\Delta$ Live $_{\mathrm{MNGD}}{ }^{3}$ & -11.90 & $11 \%$ & -13.21 & -10.59 \\
\hline Total Forest Land NEE ${ }^{4}$ & -245.30 & $41 \%$ & -346.21 & -144.40 \\
\hline Canada Crop $\mathrm{H}_{\mathrm{R}}^{5}$ & -30.05 & $16 \%$ & -34.86 & -25.25 \\
\hline Canada Crop Land $\Delta$ SoilC $^{5}$ & -2.73 & $30 \%$ & -3.55 & -1.91 \\
\hline U.S. Crop $\mathrm{H}_{\mathrm{R}}^{5}$ & -246.38 & $16 \%$ & -285.80 & -206.96 \\
\hline U.S. Crop Land $\Delta$ SoilC $^{5}$ & -17.94 & $30 \%$ & -23.32 & -12.56 \\
\hline Total Crop Land NEE ${ }^{4}$ & -297.11 & $17 \%$ & -347.54 & -246.68 \\
\hline $\begin{array}{l}\text { Canada HCP Emissions }\left(\mathrm{E}_{\mathrm{H}}+\right. \\
\left.\mathrm{E}_{\mathrm{L}}\right)^{5}\end{array}$ & 21.60 & $16 \%$ & 18.15 & 25.06 \\
\hline Canada HWP Emissions $\left(\mathrm{E}_{\mathrm{F}}\right)^{1}$ & 5.35 & $10 \%$ & 4.81 & 5.88 \\
\hline $\begin{array}{l}\text { U.S. HCP Emissions }\left(\mathrm{E}_{\mathrm{H}}+\right. \\
\left.\mathrm{E}_{\mathrm{L}}\right)^{5}\end{array}$ & 196.10 & $16 \%$ & 164.72 & 227.47 \\
\hline U.S. HWP Emissions $\left(\mathrm{E}_{\mathrm{F}}\right)^{2}$ & 50.97 & $27 \%$ & 37.21 & 64.73 \\
\hline
\end{tabular}




\begin{tabular}{|c|c|c|c|c|}
\hline $\begin{array}{l}\text { Grasslands (NEE }{ }_{G} \\
\text { Canada+U.S.) }\end{array}$ & -16.79 & $100 \%$ & -33.58 & 0.00 \\
\hline $\begin{array}{l}\text { Settlements }\left(\mathrm{NEE}_{\mathrm{S}} \text {; Canada }+\right. \\
\text { U.S. })^{7}\end{array}$ & -30.33 & $54 \%$ & -46.70 & -13.95 \\
\hline Mexico Other Land $\Delta$ Live $_{\mathrm{LUC}}{ }^{3}$ & 0.98 & $12 \%$ & 0.86 & 1.10 \\
\hline Mexico Other Land $\Delta$ Soil $_{L U C}{ }^{3}$ & -16.22 & $84 \%$ & -29.85 & -2.60 \\
\hline $\begin{array}{l}\text { Mexico Other Land } \\
\Delta \text { Live }_{\mathrm{ABND}}{ }^{3}\end{array}$ & -0.64 & $36 \%$ & -0.87 & -0.41 \\
\hline $\begin{array}{l}\text { Mexico Other Land } \\
\Delta \text { Live }_{\text {MNGD }}{ }^{3}\end{array}$ & 6.83 & $11 \%$ & 6.08 & 7.58 \\
\hline Total Other Land NEE ${ }^{4}$ & 217.84 & $45 \%$ & 120.82 & 314.86 \\
\hline Total Continental NEE ${ }^{4}$ & -324.57 & $77 \%$ & -572.93 & -76.21 \\
\hline
\end{tabular}

\footnotetext{
${ }^{1}$ Based on the Environment Canada (2011) GHG Inventory, Chapter 7: upper and lower bounds on mean estimate of ecosystem stock change, and percent uncertainty around the mean harvested wood products estimate.

${ }^{2}$ Percent uncertainty around the mean ecosystem stock change and harvested wood products estimates from the EPA (2010) U.S. GHG Inventory, Chapter 7.

${ }^{3}$ Percent uncertainty estimates from deJong et al. (2010).

${ }^{4}$ Bounds on the sector-level mean estimate calculated by summing the upper and lower bounds for each component flux of the sector; the percent uncertainty, then, is the range between the bounds relative to the mean total flux estimate of the sector.

${ }^{5}$ Percent uncertainty in $\Delta$ SoilC in U.S. croplands is based on West and Post (2002) as applied spatially and by crop type in West et al. (2008). Percent uncertainty in U.S. Crop $\mathrm{H}_{\mathrm{R}}$ is based on percent error derived from comparison between USDA NASS and AgCensus data (West et $a l$. , unpublished data). Percent uncertainty around Canada Crop Lands flux estimates is not available so the U.S. uncertainty was applied.

${ }^{6}$ Uncertainty on $\mathrm{NEE}_{\mathrm{G}}$ is not available from EPA (2010); we apply our "expert judgment" that this flux estimate is essentially $100 \%$ uncertain.

${ }^{7}$ Percent uncertainty estimate on $\mathrm{NEE}_{\mathrm{s}}$ is from the analysis by Nowak and Crane (2002) for the conterminous U.S., as cited in the SOCCR report (King et al., 2007).
}

Table S12. Estimates and uncertainty for additional component fluxes not included in the inventories.

\begin{tabular}{|c|c|c|c|c|}
\hline \multirow[b]{2}{*}{ Flux Component } & \multirow{2}{*}{ 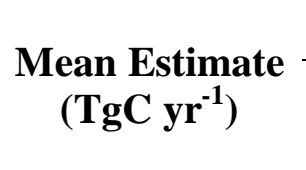 } & \multicolumn{3}{|c|}{ Uncertainty Range Relative to Estimate } \\
\hline & & $\%$ & $\begin{array}{l}\text { Lower Bound } \\
\left(\operatorname{TgC} \mathbf{y r}^{-1}\right)\end{array}$ & $\begin{array}{l}\text { Upper Bound } \\
\left({\left.\operatorname{TgC~} \mathrm{yr}^{-1}\right)}^{\text {Und }}\right.\end{array}$ \\
\hline Woody Encroachment (U.S.) ${ }^{1}$ & -120.00 & $100 \%$ & -240.00 & 0.00 \\
\hline
\end{tabular}


Wetlands (Canada + U.S. + Mexico) ${ }^{1}$

$\begin{array}{llll}-49.00 & 100 \% & -98.00 & 0.00\end{array}$

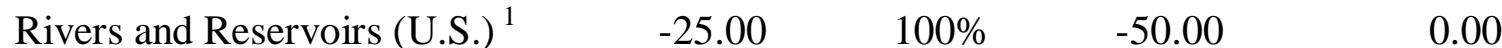

Rivers to Ocean (Canada + Alaska) $^{2}$

$\begin{array}{llll}-10.00 & 100 \% & -20.00 & 0.00\end{array}$

Rivers to Ocean (48 U.S.

States) ${ }^{1}$

$\begin{array}{llll}-35.00 & 100 \% & -70.00 & 0.00\end{array}$

$\begin{array}{lllll}\text { Total "Additional Fluxes" } & -239.00 & 100 \% & -478.00 & 0.00\end{array}$

${ }^{1}$ Mean estimate and uncertainty from Chapter 3 of SOCCR (Pacala et al., 2007).

${ }^{2}$ Mean estimate from McGuire et al. (2010) and Manizza et al. (2009); uncertainty from Chapter 3 of SOCCR (Pacala et al., 2007). 


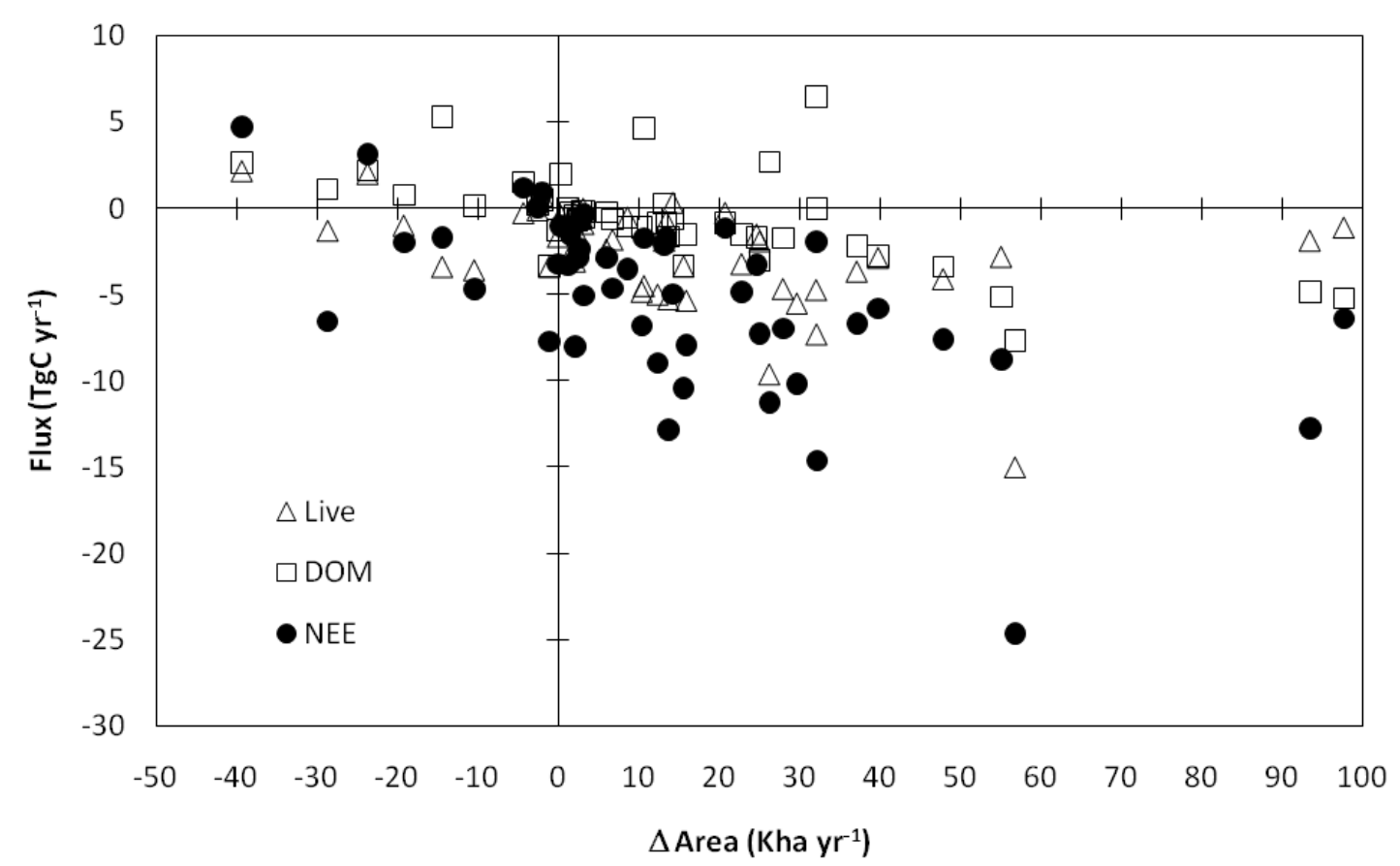

Figure S1. The relationship of the change in inventoried area ( $\triangle$ Area, in thousands of hectares per year) in the U.S. Forest Lands sector, from 2000 - 2006, against the inventorybased estimates of carbon fluxes for that sector within each state $(n=49)$ over the same time period 


\section{S5. Supporting Information References}

Bailey RG, Avers PE, King T, McNab WH, eds. (1994) Ecoregions and subregions of the United States (map). Washington, DC: USDA Forest Service.

Birdsey RA (1996) Carbon storage for major forest types and regions in the conterminous United States. In: Sampson, R. Neil; Hair, Dwight; Eds. Forests and global change, volume 2: forest management opportunities, American Forests, p 23-39.

Bechtold WA, Patterson PL (2005) The enhanced Forest Inventory and Analysis programnational sampling design and estimation procedures. SRS GTR-80. USDA Forest Service, Southern Research Station, Asheville, North Carolina, USA.

deJong B, Anaya C, Masera O, et al. (2010) Greenhouse gas emissions between 1993 and 2002 from land-use change and forestry in Mexico. Forest Ecology and Management, 260, $1689-1701$.

Environment Canada (2011) National Inventory Report 1990-2009. Greenhouse Gas Sources and Sinks in Canada. The Government of Canada's Submission to the UN Framework Convention on Climate Change. http://www.ec.gc.ca/ges-ghg/

EPA (2011) Inventory of U.S. greenhouse gas emissions and sinks: 1990-2009. USEPA \#430R-11-005 (http://www.epa.gov/climatechange/emissions/usinventoryreport.html).

Heath LS, Smith JE, Skog KE, Nowak DJ, Woodall CW (2011) Managed Forest Carbon Estimates for the US Greenhouse Gas Inventory, 1990-2008. Journal of Forestry, 109, 167-173.

Heath LS, Nichols MC, Smith JE., Mills JR (2010) FORCARB2: An updated version of the U.S. Forest Carbon Budget Model. Gen. Tech. Rep. NRS-67. Newtown Square, PA: U.S. Department of Agriculture, Forest Service, Northern Research Station. 52 p. [CD-ROM]. Intergovernmental Panel on Climate Change (IPCC) (1997) Revised 1996 IPCC Guide- lines for National Greenhouse Gas Inventories. Intergovernmental Panel on Climate Change, 
United Nations Environment Programme, Organization for Economic Co-Operation and Development, International Energy Agency, Paris, France.

Janzen HH, Campbell CA, Gregorich EG, Ellert BH (1997) Soil carbon dynamics in

Canadian agroecosystems, in: Lal R, Kimble JM, Follett RF, Stewart BA, editors. Soil Processes and Carbon Cycles. Boca Raton (FL): CRC Press. p. 57-80.

King AW, Dilling L, Zimmerman GP, Fairman DM, Houghton RA, Marland G, Rose AZ, Wilbanks TJ (2007) What Is the Carbon Cycle and Why Care? In: The First State of the Carbon Cycle Report (SOCCR): The North American Carbon Budget and Implications for the Global Carbon Cycle. A Report by the U.S. Climate Change Science Program and the Subcommittee on Global Change Research [King AW, Dilling L, Zimmerman GP, Fairman DM, Houghton RA, Marland G, Rose AZ, Wilbanks TJ (eds.)]. National Oceanic and Atmospheric Administration, National Climatic Data Center, Asheville, NC, USA, pp. 15-20.

Kurz WA, Dymond CC, White TM, et al. (2009) CBM-CFS3: A model of carbon-dynamics in forestry and land-use change implementing IPCC standards. Ecological Modelling, 220, 480-504.

Latifovic R, Zhu Z, Cihlar J, Giri C (2002) Land cover of North America 2000. Natural Resources Canada, Canada Center for Remote Sensing, US Geological Service EROS Data Center.

Manizza M, Follows MJ, Dutkiewicz S, et al. (2009) Modeling transport and fate of riverine dissolved organic carbon in the Arctic Ocean. Global Biogeochem. Cycles, 23, GB4006.

McGuire AD, Hayes DJ, Kicklighter DW, et al. (2010) An analysis of the carbon balance of the Arctic Basin from 1997 to 2006. Tellus Series B-Chemical and Physical Meteorology. 
Nowak DJ, Crane DE (2002) Carbon storage and sequestration by urban trees in the United States. Environ. Poll., 116, 381-389.

Pacala S, Birdsey RA, Bridgham SD, et al. (2007) The North American Carbon Budget Past and Present. In The First State of the Carbon Cycle Report (SOCCR): The North American Carbon Budget and Implications for the Global Carbon Cycle (eds King AW, Dilling L, Zimmerman GP, et al.), pp. 29 - 36. National Oceanic and Atmospheric Administration, National Climatic Data Center, Asheville, NC, USA.

Parton WJ, Stewart JWB, Cole CV (1988) Dynamic of C, N, P and S in grassland soils: a model. Biogeochemistry, 5, 109-131.

Skog KW (2008) Sequestration of carbon in harvested wood products for the United States. For. Prod. J., 58, 56-72.

Smith JE, Heath LS, Nichols MC (2010) U.S. forest carbon calculation tool: Forestland carbon stocks and net annual stock change. Revised for use with FIADB4.0. NRS GTR13. USDA Forest Service, Northern Research Station, Newtown Square, Pennsylvania, USA. [DVD-ROM].

Smith WB, Miles PD, Perry CH, Pugh SA (2009) Forest resources of the United States, 2007. WO GTR-78. USDA Forest Service, Washington Office, Washington, D.C., USA.

Smith JE, Heath LS, Skog KE, Birdsey, RA (2006) Methods for calculating forest ecosystem and harvested carbon with standard estimates for forest types of the United States. Gen. Tech. Rep. NE-343. Newtown Square, PA: U.S. Department of Agriculture, Forest Service, Northeastern Research Station. 216 p.

Stinson G, Kurz WA, Smyth CE, et al. (2011) An inventory-based analysis of Canada's managed forest carbon dynamics, 1990 to 2008. Global Change Biology, 17, 2227-2244. 
USDA (2008) U.S. Agriculture and Forestry Greenhouse Gas Inventory: 1990-2005, Technical Bulletin No. 1921, Global Change Program Office, Office of the Chief Economist, U.S. Department of Agriculture, 2008.

VandenBygaart AJ, Gregorich EG, Angers DA (2003) Influence of agricultural management on soil organic carbon: A compendium and assessment of Canadian studies. Canadian Journal of Soil Science, 83, 363-380.

West TO, Brandt CC, Baskaran LM, et al. (2010) Cropland carbon fluxes in the United States: increasing geospatial resolution of inventory-based carbon accounting. Ecological Applications, 20, 1074-1086.

West TO, Brandt CC, Wilson BS, et al. (2008) Estimating Regional Changes in Soil Carbon with High Spatial Resolution. Soil Sci. Soc. Am. J., 72, 285-294.

West T, Marland G, Singh N, Bhaduri B, Roddy A (2009) The human carbon budget: an estimate of the spatial distribution of metabolic carbon consumption and release in the United States. Biogeochemistry, 94, 29-41.

West TO, Post WM (2002) Soil organic carbon sequestration rates by tillage and crop rotation: a global data analysis. Soil Science Society of America Journal, 66, 1930-1946.

Woodbury PB, Smith JE, Heath LS (2007) Carbon sequestration in the US forest sector from 1990 to 2010. Forest Ecology and Management, 241, 14-27.

Zheng D, Heath LS, Ducey MJ, Smith JE (2011) Carbon changes in conterminous US forests associated with growth and major disturbances: 1992-2001. Environ. Res. Lett. 6, 014012, doi:10.1088/1748-9326/6/1/014012. 